\title{
Constitutive Models for Nonlinear Finite Element Analysis of Masonry Prisms and Infill Walls
}

Ghassan K. Al-Chaar and Armin Mehrabi

March 2008

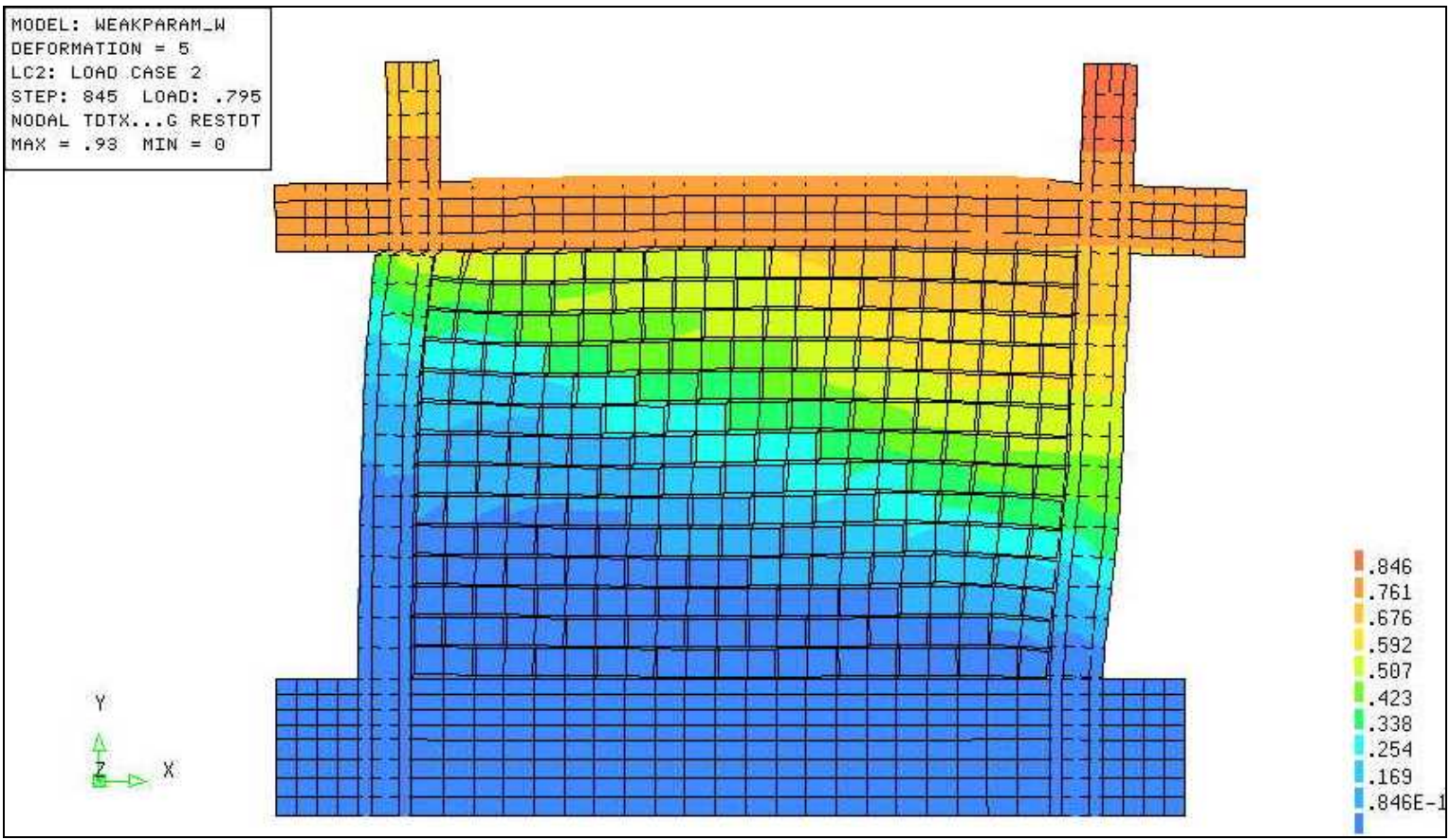




\title{
Constitutive Models for Nonlinear Finite Element Analysis of Masonry Prisms and Infill Walls
}

\author{
Ghassan K. Al-Chaar \\ Construction Engineering Research Laboratory \\ U.S. Army Engineer Research and Development Center \\ 2902 Newmark Drive \\ Champaign, IL 61822 \\ Armin B. Mehrabi \\ CTL Group \\ 5400 Old Orchard Road \\ Skokie, IL 60077-1030
}

Final report

Approved for public release; distribution is unlimited.

Prepared for U.S. Army Corps of Engineers

Washington, DC 20314-1000

Under Project 8740, Constitutive Modeling of Masonry Walls Under Seismic Response 


\begin{abstract}
After much previous research, many controversial issues related to well developed design recommendations and well accepted analytical procedures for infilled frames are still unresolved. The main difficulty in evaluating the performance of bearing and shear wall structures is determining the type of interaction between the infill and the frame, which has a major impact on the structural behavior and load-resisting mechanism. A simplified model that captures the characteristics of infill masonry would be valuable, but developing one requires understanding of masonry-infilled frame behavior in much more detail than strut or beam behavior. Numerical simulations using well calibrated constitutive models are needed for parametric studies to facilitate the development and calibration of a simple, accurate infill masonry model. The objective of this study was to identify suitable numerical constitutive models and demonstrate their capabilities. Two were studied here: a cohesive interface model to simulate the behavior of mortar joints between masonry units as well as the behavior of the frame-to-panel interface; and a smeared crack finite element formulation. The interface model was able to account for the shearing, residual shear strength, and opening and closing of joints under cyclic shear loads in simple combinations of concrete blocks and mortar joints.
\end{abstract}

DISCLAIMER: The contents of this report are not to be used for advertising, publication, or promotional purposes. Citation of trade names does not constitute an official endorsement or approval of the use of such commercial products. All product names and trademarks cited are the property of their respective owners. The findings of this report are not to be construed as an official Department of the Army position unless so designated by other authorized documents. 


\section{Table of Contents}

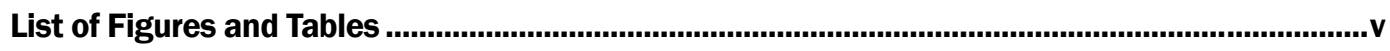

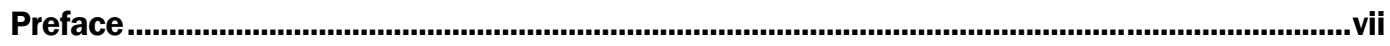

Unit Conversion Factors..........................................................................................................................viii

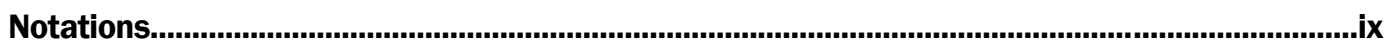

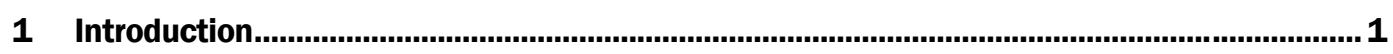

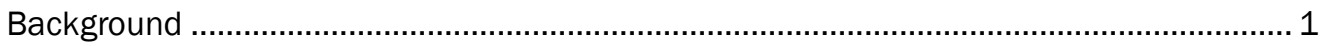

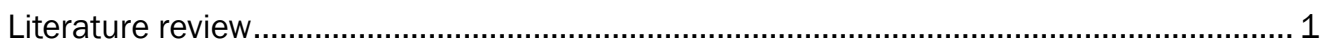

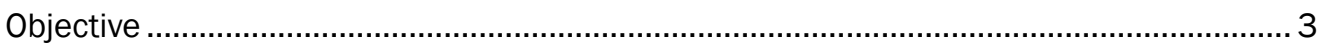

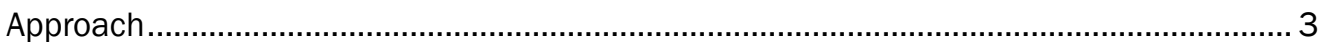

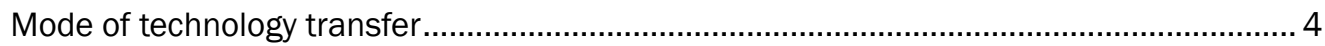

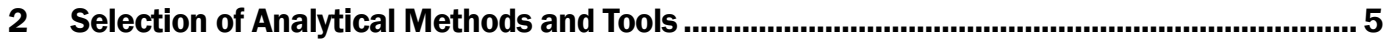

Failure mechanisms of infilled panels under in-plane lateral loading ................................. 5

Available analytical modeling approaches..................................................................... 6

Evaluation of constitutive model alternatives ................................................................ 7

Candidate models for concrete, masonry, and interface elements ....................................... 8

Selection of constitutive models ................................................................................... 12

Characteristics and application of selected constitutive models....................................... 12

The smeared-crack model ................................................................................................ 13

The dilatant interface model ........................................................................................ 14

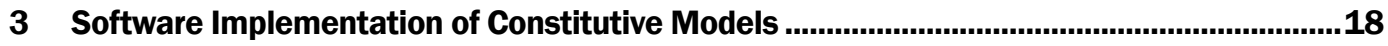

Constitutive model performance in previous FE analysis ................................................ 18

FE software selection ................................................................................................ 18

Capabilities of the DIANA program ............................................................................... 19

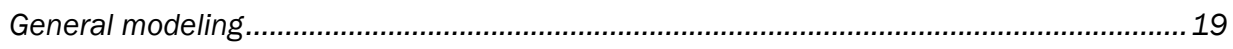

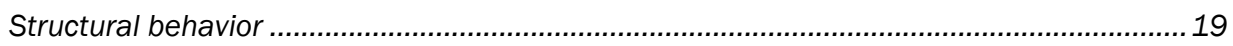

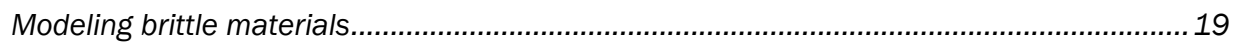

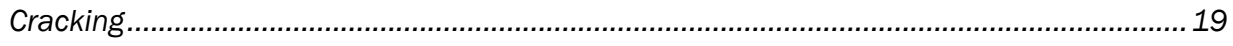

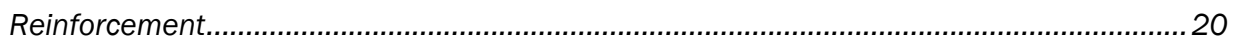

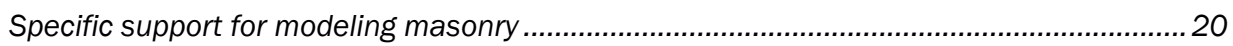

Verification of constitutive models in DIANA.......................................................... 21

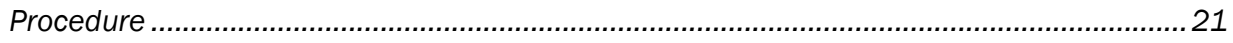

Verification and calibration of smeared crack model ....................................................... 32

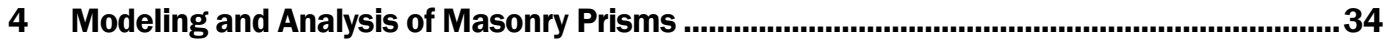

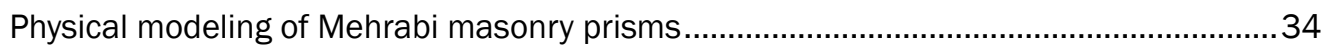

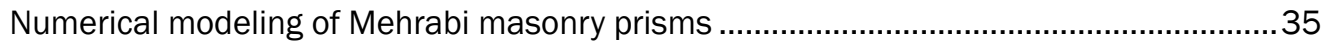

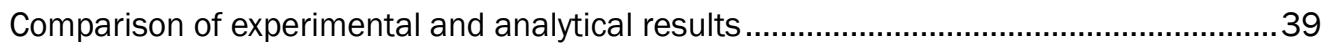


5 Modeling and Analysis of Masonry-Infilled R/C Frames .........................................................43

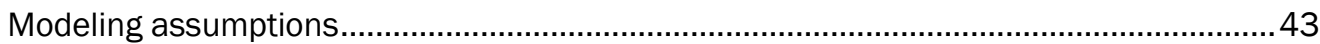

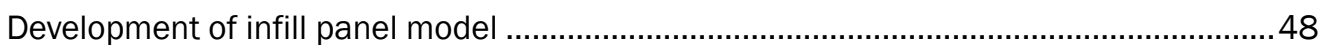

Frame and infill elements.......................................................................................... 48

Parameter setting and analysis................................................................................ 48

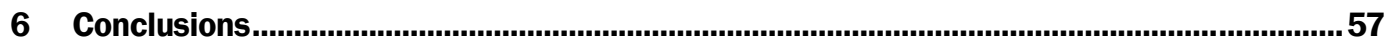

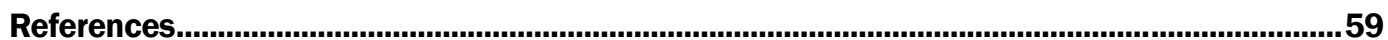

Report Documentation Page 


\section{List of Figures and Tables}

\section{Figures}

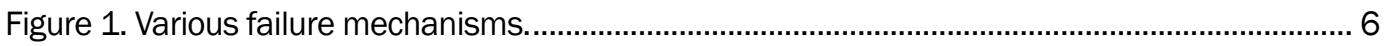

Figure 2. Smeared crack model failure criteria.............................................................................. 14

Figure 3. Wedging action of the asperities. ............................................................................... 15

Figure 4. Hyperbolic yield criterion for cohesive interfaces............................................................ 16

Figure 5. Plastic potential (non associated flow rule) ................................................................ 16

Figure 6. Interface element tension softening curve from DIANA analysis. .................................... 24

Figure 7. Interface shear softening under zero normal stress from DIANA analysis. ....................... 24

Figure 8. Interface shear softening under 100 psi normal stress from DIANA analysis.................. 25

Figure 9. Interface element subjected to cyclic shear loading under 100 psi normal stress........... 25

Figure 10. Interface element subjected to cyclic shear loading under 100 psi normal

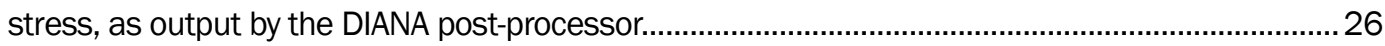

Figure 11. Shear deformation of the interface element shown as DIANA output. ............................28

Figure 12. Calibrated DIANA interface element (100 psi normal stress, $\left.\sigma_{v}=150 \mathrm{psi}\right)$......................28

Figure 13. Comparative model results for shear under a 100 psi normal stress.............................29

Figure 14. DIANA window showing dilatancy under 100 psi normal stress ( $\left.\sigma_{u}=150 \mathrm{psi}\right)$............... 29

Figure 15. Comparative model results for dilatancy under 100 psi normal stress. ..........................30

Figure 16. Calibrated DIANA interface element under 150 psi normal stress.................................30

Figure 17. DIANA dilatancy under $150 \mathrm{psi}$ normal stress........................................................... 31

Figure 18. Comparative model results for dilatancy under 150 psi normal stress. .......................... 31

Figure 19. Compressive elastic/plastic hardening/softening for a CMU..........................................33

Figure 20.Tensile elastic/plastic softening of a CMU element........................................................33

Figure 21. A sample stress/strain curve for axial testing of masonry prisms.................................35

Figure 22. A sample finite element mesh and stress contour for masonry prism analyses. ...........38

Figure 23. Normal stress/normal strain curves for hollow and solid block masonry prisms...........39

Figure 24. The prism at step 1.............................................................................................. 40

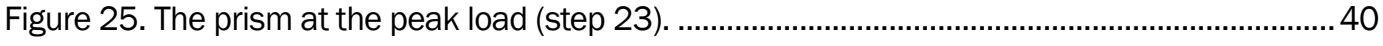

Figure 26. Load-displacement of node 447.................................................................................... 41

Figure 27. Element stress distribution step 6............................................................................. 42

Figure 28. Geometry and details of test specimen (Mehrabi et al. 1994)....................................... 44

Figure 29. Loading scheme for test specimen (Mehrabi et al. 1994)............................................ 45

Figure 30. Failure pattern from laboratory test of frame with weak infill (Mehrabi et al.

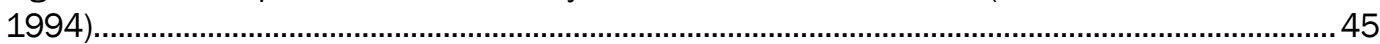

Figure 31. Failure pattern from laboratory test of frame with strong infill (Mehrabi et al. 1994).

Figure 32. Deformed shape predicted by analysis of frame with weak infill (Mehrabi et al. 1994). 
Figure 33. Deformed shape predicted by analysis of frame with strong infill (Mehrabi et

Figure 34. Finite element mesh for frame with weak infill analysis using DIANA.

Figure 35. Deformed shape and stress contour for frame with weak infill, analysis using DIANA.....

Figure 36. Experimental and numerical (DIANA) lateral load/lateral displacement curves for frame with weak infill.

Figure 37. Experimental and numerical (DIANA) lateral load/lateral displacement curves for frame with strong infill.

Figure 38. Deformed shape and stress contour for frame with strong infill at 0.215 in. lateral displacement, analysis using DIANA.

Figure 39. Deformed shape and displacement field contour for frame with strong infill at $0.795 \mathrm{in}$. lateral displacement, analysis using DIANA.

\section{Tables}

Table 1. Comparison of DIANA model and comparative model........................................................2 22

Table 2. Material parameters for DIANA interface element verification analysis. .............................2 23

Table 3. Material parameters of the comparative model................................................................. 27

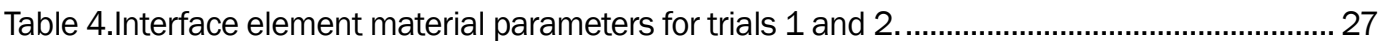

Table 5. Material parameters for a single-unit CMU element test..................................................32

Table 6. Average material properties and axial test results for masonry prisms (Mehrabi et

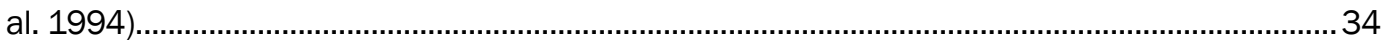

Table 7. Material parameters for concrete in masonry units, prism analysis.....................................36

Table 8. Parameters defining interface model, prism analysis......................................................... 37

Table 9. Material parameters for the prism masonry assembly....................................................39

Table 10. Material parameters for concrete in frame and masonry units......................................50

Table 11. Material parameters for hollow block infill, DIANA interface model................................. 51

Table 12. Material parameters for mortar joints in solid block infill that are different from hollow block infill, DIANA interface. 


\section{Preface}

This study was conducted for Headquarters, U.S. Army Corps of Engineers, under Research, Development, Test, \& Evaluation (RDTE) Program AT23, "Basic Research/ Military Construction"; Work Unit 8740, "Constitutive Modeling of Masonry Walls Under Seismic Response." The technical monitor was Peter J . Rossbach, CECW-CE.

The work was performed by the Materials and Structures Branch (CF-M) of the Facilities Division (CF), U.S. Army Engineer Research and Development Center - Construction Engineering Research Laboratory (ERDCCERL). The project manager was Dr. Ghassan K. Al-Chaar. At the time of publication, Vicki L. Van Blaricum was Chief, CEERD-CF-M, L. Michael Golish was Chief, CEERD-CF, and Martin J . Savoie was the Technical Director for Installations. The Deputy Director of ERDC-CERL was Dr. Kirankumar Topudurti and the Director was Dr. Ilker Adiguzel.

The Commander and Executive Director of ERDC was COL Richard B. J enkins and the Director was Dr. J ames R. Houston. 


\section{Unit Conversion Factors}

\begin{tabular}{|l|c|l|}
\hline Multiply & By & To Obtain \\
\hline feet & 0.3048 & meters \\
\hline foot-pounds force & 1.355818 & joules \\
\hline inches & 0.0254 & meters \\
\hline inch-pounds (force) & 0.1129848 & newton meters \\
\hline pounds (force) & 4.448222 & newtons \\
\hline pounds (force) per foot & 14.59390 & newtons per meter \\
\hline pounds (force) per inch & 175.1268 & newtons per meter \\
\hline pounds (force) per square inch & 6.894757 & kilopascals \\
\hline pounds (mass) & 0.45359237 & kilograms \\
\hline square feet & 0.09290304 & square meters \\
\hline square inches & $6.4516 \mathrm{E}-04$ & square meters \\
\hline tons (force) & $8,896.443$ & newtons \\
\hline tons (force) per square foot & 95.76052 & kilopascals \\
\hline tons (long) per cubic yard & $1,328.939$ & kilograms per cubic meter \\
\hline
\end{tabular}




\section{Notations}

$\mathrm{C}_{\mathrm{s}}=$ parameter controlling the shear stress contribution to failure, DIANA interface model

$\mathrm{E}=$ modulus of elasticity, psi, DIANA smeared crack model

$\mathrm{G}_{\mathrm{fc}}=$ fracture energy in compression, psi-in., DIANA models

$\mathrm{G}_{\mathrm{I}}^{\mathrm{I}}=$ first mode fracture energy, psi-in.

$\mathrm{G}_{\mathrm{f}}^{\mathrm{II}}=$ shear mode fracture energy, psi-in.

$\mathrm{K}_{\mathrm{nn}}=$ normal numerical elastic stiffness parameter, psi/in.

$\mathrm{K}_{\mathrm{ss}}=$ tangential numerical elastic stiffness parameter, psi/in, DIANA interface model

$\mathrm{C}_{\mathrm{o}}=$ initial cohesion, psi, DIANA interface model

$\mathrm{f}_{\mathrm{c}}=$ compressive strength, psi, DIANA models

$\mathrm{f}_{\mathrm{cm}}^{\prime}=$ compressive strength of masonry mortar cubes, psi

$\mathrm{f}_{\mathrm{cu}}^{\prime}=$ compressive strength of masonry units, psi (with respect to net cross-sectional area)

$\mathrm{f}_{\mathrm{m}}^{\prime}=$ compressive strength of masonry prisms, psi (with respect to net cross-sectional area)

$\mathrm{f}_{\mathrm{t}}=$ joint tensile strength, psi, DIANA models

$\psi=$ dilatancy angle, radian, DIANA interface model

$\beta=$ shear retention factor, DIANA smeared crack model

$\delta=$ dilatancy shear slip degradation coefficient, DIANA interface model

$\varepsilon_{\mathrm{u}}=$ strain at maximum strength for axial testing of masonry prisms (in./in.)

$\phi=$ internal friction angle, radian, DIANA interface model

$\phi_{\mathrm{i}}=$ initial internal friction angle, radian, DIANA interface model

$\phi_{\mathrm{r}}=$ residual internal friction angle, radian, DIANA interface model

$\kappa_{\mathrm{p}}=$ norm of plastic strain associated with peak compressive strength, DIANA interface model

$v=$ Poisson's ratio, DIANA smeared crack model

$\sigma_{\mathrm{u}}=$ confining stress over which the dilatancy will be zero, psi, DIANA interface model 


\section{Introduction}

\section{Background}

Masonry walls have long been used as both load-bearing structural elements and architectural non-structural elements in single- and multi-story buildings. Both reinforced and unreinforced masonry have been used in such structures on military installations. In some cases, masonry walls fill the space within structural frames to separate interior spaces. In other cases load-bearing masonry walls are not bounded by structural frames, but are joined with the structural frame using ties and columns to provide better structural integrity to the masonry.

Masonry infills are usually treated as non-structural elements in buildings, and their interaction with the bounding frame is often ignored in design. Nevertheless, infills contribute strength to a structure and will interact with the bounding frame when the structure is subjected to strong lateral seismic loads. This interaction may or may not be beneficial to the performance of the structure, however, and it has been a topic of much debate in the last few decades.

Infill walls have been identified as a contributing factor to catastrophic structural failures in earthquakes. Frame/ partial infill interaction can cause brittle shear failures of reinforced concrete columns and shortcolumn effect. Furthermore, infills can over-strengthen the upper stories of a structure and result in a "soft" first story, which is highly undesirable from the perspective of seismic safety.

In spite of the shortcomings that have been observed in this type of construction, there is strong laboratory and field evidence that masonry infills can improve the earthquake resistance of a frame structure if they are properly designed.

\section{Literature review}

The behavior of masonry-infilled steel and reinforced concrete frames under in-plane lateral loading has been the subject of many investigations. Fiorato et al. (1970) tested 1/ 8-scale non-ductile reinforced concrete frames infilled with brick masonry under monotonically increasing as well 
as cyclic lateral loading. Those tests were followed by the studies of Klingner and Bertero (1976), Bertero and Brokken (1983), Zarnic and Tomazevic (1985), and Schmidt (1989). More recently, single-story reinforced concrete frames with masonry infills were studied by Mehrabi et al. (1994, 1997), Angel et al. (1994), and Al-Chaar et al. (1998, 2002). The latter study also examined the behavior of masonry infill under out-of-plane loading.

Masonry infilled steel frames were tested by Dkanasekar et al. (1985), Dawe and Seah (1989), Mander et al. (1993), Mosalam and Paulino (1997), and Buonopane and White (1997). Flanagan and Bennett (1999a) investigated steel frames with structural clay tile infills.

All studies cited above have shown that the behavior of an infilled frame is heavily influenced by the interaction of the infill with its bounding frame. In most instances, the lateral resistance of an infilled frame is not equal to a simple sum of the resistance if its components because frame/ infill interaction can alter the load-resisting mechanisms of the individual components. At low lateral loading, an infilled frame acts as a monolithic loadresisting system. However, as loading increases, the infill tends to partially separate from the bounding frame and form a compression strut mechanism, as observed in many earlier studies (e.g., Stafford Smith 1962). However, the compression strut may or may not evolve into a primary load-resistance mechanism for the structure, depending on the strength and stiffness properties of the infill with respect to those of the bounding frame.

Dhanasekar and Page (1986) and Liauw and Lo (1988) have used linear and nonlinear beam elements to model the behavior of steel frames, and interface elements to model the interaction between the infill and the frame. Dhanasekar and Page used a nonlinear orthotropic model to simulate the behavior of brick infills, and Liauw and Lo used a simple smeared crack model to simulate the behavior of micro-concrete infills. Schmidt (1989) used smeared crack elements to model both reinforced concrete frames and brick infills. In all those analyses, infill panels have been modeled as a homogenous material before fracture, and the effects of mortar joints have been smeared out. While smeared crack models have been used to analyze reinforced concrete structures where cracks are often diffuse, they suffer from a major deficiency in that they cannot properly capture diagonal shear cracks and the shear sliding of cracked concrete or ma- 
sonry mortar joints. Those deficiencies are inherent in the kinematic constraints related to trying to account for cracking in a continuum (i.e., a homogeneous material). The use of smeared crack elements alone will lead to non-conservative design results for unreinforced masonry infill because the masonry has natural planes of weakness introduced by mortar joints. The most realistic approach to accounting for those weak planes is to incorporate interface elements into the model.

A number of plasticity-based continuous-interface models have been developed to model the tension and shear behavior of masonry mortar joints (Rots 1991; Lotfi and Shing 1994; Lourenco 1996). Those models account for the interaction between normal compression and shear as well as the shear dilatation often observed in experiments. Mehrabi and Shing (1997) have developed an interface model for analyzing masonry infills that accounts for the increase of contact stress due to joint closing, the geometric shear dilatation, and the plastic compaction of a mortar joint. The failure surface of the model is based on a hyperbolic function proposed by Lotfi and Shing (1994), and is capable of modeling damage accumulation at mortar joints under increasing displacement and cyclic loading. This is reflected by shear strength reduction and mortar compaction (loss of material) at interfaces. The model has been used to analyze the infilled frames tested by Mehrabi et al. (1994).

\section{Objective}

The objective of this study was to carry out numerical simulation and parametric studies and compare them with the results of a previous experimental investigation. The investigation also attempted to determine the type of interaction between the infill and the frame, which has a major impact on the structural behavior and load-resisting mechanism, and would capture characteristics of reinforced concrete infilled with masonry in much more detail than a strut or beam.

\section{Approach}

A review of the literature was performed to summarize the state of the technical domain in terms of published experimental and analytical research results.

Advanced finite element modeling approaches were selected for detailed analysis of the nonlinear behavior of infilled frames. The capabilities of 
various numerical models are described. Also, to facilitate the use of these models by structures researchers and designers, a commercial finite element program with similar analytical capabilities was identified and tested.

The finite element models used in this study were (1) a cohesive interface model to simulate the behavior of mortar joints between masonry units and the behavior of the frame-to-panel interface, and (2) a smeared crack finite element formulation to model the concrete in R/C frames and masonry units. The interface model was used to analyze simple combinations of concrete blocks and mortar joints because it can account for the shearing, residual shear strength, and opening and closing of joints under cyclic shear loads. The analytical models are compared with experimental models used in previous investigations to verify results and validate used analytical parameters. The numerical models were compared with previous experimental results to verify the adequacy of assumptions employed in the numerical models and to compare results.

\section{Mode of technology transfer}

The constitutive models employed in this investigation can be applied by the qualified structural engineer to the analysis of critical and complex masonry-infilled R/C frames using the DIANA finite element modeling and simulation program. The results may be expected to have an acceptable level of accuracy, but must be considered within the context of the several caveats discussed in the text. 


\section{Selection of Analytical Methods and Tools}

\section{Failure mechanisms of infilled panels under in-plane lateral loading}

Studies have shown that infilled frames can develop a number of possible failure mechanisms depending on the strength and stiffness of the bounding frames with respect to the strength and stiffness of the infills and the geometric configuration of the framing system. Most analytical models proposed today focus on one type of mechanism or the other, but neither is universally applicable to all infilled structures. However, recent research has shed more light on the behavior of infilled frames and has resulted in the development of advanced analytic tools. Out-of-plane behavior of infilled frames has been studied in addition to the in-plane response. Classical diagonal strut models have been subjected to more thorough evaluations with new experimental data, and various limit analysis methods have been developed to account for the different load-resisting mechanisms of infilled frames.

Based on experimental observations, one can identify five main failure mechanisms of infilled frames. They are illustrated in Figure 1 (Mehrabi et al. 1994). While most of the studies to date have focused on unreinforced masonry panels, Klingner and Bertero (1976) and Bertero and Brokken (1983) investigated the behavior of engineered infilled frames. Both investigations tested one-third scale, three-story reinforced concrete frames infilled with fully grouted concrete masonry that had both horizontal and vertical reinforcement. The infill panels were securely tied to the bounding frames. Both studies demonstrated that properly engineered infilled frames can provide superior performance, in terms of strength, stiffness, and energy dissipation, as compared with a bare frame. However, reinforced infills are not common, and an over-reinforced infill may create a risk of brittle shear failure in the bounding reinforced concrete columns. Studies by Mehrabi et al. $(1994,1996)$ have shown that relatively weak unreinforced masonry infills can significantly enhance the stiffness and strength of a non-ductile reinforced concrete frame without jeopardizing ductility. 


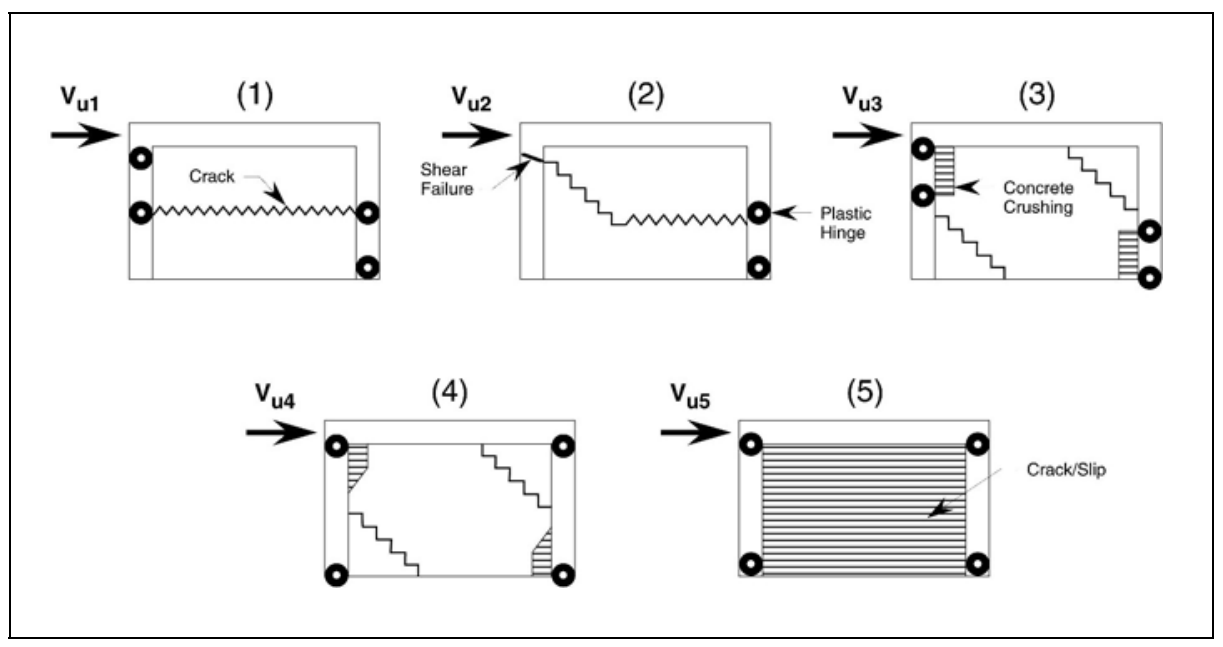

Figure 1. Various failure mechanisms.

In summary, the failure mechanism and load-resistance of an infilled frame depend very much on the strength and stiffness of the infill with respect to the bounding frame. It is evident that the strength of the mortar joints is also a dominant factor. A relatively weak infill is most desirable. Studies have shown that infill panels can significantly enhance the performance of a bare frame under earthquake loads provided the short column phenomenon and the brittle shear behavior of the columns can be prohibited (Bertero and Brokken 1983; Mehrabi et al. 1994).

An accurate, computer-assisted analytical method for assessing alternate infill panel designs would be much more affordable than the construction and testing of individual scaled physical models for a specific application. Owing to the compound complexities of the modeling and simulation problem, however, two fundamental questions first needed to be answered:

- What is the most suitable analytical approach to the problem?

- What available numerical models best fit the requirements of the selected analytical approach and the physical characteristics of masonryinfilled panels?

\section{Available analytical modeling approaches}

The candidate analytical methods fall into three categories:

1. simple modeling

2. limit analysis 
3. constitutive micro- or macro-mechanical models for finite element analysis.

In the simple modeling method, infill panels are usually simplified as one or more distinct elements in an attempt to capture the important behavioral parameters of an actual infilled frame structure. Limit analysis methods are based on a lower-bound solution for lateral strength of an infilled frame based on a series of assumed failure mechanisms. Constitutive finite element modeling methods attempt to simulate the "actual behavior" of infill panels by dividing the panels into finite elements and implementing constitutive models for these elements that could capture the mechanical characteristics of the material in infill panels. In this paper, only constitutive models for finite element analysis are reviewed.

\section{Evaluation of constitutive model alternatives}

Finite element analysis may be the most powerful tool for evaluating the behavior of infilled frames. However, the reliability of the finite element method depends on the appropriateness of the model and elements used. A properly developed finite element model can account for all possible failure mechanisms of infilled frames, but improper use of such models can produce non-conservative results. Therefore, extreme care must be exercised when performing a finite element analysis.

Many different approaches have been used for finite element modeling of masonry infills. Recent approaches have recognized the inelastic and plastic behavior of masonry from the initial stage of loading and the effect that damage accumulation has on the modeling of the masonry infills. The review presented here discusses models that consider nonlinear, plastic behavior and damage effects resulting from masonry infill as an isotropic or orthotropic brittle or quasi-brittle material and/ or brittle mortar joints.

Simpler models have considered the masonry infill to be a homogeneous isotropic continuum medium with no tensile strength (Del Piero 1989) or by applying the smeared crack approach. However, more detailed constitutive models must be considered to describe the unique characteristics of masonry infills, namely a highly orthotropic nature due to the presence of mortar joints and shear strength degradation mostly focused along mortar joints. The first task in incorporating more detail is to introduce appropriate constitutive models for both the masonry units and mortar joints. To 
this end, three different approaches can be considered based on different levels of complexity (Gambarotta and Lagomarsino 1997):

1. modeling masonry units and mortar joints as continuum elements

2. continuum modeling of combination units and joints using a homogenization procedure

3. introduction of interface elements.

A more effective approach, however, considers mortar joints - the weakest elements of unreinforced masonry - as interface elements (Lotfi and Shing 1994; Mehrabi and Shing 1997). The constitutive modeling of interfaces has improved over time to accommodate the orthotropic behavior of masonry and model separation, shear degradation, and closing due to unloading. The interfaces connect masonry units. Loading caused by unloading can be modeled using available smeared crack models with or without damage consideration. The presence of interfaces overcomes the shear locking and mesh dependency often associated with the use of smeared-crack models alone.

There exist various approaches to the constitutive modeling of brittle and quasi-brittle materials. Many use continuum damage modeling. Some address the modeling of concrete-type material and not necessarily composite masonry material. However, those models form the basis for the smeared crack models that can be effectively used for modeling of masonry units and R/C frames. Several other models directly address the modeling of masonry in general and some masonry infilled frames in particular. However, a review of continuum damage modeling is beyond the scope of this report. It should be noted that for the case of unreinforced concrete masonry, infills are not necessarily as sensitive to damage in masonry units as to damage in mortar joints. Nevertheless, the majority of smeared crack models introduced in recent years consider one or another type of damage propagation and permanent mechanical property variation. Some of the interface models discussed below effectively consider the damage initiation and progress in mortar joints, and therefore offer the best candidates from which to select a best-fit model for unreinforced concrete masonry infilled frames.

\section{Candidate models for concrete, masonry, and interface elements}

This section reviews in more detail work presented by several researchers addressing finite element modeling of brittle and quasi-brittle materials 
including masonry infills. The continuum models presented here mostly consider the unique characteristics of such material, e.g., cracking and damage, smeared over a finite element.

Mosalam and Paulino (1997) employed fixed smeared-crack concepts with strain decomposition to carry out nonlinear finite element simulations of either unreinforced or reinforced concrete structures. To alleviate spurious mesh dependence, researchers adapted the finite element mesh to the present level of damage (cracking) in space and time. Willam and Warnke (1974) described different models for the failure surface and the constitutive behavior of concrete under triaxial stress. Dhanasekar et al. (1985) derived simple nonlinear stress/ strain relations for brick masonry constructed with solid pressed bricks from the results of a large number of biaxial tests on square panels using various angles of the bed joint in relation to the principal stress axes. Macroscopic elastic and nonlinear stress/ strain relations were determined from displacement measurements over gage lengths that included a number of mortar joints. Bedard and Kotsovos (1986) presented a numerical description of the fracture processes of concrete that is suitable for use with nonlinear finite element analysis methods.

Dhanasekar and Page (1986) studied the influence of brick masonry infill properties on the behavior of infilled frames, using a finite element model to simulate the behavior of infilled frames subjected to a racking load. The finite element program incorporated a material model for the infill brick masonry that includes appropriate elastic properties, inelastic stress/ strain relations, and a failure surface. Han and Chen (1987) summarized the efforts in developing a model for progressive failure analysis of concrete structures. The main features of the proposed short-term, time-independent constitutive model included the William and Warnke (1974) five-parameter or Hsieh-Ting-Chen (1988) four-parameter failure surface, the nonuniform hardening rule, the nonassociated flow rule with changing dilatancy factor, linear softening for post-cracking in tension, and multiaxial softening for post-failure in compressions. Rots and Borst (1987) described a smeared crack model that covers tensile softening in Mode I and shear softening in Mode II fracture. In addition, the model accounted for unloading and reloading and for multiple-crack formation. Particular forms of tension and shear softening functions and relations with more conventional models were discussed. Willam, Pramono, and Sture (1987) discussed renewed attempts in terms of fixed and rotating 
crack models that resort to fracture mechanics to refine the traditional orthotropic crack formulation. Following a similar approach, the original concept involving Mode-I type cracking is being broadened to include mixed-mode fracture interpretation of the shear-retention factor if the crack memory is fully retained. Hsieh et al. (1988) discussed an elasticplastic fracture constitutive model for concrete materials. In this model, a four-parameter failure criterion was used to define the ultimate strength. The associated flow rule for displaying mixed hardening was adopted to represent the nonlinear stress/ strain response. A crushing coefficient was introduced to identify the mode of failure, and an anisotropic elastic relationship was used to describe the post-failure behavior. Yazdani and Schreyer (1990) developed a combined plasticity and damage mechanics model for concrete within the general framework of the internal variable theory of thermodynamics. The necessity of using both plasticity and damage mechanics was discussed, and the corresponding surfaces were developed via the internal dissipation inequality.

Lotfi and Shing (1991) assessed the capability of smeared crack models in capturing the strength and various failure mechanisms of reinforced masonry shear walls. A smeared finite element formulation adopting the $\mathrm{J}_{2}$ plasticity model for uncracked masonry and a nonlinear orthotropic constitutive model for crack masonry were developed. Stevens and Liu (1992) combined the theories of continuum damage mechanics and plasticity in a strain-based phenomenological approach to yield an effective constitutive model for plain concrete. J amal et al. (1992) conducted a nonlinear finite element study to evaluate the in-plane behavior of masonry infilled steel frames.

Stankowski et al. (1993) presented a constitutive theory that describes fracture and slip of an interface in cementitious composites such as concrete. The constitutive model was developed and formulated in analogy to the theory of incremental plasticity. Adhesion, debonding, and mobilized friction mechanisms were considered in the characterization of the interface behavior. Abu-Lebdeh and Voyiadjis (1993) developed a model that combined plasticity and damage mechanics to assess both multi-axial monotonic and cyclic behavior of concrete. The model adopted a bounding surface concept and combined plastic deformation with the deformation due to damage. Lotfi and Shing (1994) simulated the failure of unreinforced masonry panels subjected to lateral loads by means of a finite element approach in which the mortar joints were modeled with interface 
elements and the masonry units were modeled with smeared crack elements. Lourenco et al. (1995) presented two models for the micro and macro analysis of masonry structures. For the micro modeling of masonry, an interface failure criterion that included a straight tension cutoff, the Coulomb friction law, and an elliptical cap was proposed. Fuschi et al. (1995) used a numerical approach for the structural analysis of masonry walls under in-plane stress conditions. Manzouri et al. (1996) presented two elastic/ viscoplastic constitutive models for the modeling of masonry structures: (1) a two-dimensional continuum model based on the DruckerPrager failure criterion for modeling masonry units and (2) an interface model for modeling mortar joints. Lee et al. (1996) introduced a homogenization technique to investigate the elastic-brittle behavior of masonry panels subject to incremental lateral loading. Two successive steps of homogenization were used to obtain equivalent elastic properties for modeling the elastic behavior of masonry. Barzegar and Maddipudi (1997) presented a triaxial constitutive model for finite-element analysis of pre- and post-cracking behavior of concrete. A five-parameter ultimate strength envelope was used in the stress space. Lourenco and Rots (1997) evaluated the performance of an interface elastoplastic constitutive model for the analysis of unreinforced masonry structures. Both masonry components were discretized, aiming for a rational unit/joint model able to describe cracking, slip, and crushing of the material.

Mehrabi and Shing (1997) carried out experimental and analytical studies to investigate the performance of masonry-infilled R/C frames under inplane lateral loadings. A smeared-crack finite element model was used to model the behavior of concrete in the $\mathrm{R} / \mathrm{C}$ frames and masonry units. It was shown that finite element models are able to simulate the failure mechanisms exhibited by infilled frames, including the crushing and cracking of the concrete frames and masonry panels, and the sliding and separation of the mortar joints. Balan et al. (1997) presented a threedimensional concrete material model for nonlinear finite-element analysis of concrete solids under short-term cyclic loading. The proposed model was a hypoplastic orthotropic model based on a stress-equivalent uniaxial strain relation that was generalized to take into account triaxial stress conditions. Carol et al. (1997) presented a simple but general model for normal and shear cracking in quasi-brittle materials. The model was defined in terms of the normal and shear stresses on the average plane of the crack, and the corresponding normal and shear relative displacements. Chiou et al. (1999) investigated the structural behavior of a framed ma- 
sonry wall subjected to in-plane monotonic loading by a full-scale test and the method of discontinuous deformation analysis. The concept of artificial joints was adopted to refine discontinuous deformation analysis so it could analyze both continuous and discontinuous behavior of the masonry structure. Guinea et al. (2000) presented a micro-mechanical model for analyzing Mode-I fracture of brick masonry. The analysis was based on a detailed modeling of brick and mortar fracture by means of the fictitious (or cohesive) crack model.

\section{Selection of constitutive models}

The behavior of reinforced concrete $(\mathrm{R} / \mathrm{C})$ frames infilled with unreinforced concrete masonry (UCM) blocks under lateral in-plane loading depends strongly on the development of diagonal and horizontal cracks through mortar joints and the evolution of these cracks under shear reversal, and repetitive displacements. Mehrabi et al. (1994) demonstrated through experimental and analytical studies that diagonal and horizontal cracking within the infill and slip at cracked joints is the dominant failure mechanism for $\mathrm{R} / \mathrm{C}$ frames infilled with unreinforced masonry. Although cracking and crushing and accumulation of damage also occur in the masonry units, it is the degradation of shear resistance of cracked masonry which defines degradation of lateral stiffness and resistance of a masonry infilled frame. Therefore, if a constitutive model is adopted that is capable of simulation of shear degradation along masonry joints and is able to model quasi-brittle material such as concrete and masonry, the behavior of an infilled frame could be modeled properly. Hence, the model selection was based on capabilities of reviewed models in simulation of masonry joint behavior.

Based on the results of the literature review reported above, it is concluded that a combination of continuum and interface constitutive models are the most appropriate for R/ C frames infilled with UCM. The continuum model is used for R/C in frame and masonry units in infill, and the interface model is used for mortar joints between masonry units as well as joints between the infill and frame.

\section{Characteristics and application of selected constitutive models}

To model the concrete in the $\mathrm{R} / \mathrm{C}$ frames and the masonry units in the infill panels, the smeared-crack finite element formulation developed by Lotfi and Shing (1991) was selected. In this formulation, a J 2-plasticity 
model with an isotropic strain-hardening/ softening law was utilized to model an uncracked material. The plasticity model is combined with the Rankine tension-cutoff criterion to signal the onset of cracking.

To model the behavior of the mortar joints between masonry units as well as the joints at the infill-to-frame interfaces, the interface model developed by Mehrabi and Shing (1995) was selected.

The longitudinal reinforcing bars in the $\mathrm{R} / \mathrm{C}$ frame members can be modeled as one-dimensional (1D) truss elements using an elastic-hardeningplastic material model available in all commercial FE programs. The shear reinforcement in $\mathrm{R} / \mathrm{C}$ frame members can be modeled as two-dimensional (2D) shell elements using elastic-hardening-plastic material model. The reinforcement can be connected to concrete elements assuming a perfect bond, or through bond-slip FE elements such as those developed by Mehrabi and Shing (1995). However, Mehrabi and Shing demonstrated that the use of bond-slip elements between concrete and reinforcement at nodal points has a minimal effect on modeling the behavior of infilled frames. Therefore, the use of bond-slip elements for reinforcement does not seem necessary.

\section{The smeared-crack model}

The smeared-crack model developed by Lotfi and Shing (1991) uses a J 2 plasticity model with an isotropic strain-hardening/ softening law for modeling an uncracked material. The plasticity model is combined with the Rankine tension-cutoff criterion to signal the onset of cracking. The failure criteria are shown in terms of the principal stresses, $\sigma_{1}$ and $\sigma_{2}$, in Figure 2. The isotropic strain-hardening/ softening is governed by $\sigma_{e}=\sigma_{e}\left(\varepsilon_{p}\right)$, which consists of a parabolic curve and an exponential tail as shown in Figure 2d. A crack initiates when the maximum principal stress reaches the tensile strength, $f_{t}^{\prime}$, in a direction normal to the maximum principle stress. The cracked material is assumed to be nonlinear orthotropic, with the axes of orthotropy, $n-t$, normal and tangential to the direction of the crack (Figure 2b). For a coaxial rotating crack model, which is considered for this model, the crack direction and the axes of orthotropy rotate with the principal axes of strain in such a way that the crack remains normal to the direction of the maximum principal strain. Variations of tension stress and tension stiffness before and after cracking are shown in Figure 2c. 


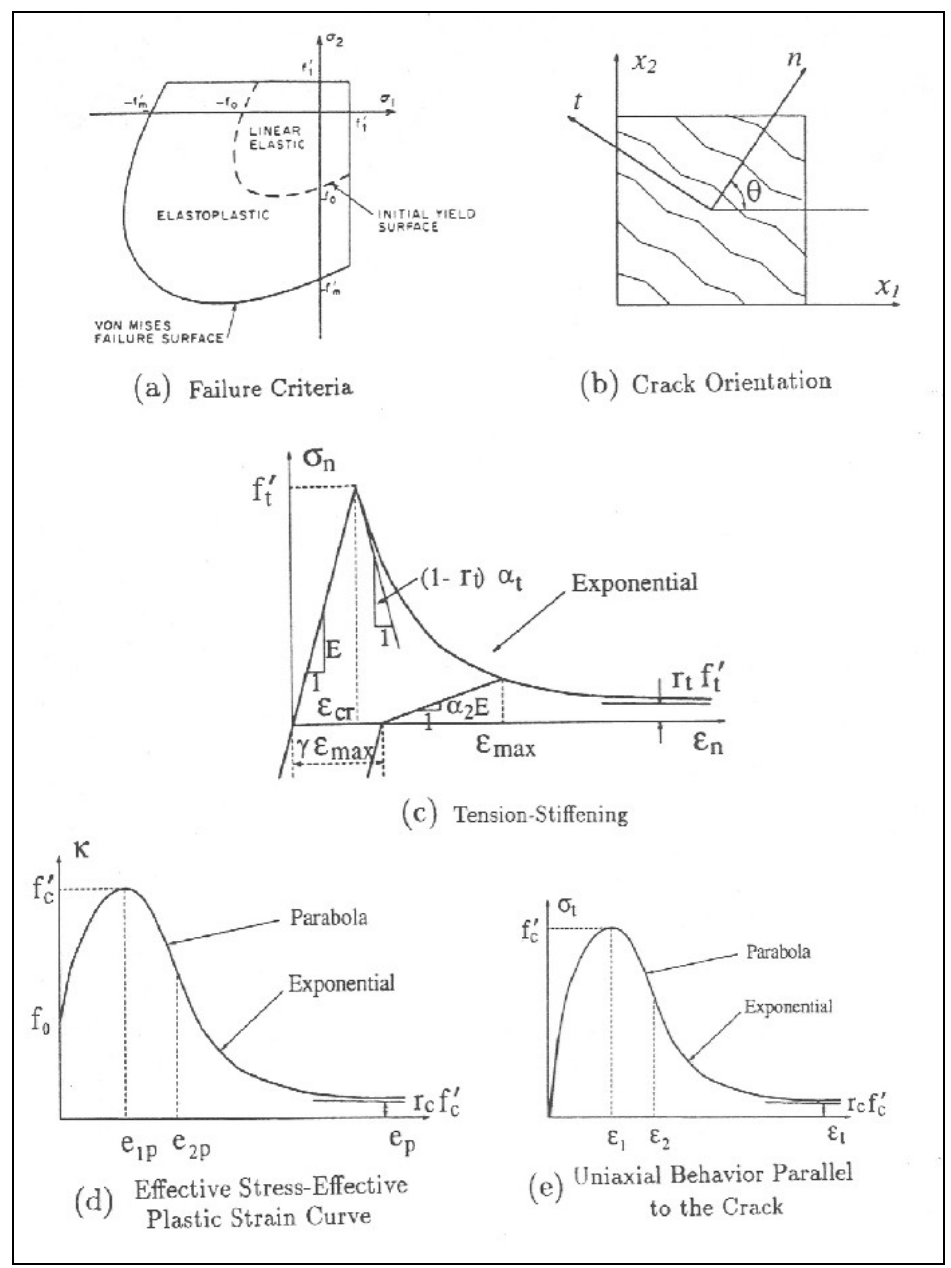

Figure 2. Smeared crack model failure criteria.

For the case of a coaxial rotating crack, the shear modulus is given by $G_{n t}=\frac{\left(\sigma_{1}-\sigma_{2}\right)}{2\left(\varepsilon_{1}-\varepsilon_{2}\right)}$, where $\sigma_{1}$ and $\sigma_{2}$ are the principal stresses, and $\varepsilon_{1}$ and $\varepsilon_{2}$ are the principal strains (Bazant 1983). The tangent modulus in the direction parallel to the crack is represented by $\mathrm{E}_{\mathrm{tt}}$. The compression behavior in a direction parallel to the crack is modeled by a nonlinear hardening/ softening law similar to the uniaxial compressive behavior given by the plasticity model for an uncracked material. The uniaxial effective stress versus effective plastic strain and uniaxial behavior parallel to the crack are shown in Figure 2d and 9e, respectively. Additional details of the crack model can be found in Lotfi and Shing (1991).

\section{The dilatant interface model}

To model the behavior of concrete, rock, and mortar joints, various plasticity-based interface constitutive models have been proposed by Plesha et al. 
(1989), Stankowski (1990), Stankowski et al. (1993), Carol and Prat (1991), and Lotfi and Shing (1994). However, there are still some aspects of the physical behavior of interfaces that have not been considered properly in most existing models. These include the compressive hardening behavior of interfaces, the reversal of shear dilatancy in the case of cyclic loading, and the normal contraction of an interface under shear sliding. These physical properties of interfaces are incorporated in the constitutive model proposed by Mehrabi and Shing (1997).

In this model, the nonlinear hardening behavior of an interface under a compressive stress is assumed to be an elastic phenomenon. No dilatation is assumed in the elastic regime. In the plastic regime, the total shear dilatation exhibited by an interface is considered to be the sum of a normal compaction and geometric dilatation. The latter is due to the wedging action of the asperities, as shown in Figure 3. Owing to the reversible nature of this dilatation, the dilatation is conceived as a geometric phenomenon. The normal contraction of an interface, due to the loss of loose particles, is an irreversible phenomenon that is modeled using plasticity theory.

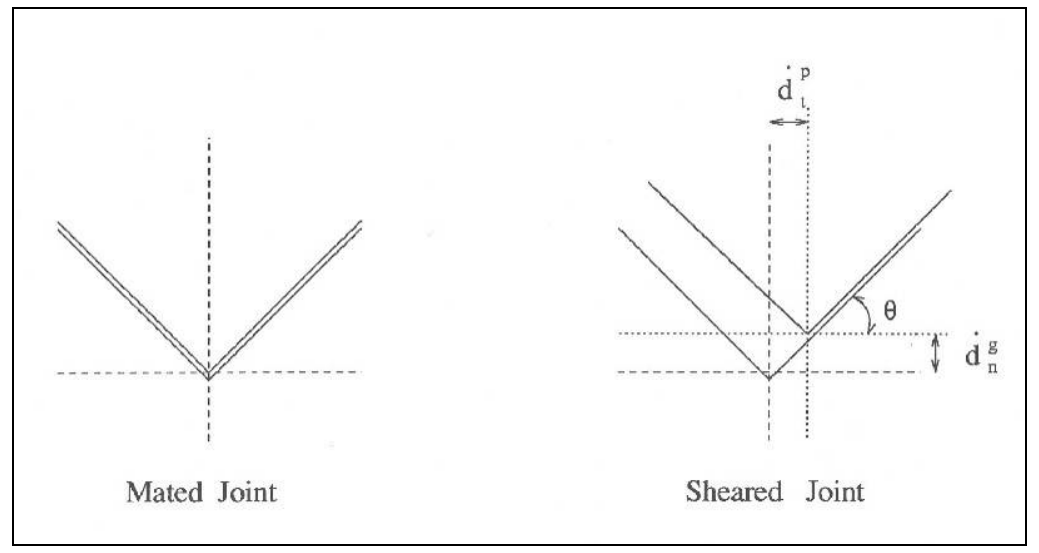

Figure 3. Wedging action of the asperities.

A three-parameter hyperbolic yield criterion proposed by Lotfi and Shing (1994) for cohesive interfaces is adopted here, as shown in Figure 4. As illustrated, evolution and shrinkage of the yield surface occurs with the occurrence of plastic work. 


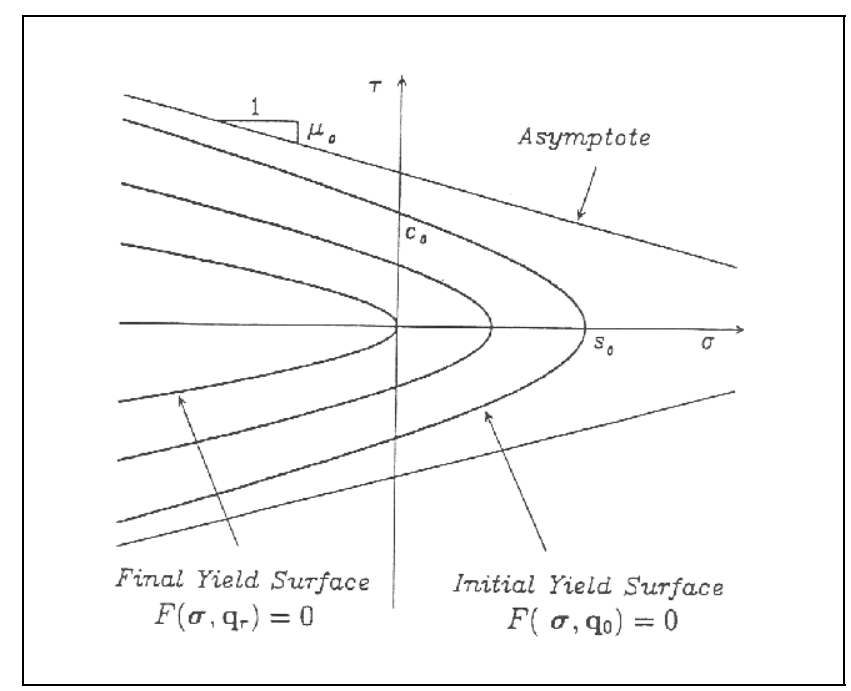

Figure 4. Hyperbolic yield criterion for cohesive interfaces.

To model the normal compaction of an interface due to the loss of damaged materials as well as the opening of a fractured interface, a nonassociated flow rule is proposed, as shown in Figure 5. The direction of the plastic relative displacement is governed by the flow rule.

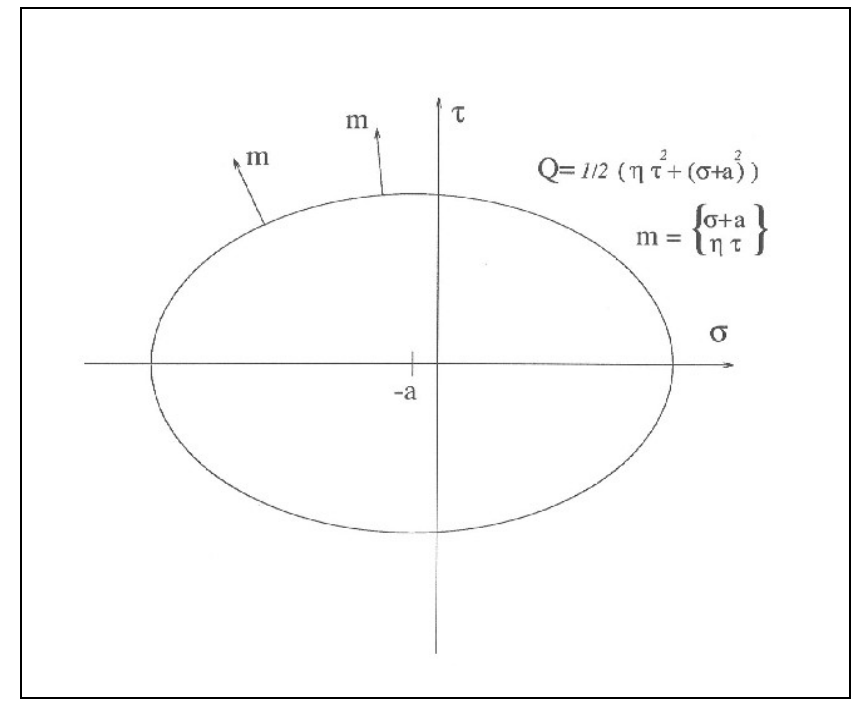

Figure 5. Plastic potential (non associated flow rule).

The shear dilatancy is considered as the sum of geometric dilatation and normal plastic compaction. Geometric dilatation occurs only after fracture, and it is expressed as a function of the plastic shear. The interface is assumed to function as an asperity, the slope of which decreases with respect to the cumulative plastic work performed by shear. The loading and unloading satisfy the Kuhn-Tucker conditions. For the integration of the above constitutive relations, the return mapping algorithm based on the 
operator-splitting method proposed by Ortiz (1981) is adopted. The solution of the rate equations is decomposed into an elastic prediction and a plastic correction. In the elastic prediction, the plastic strains and internal variables are assumed to remain constant, and the applied displacement increment is assumed to be totally elastic. For the plastic correction, there is no additional displacement increment. 


\section{Software Implementation of Constitutive Models}

\section{Constitutive model performance in previous FE analysis}

Mehrabi et al. (1994) and Mehrabi and Shing (1997) examined the validity of the constitutive models by using them in a finite element analysis based on previous experimental testing of physical masonry-infilled $\mathrm{R} / \mathrm{C}$ frame models. Specimens with weak and strong frame designs were analyzed for performance when subjected to a constant vertical compressive load. The concrete frames were modeled with nine-node quadrilateral smeared crack elements, and the shear reinforcement was smeared out over concrete elements. The longitudinal bars in the frame were modeled with two-node bar elements. They were connected to the nine-node concrete elements at the two external nodes. For masonry units, four-node smeared crack elements were used. The mortar joints in the masonry panels and along the interfaces between an infill and the frame were modeled by two doublenode interface elements. To model the possible shear failure of the columns, three double-node interface elements were used at critical locations near the top and bottom sections of the columns. Extensive materials testing was also carried out. The constitutive models were calibrated with the results of the physical modeling reported in Mehrabi et al. (1994).

\section{FE software selection}

It was decided to use a commercial FE software program in this study for purposes of economy, ease of model construction, inclusion of userfriendly input and output formats, and integrated graphics capabilities. Four finite element packages, each with capabilities for modeling concrete elements and interfaces, were reviewed. They were ANSYS, ADINA, ABAQUS, and DIANA. The programs were reviewed to understand their capabilities in modeling structural discontinuities such as mortar joints and modeling a concrete and masonry continuum. For the type of infilled frames considered in this study, the defining parameters are cracking and separation of mortar joints and infill-to-frame interfaces, and cracking and crushing of the infill material. Degradation of shear properties, especially at the interfaces and joints, are of specific interest. Based on those criteria, DIANA identified as the best fit for the purposes of this study. 


\section{Capabilities of the DIANA program}

This section examines the capabilities and limitations of DIANA in terms of analyzing masonry-infilled R/ C frames subjected to in-plane lateral loading.

\section{General modeling}

In DIANA, the analytical model of a structure can be divided into three major parts: (1) the discretization of the geometry through a finite element mesh, (2) the modeling of the physical behavior of the materials used in the structure, such as concrete and reinforcing steel, and (3) the modeling of the structural effects that influence the behavior of the structure, such as large displacements or time-dependent behavior.

\section{Structural behavior}

To make the discretization in DIANA, the user needs knowledge of applied mechanics and finite elements in particular, but it is assumed for this part that the geometry of the structure has been discretized in a proper fashion. For the modeling of the physical behavior of the material, the user needs knowledge about failure mechanisms that can occur in the structure. In concrete structures, for example, the behavior is mainly influenced by cracking and crushing of the concrete and yielding of the reinforcement. Structural effects are those phenomena that can influence the behavior of the structure, and they depend largely on the history of the structure.

\section{Modeling brittle materials}

To model concrete structures, or structures made of brittle and quasibrittle materials in general, DIANA offers a broad range of element types. The constitutive behavior of quasi-brittle material is characterized by tensile cracking and compressive crushing, and by long-term effects like shrinkage and creep.

\section{Cracking}

Cracking can be modeled in DIANA with a multidirectional fixed-crack model with tension softening and shear retention. Brittle cracking, linear tension softening, multilinear softening, and nonlinear softening according to Hordijk (1991) is available. Also a plasticity-based formulation for cracking is available: the principal Rankine stress criterion resembles the 
rotating crack model. However, this model is applicable only to plane stress, plane strain, and axisymmetric elements.

In multi-axial stress states, the compressive stress accounted for in the model can exceed the compressive strength of the material. In such a case, the crack model can be combined with a plasticity model that describes the crushing of the material. The Mohr-Coulomb and Drucker-Prager models are especially applicable to quasi-brittle structures.

The combination of tensile and compressive stresses can also be modeled in DIANA with a multi-surface plasticity model that is available for biaxial stress states. However, this model too is applicable only to plane stress, plane strain, and axisymmetric elements.

\section{Reinforcement}

The reinforcement in a concrete structure can be modeled with the embedded reinforcement types available in DIANA. The constitutive behavior of the reinforcement can be modeled by an elastoplastic material model with hardening. Furthermore, temperature influence on the material's Young's modulus and the thermal expansion coefficient can be taken into account.

\section{Specific support for modeling masonry}

Masonry structures are analyzed on two different levels: the macro level, where global behavior is simulated; and the meso level, where behavior is analyzed in more detail. For macro-level analysis, DIANA offers multidirectional fixed-crack models and plasticity models to simulate cracking and crushing, respectively. However, the orthotropic nature of masonry cannot be modeled with the fixed crack and standard plasticity models because these models involve isotropic elasticity, and they do not allow combination with orthotropic elasticity. The anisotropic Rankine-Hill plasticity model is appropriate for modeling masonry because it allows orthotropic elasticity to be employed and incorporates different strength and degradation parameters to simulate the different behaviors parallel and perpendicular to the masonry bed.

For meso-level analysis, the orthotropy of masonry blocks can be modeled by continuum elements, and the joints can be modeled by interface elements. For this type of task there are various models to describe the inter- 
face behavior, including a discrete crack model, a Coulomb friction model, and a combined Coulomb friction/ tension cutoff/ compression cap model.

The models described above are not the only models that can be applied to masonry. In some cases, inclusion of the elastic orthotropy of the masonry may not be essential, and a standard smeared or total strain crack model with isotropic elasticity may be applied as well. That, for instance, is the case when the orthotropy factor is low or when cracks are expected to occur predominantly in only one direction. Also, the combined friction/ tension/ compression interface model is not always required, and one may choose to use a standard discrete crack or Coulomb friction model. It should be realized that the Rankine-Hill continuum model and the composite interface model are plasticity based, which means that unloading takes place elastically. To model secant unloading and crack closure/ reopening specifically, other constitutive models may be chosen.

\section{Verification of constitutive models in DIANA}

\section{Procedure}

For the purpose of this study, it was decided to perform modeling and analysis at the meso level as follows: (1) masonry units and R/C frames were modeled using continuum elements with smeared-crack-type constitutive models capable of cracking and crushing, and (2) mortar joints were modeled using structural interfaces capable of modeling cohesion, separation, shear degradation, cyclic behavior, and closing.

In order to evaluate how the finite element models of interest in this investigation perform within DIANA, it was necessary to observe the behavior of those models under different modes of deformation. The selected interface analytical model for the mortar joints was calibrated by evaluating it against results from an established discrete crack interface model (here called the comparative model). Displacement comparisons between the two models were made normal to the interface, parallel to the interface, and in combinations of the two. The solid masonry material was modeled using a smeared crack model in order to demonstrate different modes of progressive failure. The basic interface and solid smeared crack definitions and implementations were shown previously, in Figure 2.

Prior to performing evaluations and comparisons, the intended capabilities of each analytical model were listed in a table and compared. Table 1 
shows those basic comparisons for the interface model. The interface model built into DIANA includes a compression cap that can represent compressive damage associated with the failure in joints, but the comparative model does not have this feature. That difference may show up in a three-dimensional analysis. Another difference is that the DIANA interface model does not represent cumulative damage to the joints in the form of loss of material while the comparative model does have this feature. This cumulative damage feature affects the active dilatancy, and it can be important once the joints are placed under constraints such as an infill frame. (A future study will address that modeling capability in more detail.)

Despite the two significant differences, the two interface models share a wide basis for representing frictional behavior, frictional and tensile degradation, and progress of damage to the properties, and they may be expected to behave similarly. Features and parameters that both models share are shown in Table 1.

Table 1. Comparison of DIANA model and comparative model.

\begin{tabular}{|c|c|c|c|c|c|c|c|c|}
\hline \multirow{2}{*}{$\begin{array}{l}\text { Model Setup } \\
\text { Description }\end{array}$} & \multirow{2}{*}{ Shape } & \multicolumn{3}{|c|}{ DIANA model } & \multicolumn{3}{|c|}{ Comparative model } & \multirow[t]{2}{*}{ Comment } \\
\hline & & Appendix & Equation & Parameters & Appendix & Equation & Parameters & \\
\hline \multirow{4}{*}{ Shear Slipping } & \multirow{4}{*}{ Coulomb } & \multirow{4}{*}{ A1 } & 4 & $\Phi, \mathrm{c}$ & \multirow{4}{*}{$A 2$} & 5 & $\mu, \mathrm{s}, \mathrm{r}$ & similar \\
\hline & & & $4 a$ & c & & 13 & $\mu$ & $\mu=\Phi$ \\
\hline & & & 5 & $\Phi$ & & 13 & s & \\
\hline & & & & & & 13 & r & $r=\left(c^{2}-\mu^{2} s^{2}\right) / 2 s$ \\
\hline Flow Rule & Plastic Potential & A1 & 13,14 & $\Psi, \delta, \sigma_{u}$ & A2 & 6 & $a, \eta$ & \\
\hline \multirow{2}{*}{$\begin{array}{l}\text { Tension } \\
\text { softening }\end{array}$} & \multirow{2}{*}{ Exponential } & \multirow{2}{*}{ A1 } & 16 & \multirow{2}{*}{$\Psi, \delta$} & \multirow{2}{*}{ A2 } & 13 & $s$ & \\
\hline & & & 8,9 & & & 13 & $r$ & \\
\hline \multirow{2}{*}{ Tension Cut-Off } & Cut-Off Line(DIANA) & A1 & 17,18 & $\mathrm{ft}_{\mathrm{t}}$ & - & - & - & \\
\hline & Tip of Hyperbola & & & & A2 & 5 & $s, r$ & \\
\hline \multirow{2}{*}{$\begin{array}{l}\text { Compression } \\
\text { Cap }\end{array}$} & \multirow[t]{2}{*}{ Elliptic } & \multirow{2}{*}{ A1 } & \multirow{2}{*}{22} & Co & \multirow{2}{*}{ NA } & \multirow{2}{*}{ NA } & \multirow{2}{*}{ NA } & \\
\hline & & & & $\sigma_{u}$ & & & & \\
\hline Dilatancy & - & A1 & 12 & $\Psi, \delta, \sigma_{u}$ & A2 & 8,12 & $\xi, \gamma$ & \\
\hline Loss of Material & & NA & NA & NA & A2 & 9 & $\xi, \gamma$ & \\
\hline
\end{tabular}

\section{Verification and calibration of interface model}

For verification, the interface model was tested for its overall behavior. A single joint placed in between two elastic masonry blocks was tested under compression, tension, and direct shear loads. The methods of analysis, 
namely Modified Newton-Raphson and the secant method with BFGS (Broyden, Fletcher, Goldfarb, and Shannoare), are used in different analyses and checked for efficiency. The direct solver is employed, and the convergence criterion is set for a small value of the norm of the residual energy at each iteration. The step size is varied for each run in order to find and fit the parameters to their best performance.

\section{Verification and calibration analyses}

For verification purposes, three different analyses of an interface element were performed using DIANA. The first analysis was executed to check the tensile capacity of the interface element, as shown in Figure 6. The interface element reached a tensile capacity of 38.2 psi before significant joint opening and tension softening occurred. The second analysis consisted of a shear softening test with no applied normal pressure, as represented by Figure 7. The third analysis was a shear softening test with an applied normal pressure of $100 \mathrm{psi}$, as shown in Figure 8. As expected, the normal compressive force increased the shear capacity, yielding a maximum shear stress of 123.8 psi. Figure 7 and Figure 8 demonstrate the DIANA implemented constitutive model. The input values for the interface element material parameters are given in Table 2 , which is followed by a definition of the parameter symbols. The behavior of the joint under a constant normal pressure of 100 psi followed by a cyclic shear load was tested for one full cycle, as shown in Figure 9. For demonstration purposes, Figure 10 is shown to represent the same plot as Figure 9 using the DIANA postprocessor.

Table 2. Material parameters for DIANA interface element verification analysis.

\begin{tabular}{|l|l|l|l|l|l|l|l|l|l|l|l|l|l|l|}
\hline $\mathrm{K}_{\mathrm{nn}}$ & $\mathrm{K}_{\mathrm{ss}}$ & $\mathrm{f}_{\mathrm{t}}$ & $\mathrm{G}_{\mathrm{f}}^{\prime}$ & $\mathrm{c}$ & $\phi_{\mathrm{i}}$ & $\Psi_{\mathrm{i}}$ & $\phi_{\mathrm{r}}$ & $\sigma_{\mathrm{u}}$ & $\delta$ & $\mathrm{G}_{\mathrm{fl}}$ & $\mathrm{f}_{c}^{\prime}$ & $\mathrm{C}_{\mathrm{s}}$ & $\mathrm{G}_{\mathrm{fc}}$ & $\mathrm{K}_{\mathrm{p}}$ \\
\hline $2.8 \mathrm{E}+5$ & $3.5 \mathrm{E}+5$ & 40 & 1.69 & 40 & 0.79 & 0.005 & 0.65 & 150 & 2.3 & 16.1 & 1,500 & 1.0 & 2 & 0.006 \\
\hline
\end{tabular}

\footnotetext{
Definition of symbols:

$\mathrm{K}_{\mathrm{nn}}$ and $\mathrm{K}_{\mathrm{ss}}$ are the normal and tangential numerical stiffness parameters of the joint

$\mathrm{f}_{\mathrm{t}}=$ joint tensile strength

$\mathrm{Gf}^{\prime}=$ first mode fracture energy

$c=$ cohesion

$\phi_{\mathrm{i}}=$ internal friction angle

$\psi=$ dilatancy angle

$\varphi_{o}=$ initial internal friction angle

$\phi_{r}=$ residual internal friction angle

$\sigma_{u}=$ confining stress over which the dilatancy will be zero

$\delta=$ dilatancy shear slip degradation coefficient
} 


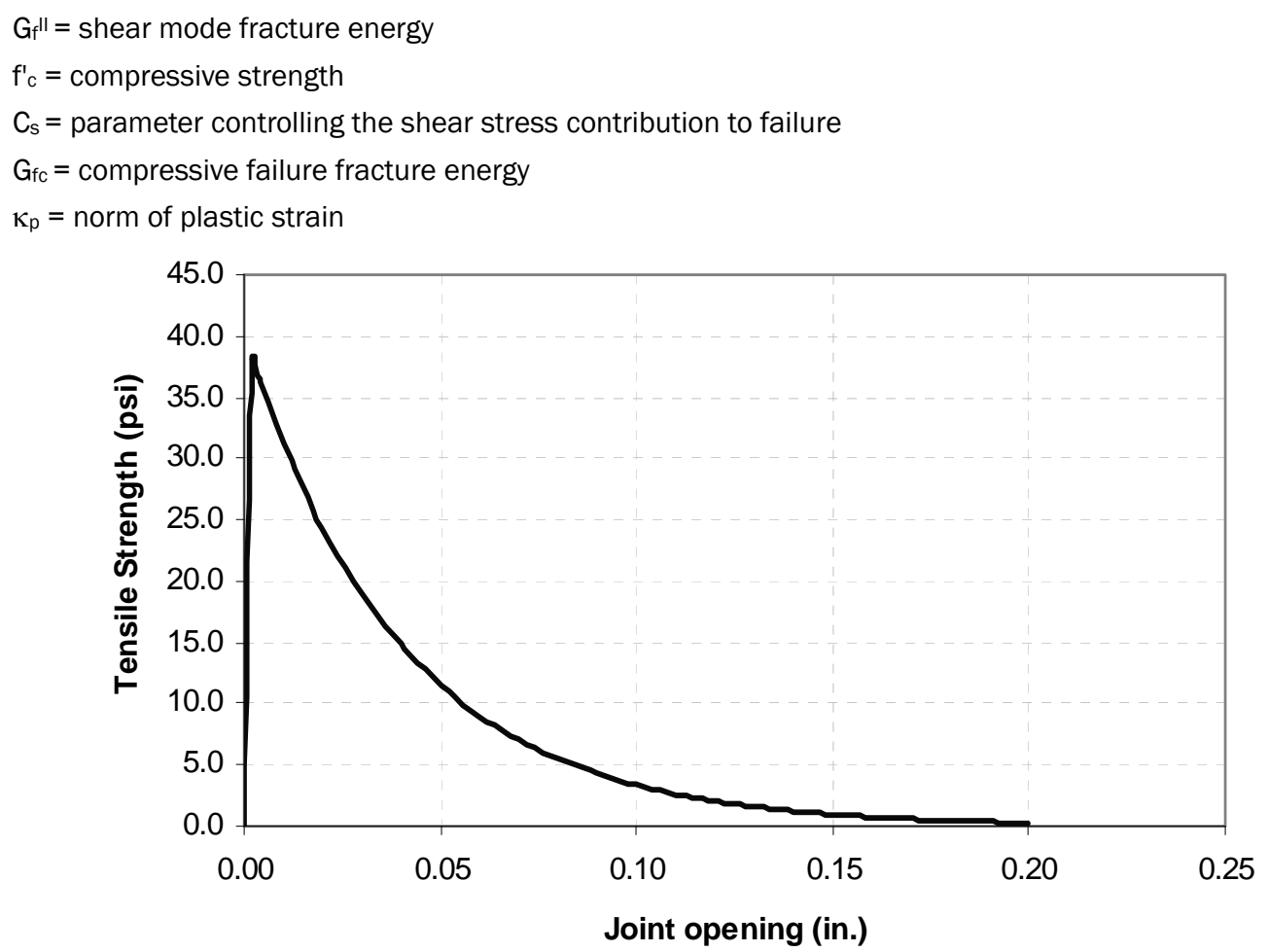

Figure 6. Interface element tension softening curve from DIANA analysis.

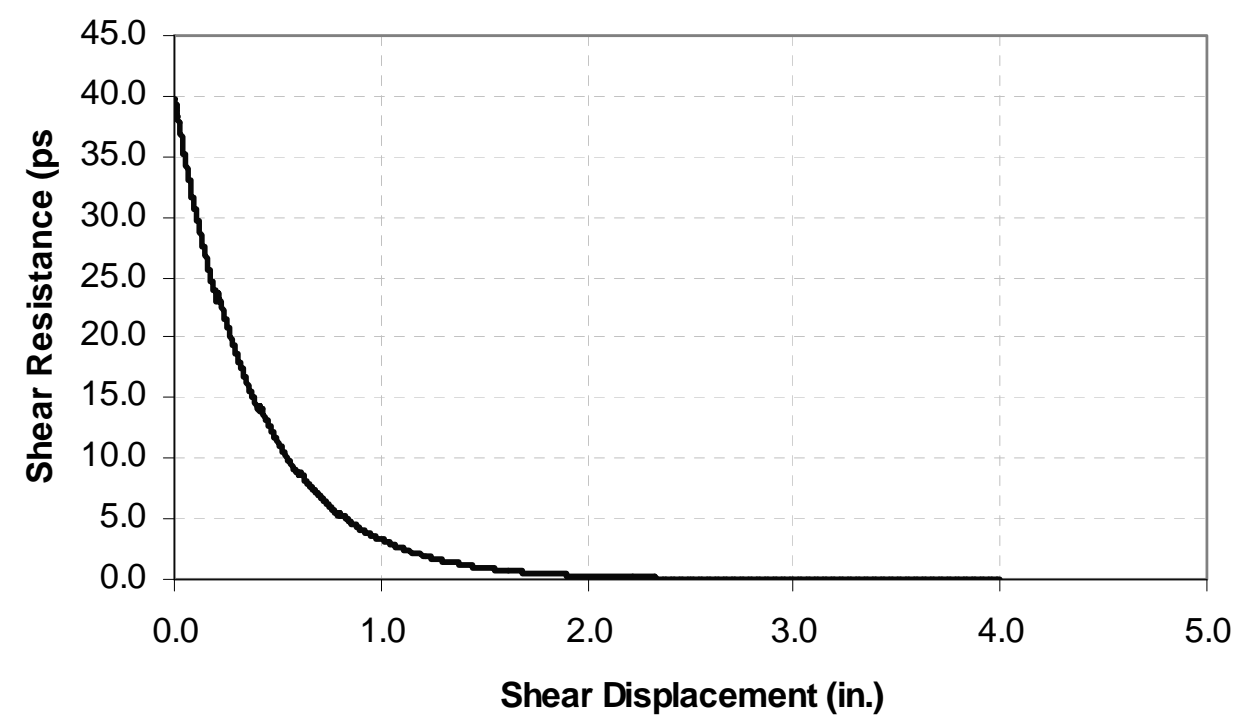

Figure 7. Interface shear softening under zero normal stress from DIANA analysis. 


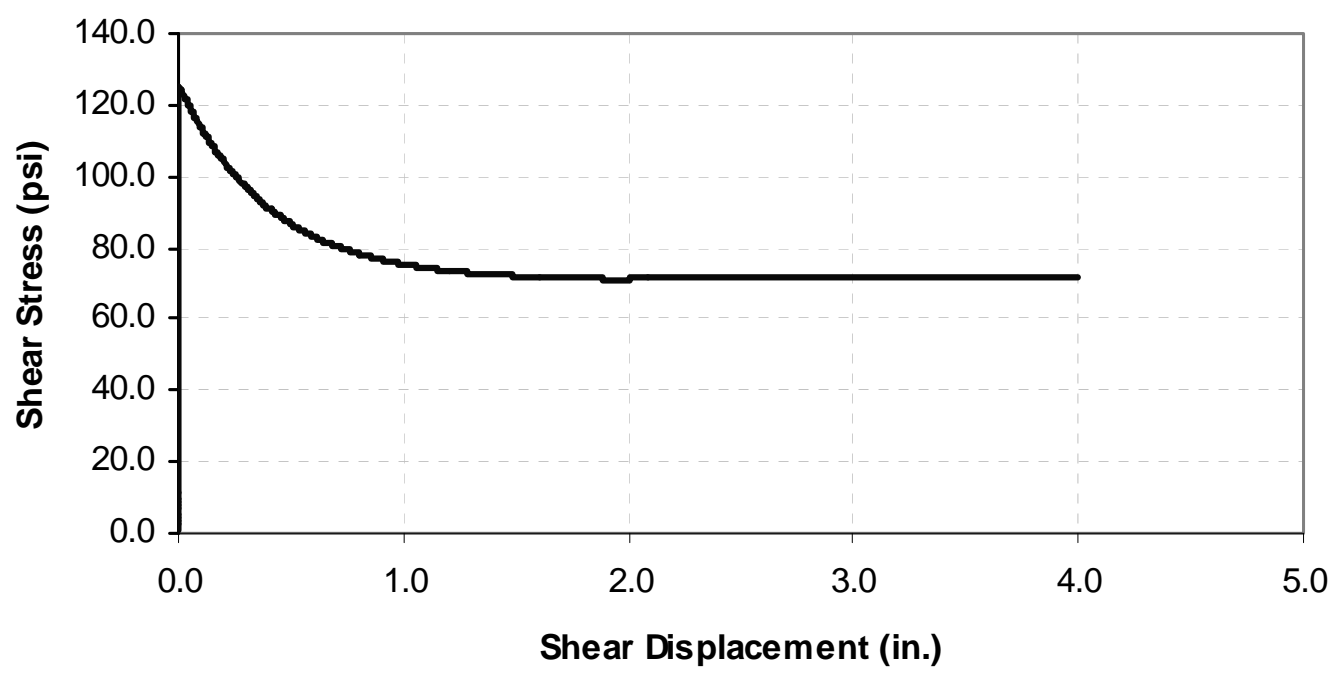

Figure 8. Interface shear softening under 100 psi normal stress from DIANA analysis.

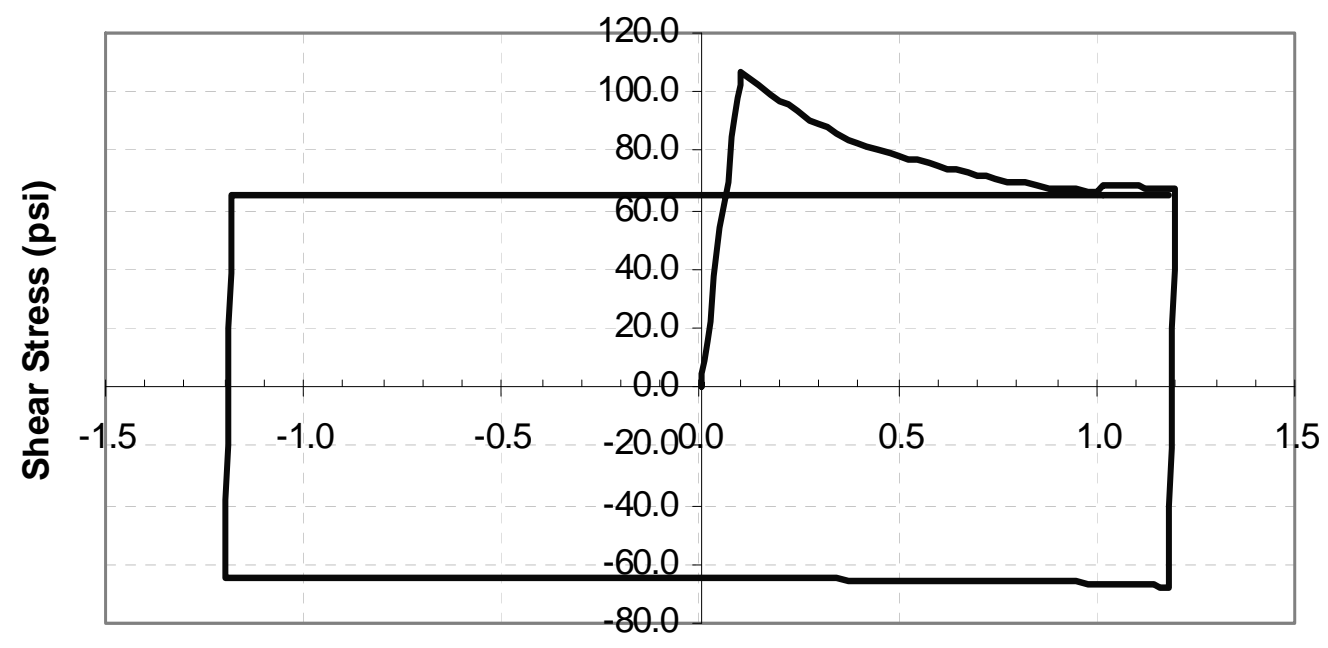

Shear Displacement (in.)

Figure 9. Interface element subjected to cyclic shear loading under 100 psi normal stress. 


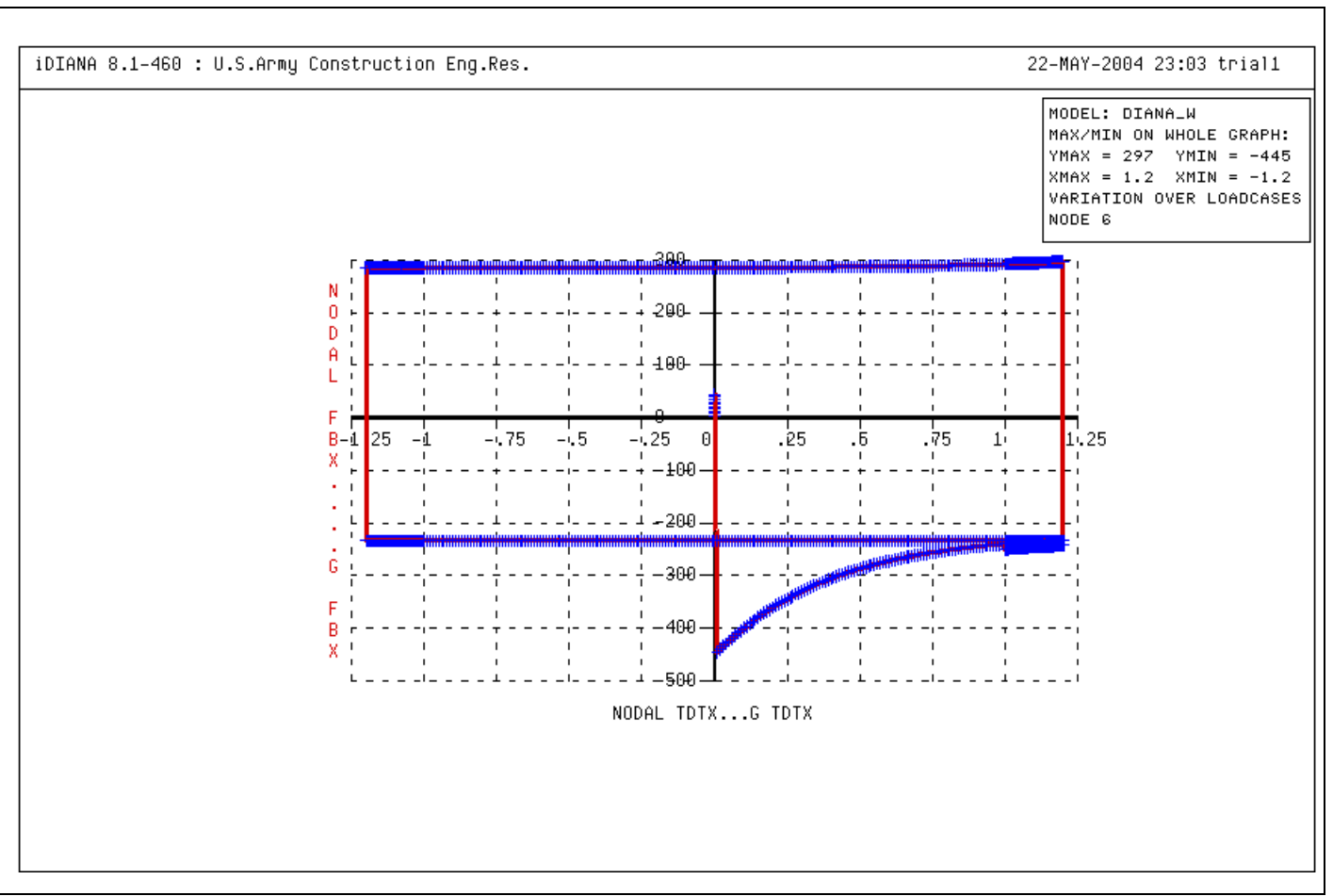

Figure 10. Interface element subjected to cyclic shear loading under 100 psi normal stress, as output by the DIANA post-processor.

Numerical verification of the interface model

The capability of the interface constitutive model was validated using data produced in the direct shear tests conducted on mortar joints performed by Mehrabi et al. (1994). The constitutive model was implemented in a one-dimensional isoparametric interface element. For the calibration of the model, data from shear tests conducted under three different levels of normal stresses (100 and 150 psi) and subjected to cyclic loading are desirable.

The model was calibrated based on the parameters of the comparative interface model. These characteristics are very similar to parameters defined previously in Table 2. The dilatancy in both models does well in the monotonic loading regime. As the loads are changed to cyclic, the cumulative damage represented by the loss of joint material is not modeled appropriately by the standard interface model built into DIANA. The loss is a physical fact observed in direct shear tests on masonry bed joints and rock joints.

To calibrate and verify the interface analytical model, two trials were run in DIANA with a slight variation in the material parameters for the inter- 
face element, namely $\delta$. Table 3 details the material parameters of the comparative model and Table 4 details the parameters used for the two different DIANA trials.

Next, the DIANA models were run, and the results were compared with the numerical and experimental results of the comparative model using the two different trials previously noted. Figure 11 represents a sample shear deformation of the interface element as shown in the DIANA postprocessing window. The shear stress versus shear displacement results of the calibrated DIANA model, subjected to a 100 psi normal stress, are shown in Figure 12. Those results are verified using the results of the comparative model under the same loading conditions, as shown in Figure 13. The results demonstrate the model's capability to simulate the cyclic behavior of rock and mortar joints under a constant normal pressure.

Table 3. Material parameters of the comparative model.

\begin{tabular}{|l|l|l|l|l|l|l|l|l|l|l|l|l|l|l|l|l|}
\hline$K_{\text {nn }}(\mathrm{ksi})$ & $\mathrm{D}_{\mathrm{tt}}(\mathrm{ksi})$ & $\mathrm{S}_{\mathrm{o}}(\mathrm{psi})$ & $\mathrm{G}_{f}(\mathrm{lb}-\mathrm{in})$ & $\mathrm{c}(\mathrm{psi})$ & $\phi \mathrm{i}$ & $\phi \mathrm{r}$ & $\boldsymbol{\alpha}$ & $\boldsymbol{\delta}$ & $\mathrm{Gfl}^{\prime}(\mathrm{lb}-\mathrm{in})$ & $\boldsymbol{\beta}$ & $\mathrm{r}_{\mathrm{o}}(\mathrm{psi})$ & $\mathrm{r}_{\mathrm{r}}(\mathrm{psi})$ & $\boldsymbol{s}_{\mathrm{o}}$ & $\boldsymbol{s}_{\mathrm{r}}$ & $\gamma$ & $\eta$ \\
\hline 28 & 35 & 40 & 1.61 & 26 & 0.9 & 0.8 & 4 & 0 & 16.1 & 2 & 10 & 5 & 0.45 & $3 \mathrm{E}-04$ & 3 & 55 \\
\hline
\end{tabular}

Table 4.Interface element material parameters for trials 1 and 2 .

\begin{tabular}{|l|l|l|l|l|l|l|l|l|l|l|l|l|l|l|l|}
\hline Trial & $\mathrm{K}_{\mathrm{nn}}$ & $\mathrm{K}_{\mathrm{ss}}$ & $\mathrm{f}_{\mathrm{t}}$ & $\mathrm{G}_{\mathrm{f}}$ & $\mathbf{c}$ & $\phi_{\mathrm{i}}$ & $\boldsymbol{\Psi}_{\mathrm{i}}$ & $\boldsymbol{\phi}_{\mathrm{r}}$ & $\sigma_{\mathrm{u}}$ & $\boldsymbol{\delta}$ & $\mathrm{G}_{\mathrm{f}}{ }^{\prime \prime}$ & $\mathbf{f}_{\mathrm{c}}^{\prime}$ & $\mathrm{C}_{\mathrm{s}}$ & $\mathrm{G}_{\mathrm{fc}}$ & $\boldsymbol{\kappa}_{\mathrm{p}}$ \\
\hline 1 & $2.8 \mathrm{E}+4$ & $3.5 \mathrm{E}+4$ & 40 & 1.69 & 26 & 0.9 & 0.005 & 0.8 & 150 & 2.3 & 16.1 & 1,500 & 1.0 & 2 & 0.006 \\
\hline 2 & $2.8 \mathrm{E}+4$ & $3.5 \mathrm{E}+4$ & 40 & 1.69 & 26 & 0.9 & 0.005 & 0.8 & 150 & 0.5 & 16.1 & 1,500 & 1.0 & 2 & 0.006 \\
\hline
\end{tabular}




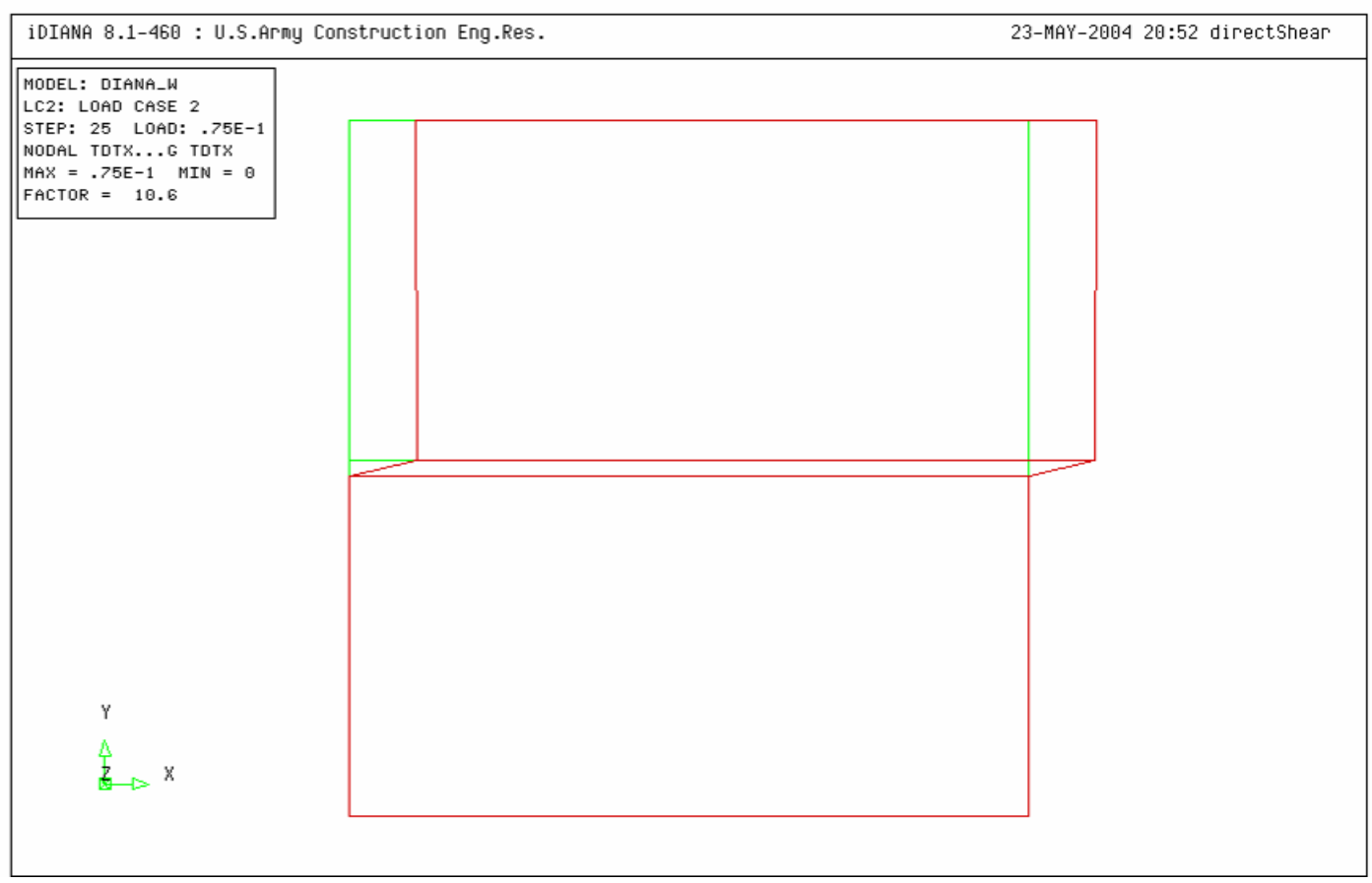

Figure 11. Shear deformation of the interface element shown as DIANA output.

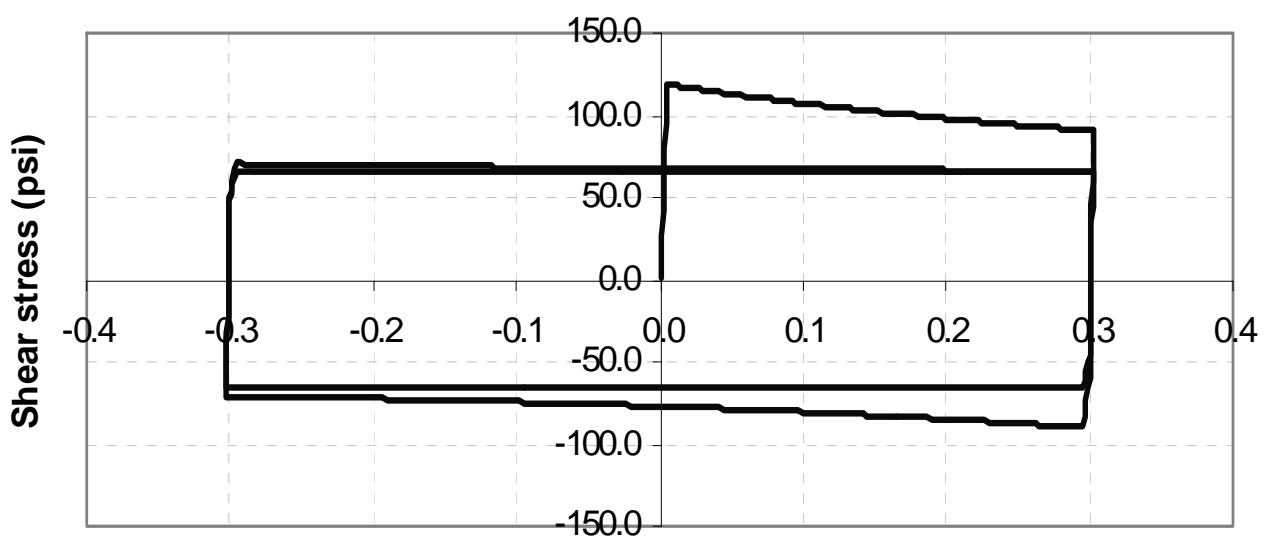

Shear Displacement (in.)

Figure 12. Calibrated DIANA interface element (100 psi normal stress, $\sigma_{v}=150 \mathrm{psi}$ ). 


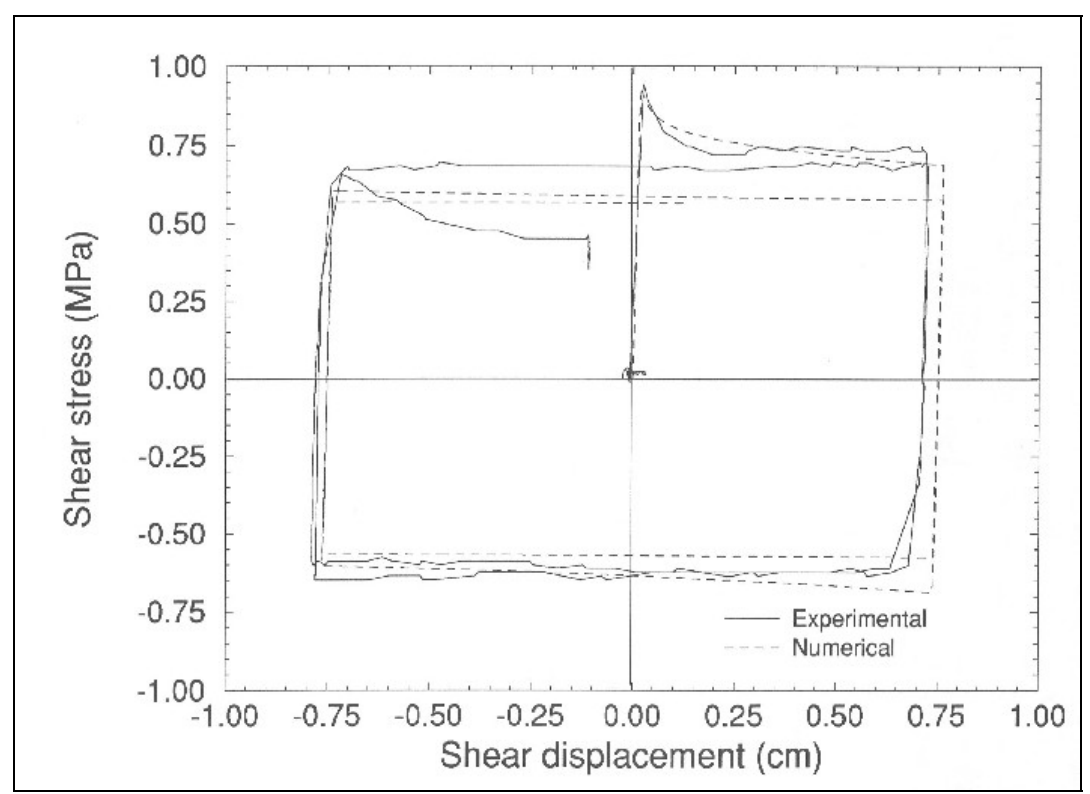

Figure 13. Comparative model results for shear under a 100 psi normal stress.

The results from DIANA match the results from the comparative model very closely. In Figure 14, the dilatancy of the interface element under a $100 \mathrm{psi}$ normal stress is compared with the results of the comparative model. Model results for dilatancy under 100 psi normal stress are shown in Figure 15.

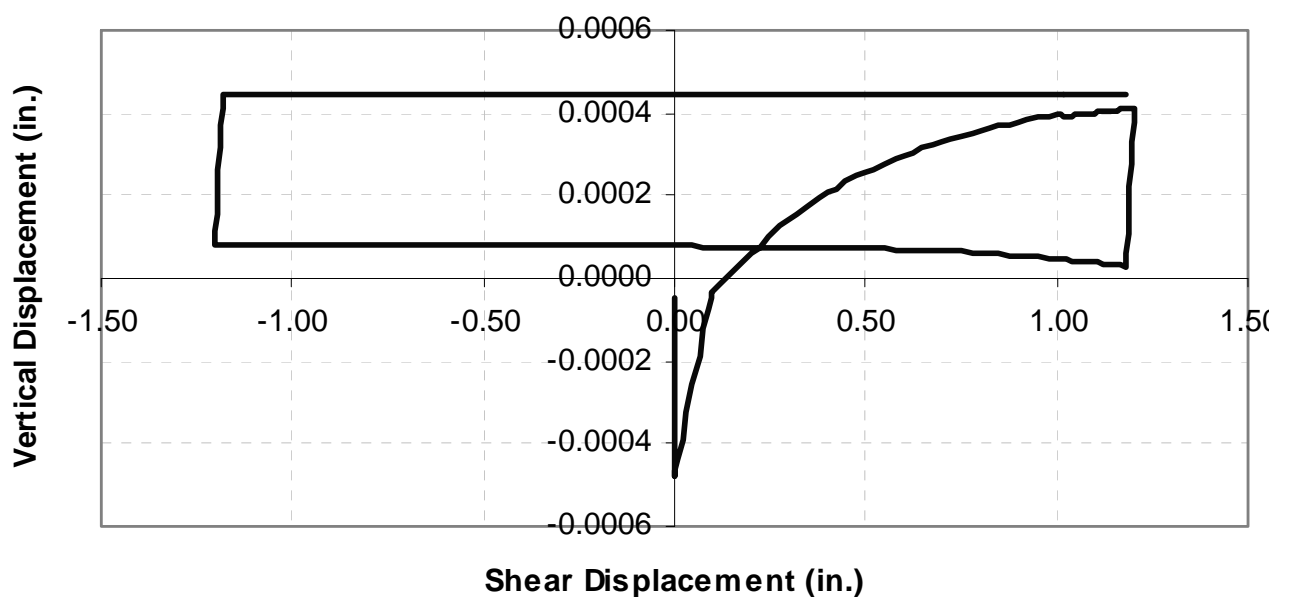

Figure 14. DIANA window showing dilatancy under $100 \mathrm{psi}$ normal stress $\left(\sigma_{u}=150 \mathrm{psi}\right)$. 


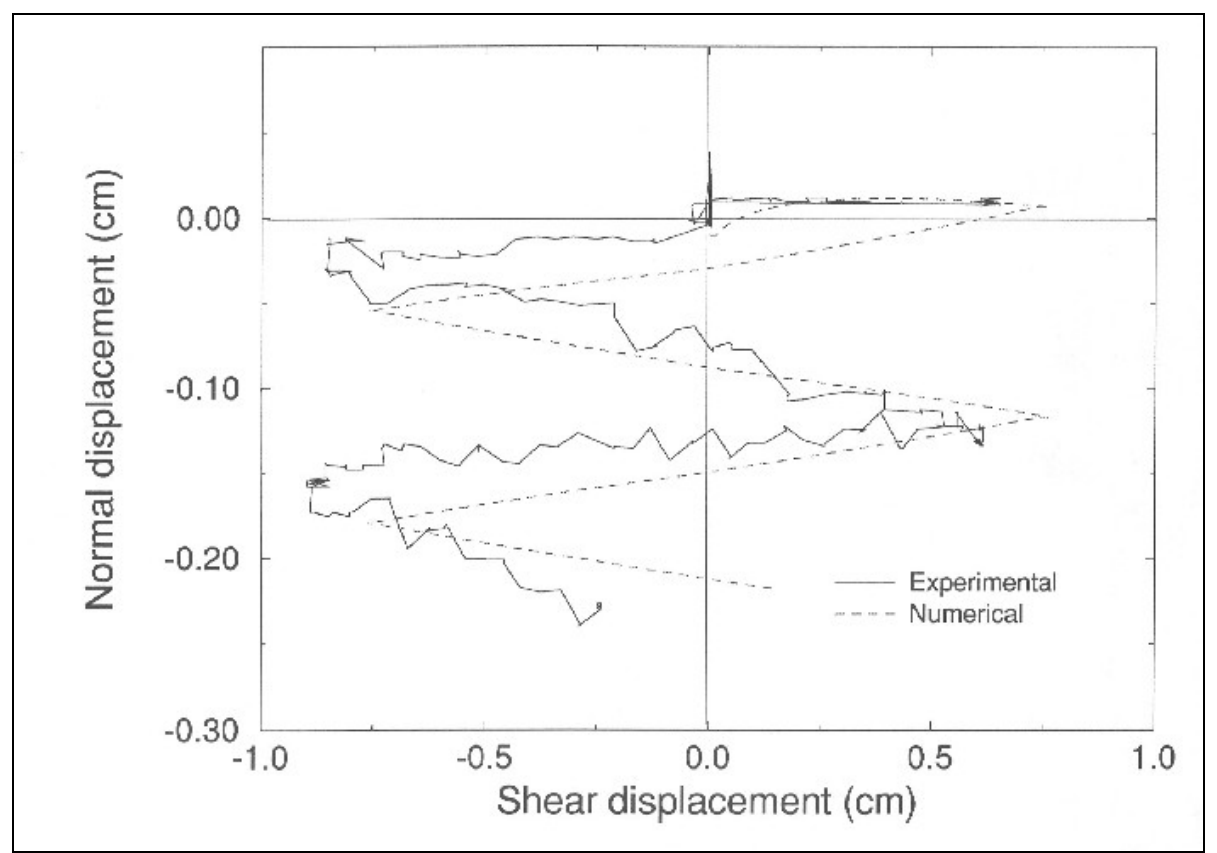

Figure 15. Comparative model results for dilatancy under 100 psi normal stress.

The calibrated DIANA interface element under 150 psi normal stress is shown in Figure 16, and the corresponding dilatancy under 150 psi normal stress is shown in Figure 17. Comparative model results for dilatancy under 150 psi normal stress are shown in Figure 18.

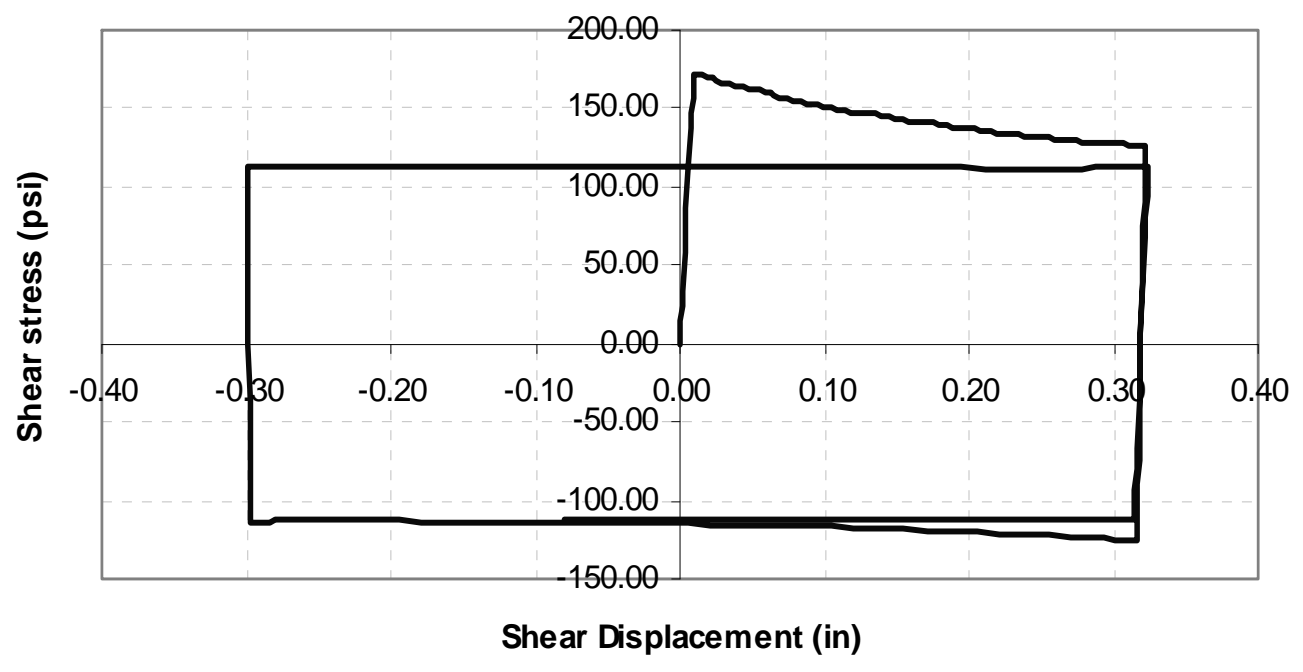

Figure 16. Calibrated DIANA interface element under 150 psi normal stress. 


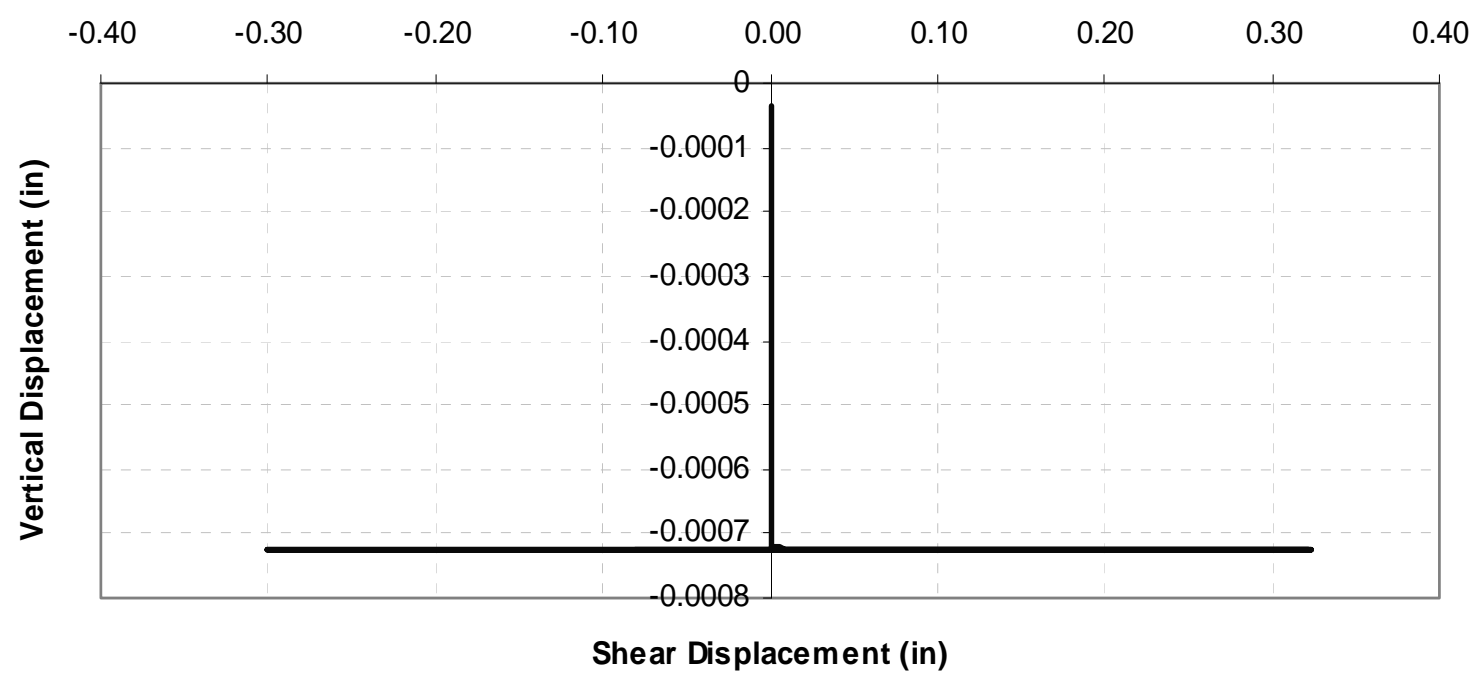

Figure 17. DIANA dilatancy under 150 psi normal stress.

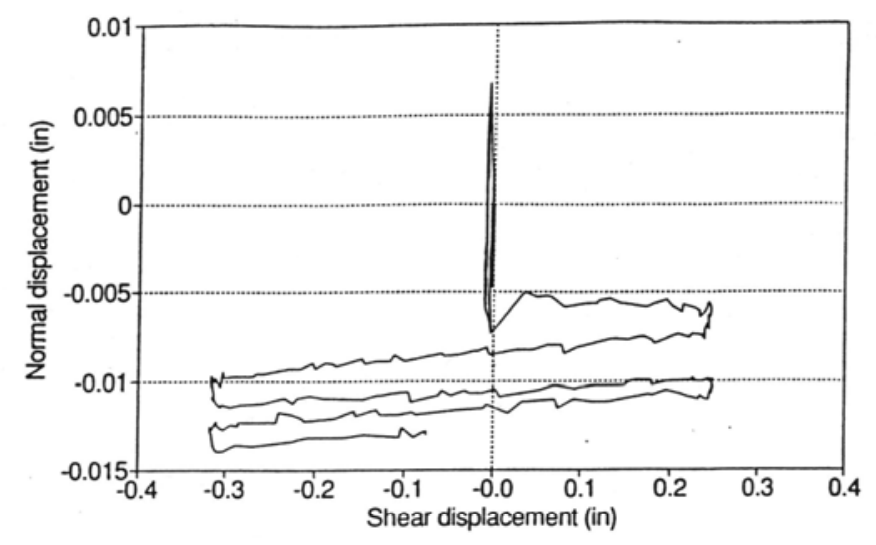

Figure 6.21. Normal Displacement-Shear Displacement Curve for Mortar Joint in Solid Concrete Masonry under 150-psi Normal Stress (Experiment).

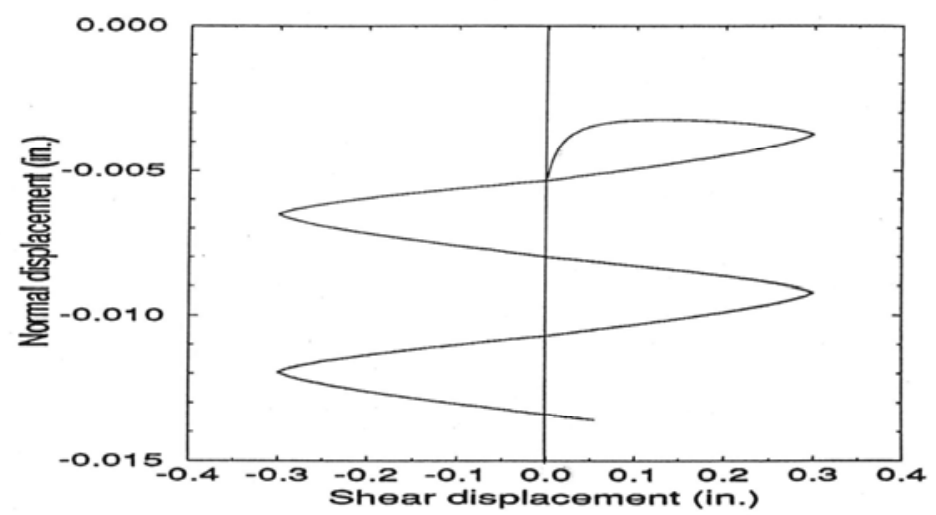

Figure 6.22. Normal Displacement-Shear Displacement Curve for Mortar Joint in Solid Concrete Masonry under 150-psi Normal Stress (Numerical Result).

Figure 18. Comparative model results for dilatancy under 150 psi normal stress. 


\section{Verification and calibration of smeared crack model}

In this section, the primary focus is on the verification of the DIANA total strain smeared crack model for concrete or clay masonry blocks. Without loss of generality, a plain stress condition is considered in this evaluation to match the two-dimensional interface model described previously because the two models will be used together to model masonry assemblages.

To verify the overall behavior of the smeared crack model, a single block was tested under compression, tension, and direct shear. A rotating smeared crack was used, for which the retention factor $G=1.0$. The material parameters for the CMU element tested under these conditions are shown in Table 5, followed by definitions of the symbols. The methods of analysis and the convergence rate are varied for each run in order to find and fit the parameters to their best performance.

Table 5. Material parameters for a single-unit CMU element test.

\begin{tabular}{|l|l|l|l|l|l|l|l|l|l|l|l|l|l|l|}
\hline $\mathrm{E}$ & $\boldsymbol{v}$ & $\mathrm{f}_{\mathrm{t}}$ & $\mathrm{G}_{\mathrm{f}}$ & $\begin{array}{l}\text { Tensile } \\
\text { Curve }\end{array}$ & $\begin{array}{l}\text { Shear* } \\
\text { Curve }\end{array}$ & $\beta$ & $\mathrm{f}_{c}$ & $\begin{array}{l}\text { Comp. } \\
\text { Curve }\end{array}$ & $\mathrm{G}_{\mathrm{c}}$ & $\mathrm{G}_{\mathrm{fl}}$ & $\mathrm{f}_{\mathrm{c}}$ & $\mathrm{C}_{\mathrm{s}}$ & $\mathrm{G}_{\mathrm{fc}}$ & $\mathrm{K}_{\mathrm{p}}$ \\
\hline $3.5 \mathrm{E}+6$ & 0.16 & 200 & 0.03 & Exponential & BEDIAG & 0.02 & 3,000 & Parabolic & 22 & 16.1 & 1500 & 1.0 & 2 & 0.006 \\
\hline
\end{tabular}

* Shear is not defined for a rotating crack model.

Definition of symbols:

$E=$ modulus of elasticity, psi

$v=$ Poisson's ratio

$\mathrm{f}_{\mathrm{t}}=$ tensile strength, $\mathrm{psi}$

$\mathrm{Gf}^{\prime}=$ first mode fracture energy

$\beta=$ the shear retention coefficient

$\mathrm{f}^{\prime}{ }_{c}=$ the compressive strength, psi

$\mathrm{G}_{\mathrm{C}}=$ the fracture energy in compression

REDCRV VC1993 = Effect of lateral cracking on compressive strength

CNFCRV VECCHI = Effect of lateral confinement on compressive strength

Compressive behavior

A set of parameter study cases was run on a four-noded element representing a concrete block. In this study, we were focused on the compressive fracture energy and its effect on the parabolic curve of compressive failure. The concrete masonry unit (CMU) model was calibrated to a value of $\mathrm{Gr}_{\mathrm{f}}^{\mathrm{l}}=55, \mathrm{f}^{\prime} \mathrm{m}=3,000 \mathrm{psi}$, and a modulus of elasticity, E, of 2,000,000 psi. The nonlinear behavior of the CMU element subjected to axial compression, as shown in Figure 19, exhibits a parabolic stress/ strain curve. 


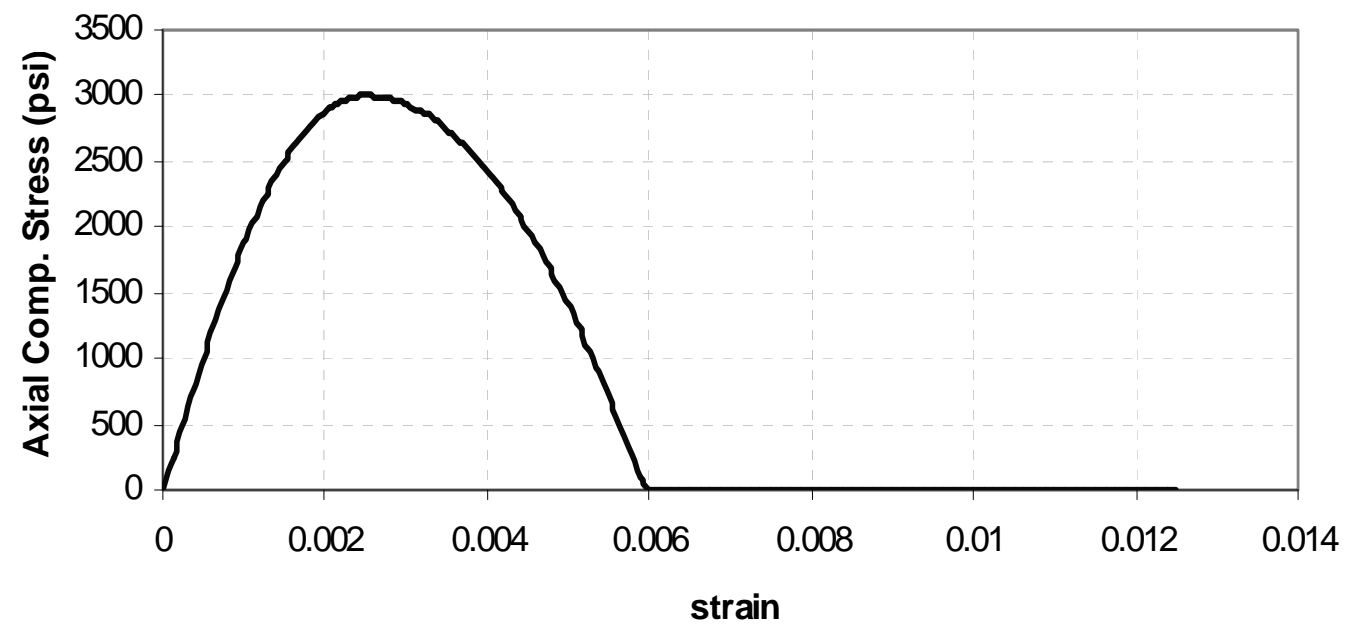

Figure 19. Compressive elastic/plastic hardening/softening for a CMU.

Tensile behavior

The model also was studied for an uniaxial tension case. No reference experiment was used for comparison in this case, so the model was just calibrated for reasonable values of tensile strain associated with the peak stress (200/2E6=0.0001). The model behaved consistently, and the algorithms appeared to be very robust. Figure 20 shows pre- and post-peak results from a monotonic tensile loading of a CMU block, which indicate an exponential curve for the tensile behavior. The model was calibrated in tension to a tensile stress of 200 psi and $\mathrm{Gl}_{\mathrm{I}}^{\mathrm{I}}=18$.

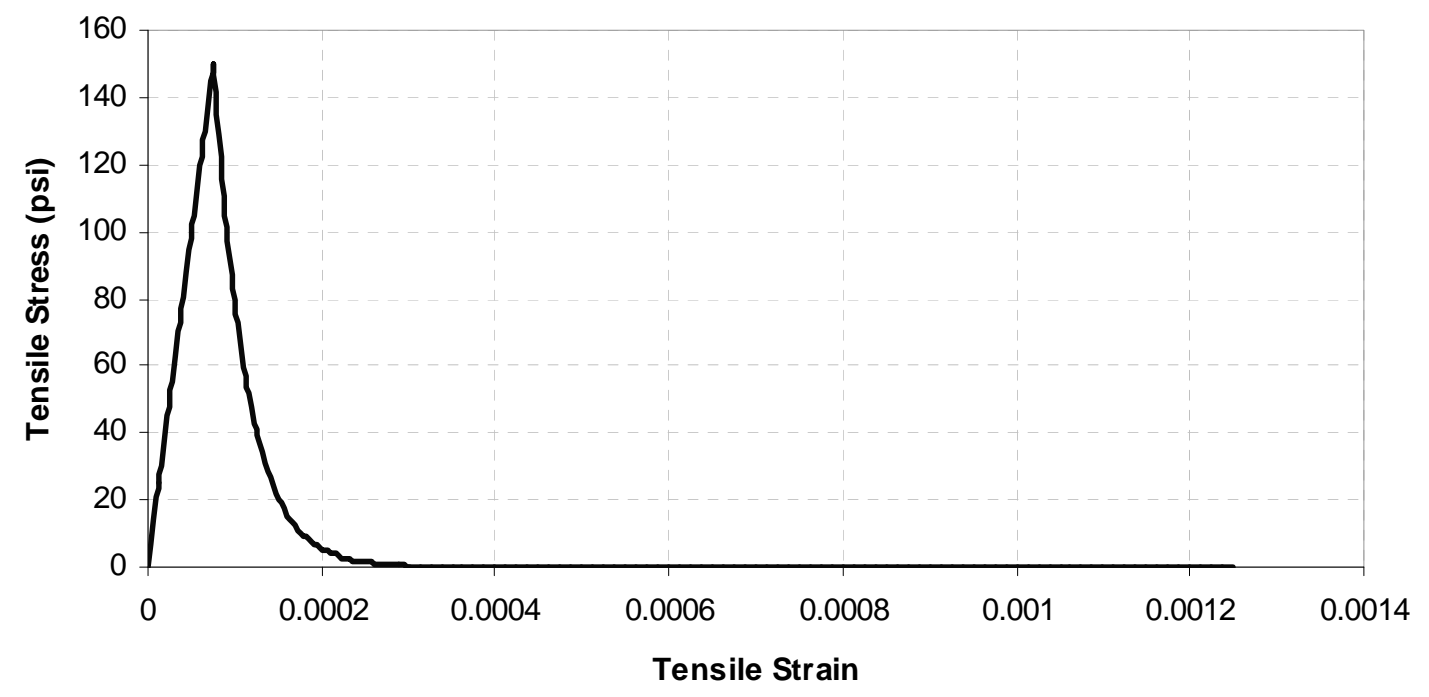

Figure 20.Tensile elastic/plastic softening of a CMU element. 


\section{Modeling and Analysis of Masonry Prisms}

\section{Physical modeling of Mehrabi masonry prisms}

The three-unit, one-half-scale masonry prisms tested by Mehrabi et al. (1994) consisted of concrete hollow or solid blocks with nominal dimensions of $4 \mathrm{in.}$ by $4 \mathrm{in.}$ by $8 \mathrm{in}$. (3.625 in. by $3.625 \mathrm{in}$. by $7.625 \mathrm{in}$. actual) with $3 / 8$ in., Type S masonry mortar joints. The mortar was applied onto face shells only for the case of prisms built with hollow blocks, and onto the entire bed joints for the case of solid block prisms. Hollow blocks had a face shell thickness of $0.625 \mathrm{in}$. Therefore, the equivalent width of mortar joint for hollow blocks was assumed to be twice the shell thickness, i.e., $1.25 \mathrm{in}$. An equivalent thickness of $1.8 \mathrm{in}$. for hollow blocks, including face shells and webs, was calculated based on proportion of net concrete crosssection with respect to the gross cross-sections of the block. Table 6 summarizes the average material properties and test results for hollow and solid masonry prisms. Calculations are based on the results reported by Mehrabi et al. (1994).

Table 6. Average material properties and axial test results for masonry prisms (Mehrabi et al. 1994).

\begin{tabular}{|c|c|c|c|c|}
\hline Type of Blocks & $\mathbf{f}_{\text {cu }}(\mathbf{p s i})$ & $\mathbf{f}_{\mathrm{cm}}$ (psi) & $\mathbf{f}^{\prime} \mathrm{m}$ (psi) & $\varepsilon_{\mathrm{u}}$ (in./in.) \\
\hline Hollow & 2,400 & 2,100 & 1,550 & 0.0031 \\
\hline Solid & 2,300 & 2,100 & 1,930 & 0.0027 \\
\hline
\end{tabular}

This table includes the average compressive strength of masonry units with respect to the net cross-sectional area $\left(f^{\prime}{ }_{c u}\right)$, average compressive strength of masonry mortar tested on cubes $\left(f^{\prime} \mathrm{cm}\right)$, compressive strength of masonry prisms with respect to the net cross-sectional area $\left(f_{m}^{\prime}\right)$, and strain at maximum strength for masonry prisms $\left(\varepsilon_{u}\right)$. A sample stress/ strain curve for one of the prism tests is shown in Figure 21. 


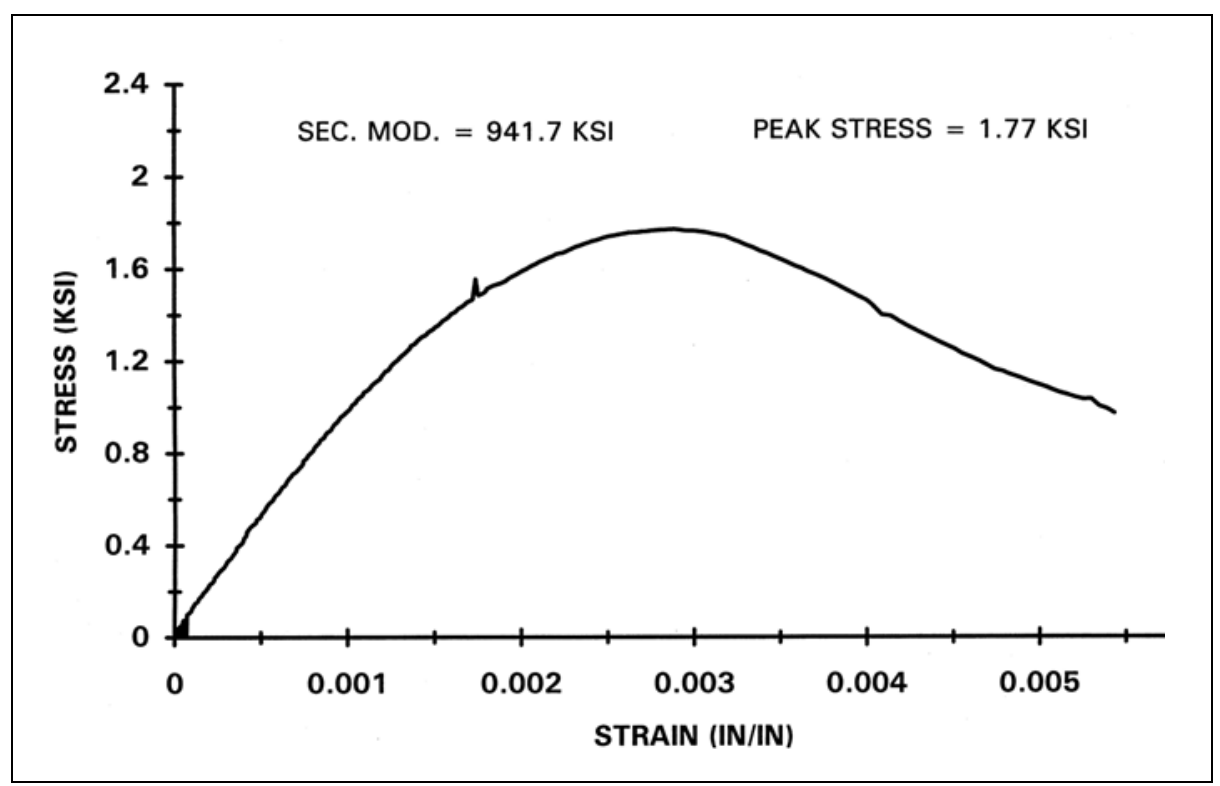

Figure 21. A sample stress/strain curve for axial testing of masonry prisms.

\section{Numerical modeling of Mehrabi masonry prisms}

Two masonry prisms, one made of hollow blocks and the other with solid blocks, were modeled using the DIANA program. Two-dimensional modeling and analysis were carried out using the dimensions and geometry described in the previous section. For the prisms with hollow blocks, equivalent thickness of the blocks was considered to be $1.8 \mathrm{in}$., and the thickness of the mortar joints to be $1.25 \mathrm{in}$. For the prisms with solid blocks, the thickness of blocks was considered to be $3.625 \mathrm{in}$., and width of mortar bed joints was $3.5 \mathrm{in}$.

Masonry units were modeled using rotating smeared crack models, and mortar joints were modeled using interface models. Two-dimensional plain-stress, four-node elements with four integration points were used for masonry units. Two-dimensional four-node interface elements with two integration points were used for mortar joints. Material parameters used for modeling of concrete in hollow and solid blocks are shown in Table 7. 
Table 7. Material parameters for concrete in masonry units, prism analysis.

\begin{tabular}{|l|l|l|l|}
\hline Parameter & Parameter Definition & Value for Hollow Blocks & Value for Solid Blocks \\
\hline $\mathrm{E}$ & Modulus of elasticity & $2 \mathrm{E}+6(\mathrm{psi})$ & $2 \mathrm{E}+6(\mathrm{psi})$ \\
\hline$v$ & Poisson's ratio & 0.16 & 0.16 \\
\hline $\mathrm{ft}_{\mathrm{t}}$ & Tensile strength & $240(\mathrm{psi})$ & $230(\mathrm{psi})$ \\
\hline $\mathrm{Gf}^{\prime}$ & First mode fracture energy & $0.09(\mathrm{psi}-\mathrm{in})$. & $0.09(\mathrm{psi}$-in.) \\
\hline$\beta$ & Shear retention factor & NA & NA \\
\hline $\mathrm{f}^{\prime} \mathrm{c}$ & Compressive strength & $2,400(\mathrm{psi})$ & $2,300(\mathrm{psi})$ \\
\hline $\mathrm{G}_{\mathrm{fc}}$ & $\begin{array}{l}\text { Fracture energy in } \\
\text { compression }\end{array}$ & $22(\mathrm{psi}-\mathrm{in})$. & $22(\mathrm{psi}-\mathrm{in})$. \\
\hline Tension Curve & $\begin{array}{l}\text { Shape of tensile stress/strain } \\
\text { curve }\end{array}$ & Exponential & Exponential \\
\hline $\begin{array}{l}\text { Compression } \\
\text { Curve }\end{array}$ & $\begin{array}{l}\text { Shape of compressive } \\
\text { stress/strain curve }\end{array}$ & Parabolic & Parabolic \\
\hline
\end{tabular}

The parameters are defined also in Table 7. The values of the parameters were determined mostly by the material test results and infilled frame analysis calibration process reported by Mehrabi et al. (1994), and by values defined by verification studies reported in Chapter 2 (page 21). For simplicity, interface normal and shear stiffnesses for solid and hollow blocks are assumed to be the same, and minor differences introduced by Mehrabi et al. (1994) in their calibration process were ignored. The tensile strength of concrete for which no test result was reported is assumed to be $10 \%$ of the compressive strength. The fracture energy in compression, $\mathrm{G}_{\mathrm{fc}}$, was increased to 22 psi-in. to provide strain at maximum strength and a shape of descending branch (softening) in normal stress/normal strain curve similar to that obtained from the test results.

Material parameters and their definitions for interface elements are shown in Table 8. The values for the parameters are mostly determined according to those used by Mehrabi et al. (1994) for bed joints in modeling of the infill walls, and by values defined by verification studies in the first phase of this study. Mehrabi et al. used shear stiffness values for bed joints in analysis of infill walls that are considerably larger than those used for their verification studies for individual mortar joints. It was their conclusion that lower values calibrated according to single joint shear testing do not correspond to practical values due to the fact that deformation of the test machine had distorted the joint deformation measurements. The higher 
stiffness values were the result of their calibration efforts in modeling infilled frames.

Table 8. Parameters defining interface model, prism analysis.

\begin{tabular}{|l|l|}
\hline Parameter and definition & Parameter value \\
\hline $\mathrm{K}_{\mathrm{nn}}=$ normal numerical elastic stiffness parameter & $74 \mathrm{E}+4$ (psi/in.) \\
\hline $\mathrm{K}_{\mathrm{ss}}=$ tangential numerical elastic stiffness parameter & $90 \mathrm{E}+4$ (psi/in.) \\
\hline $\mathrm{f}_{\mathrm{t}}=$ joint tensile strength & $40(\mathrm{psi})$ \\
\hline $\mathrm{G}_{\mathrm{f}}{ }^{\prime}=$ first mode fracture energy & 1.61 (psi-in.) \\
\hline $\mathrm{C}_{\mathrm{o}}=$ initial cohesion & $40(\mathrm{psi})$ \\
\hline$\phi_{\mathrm{i}}=$ tangent of initial internal friction angle & 0.9 \\
\hline$\Psi=$ tangent of dilatancy angle & 0.005 \\
\hline$\phi_{\mathrm{r}}=$ tangent of residual internal friction angle & 0.75 \\
\hline$\sigma_{\mathrm{u}}=$ confining stress over which the dilatancy will be zero & $150(\mathrm{psi})$ \\
\hline$\delta=$ dilatancy shear slip degradation coefficient & 2.3 \\
\hline $\mathrm{G}_{\mathrm{f}}^{\prime \prime}=$ shear mode fracture energy & 16.1 (psi-in.) \\
\hline $\mathrm{f}_{\mathrm{c}} \mathrm{c}=$ compressive strength & $2,100(\mathrm{psi})$ \\
\hline $\mathrm{C}_{\mathrm{s}}=$ parameter controlling the shear stress contribution to failure & 1 \\
\hline $\mathrm{G}_{\mathrm{fc}}=$ fracture energy in compression, interface & 55 (psi-in) \\
\hline $\begin{array}{l}\kappa_{\mathrm{p}}=\text { norm of plastic strain associated with peak compressive } \\
\text { strength }\end{array}$ & 0.006 \\
\hline
\end{tabular}

The compression cap value, $\mathrm{f}_{\mathrm{c}}^{\prime}$, was defined by the compressive strength of masonry mortar reported by Mehrabi et al. (1994). The fracture energy in compression, $\mathrm{G}_{\mathrm{fc}}$, was increased to $55 \mathrm{psi}$-in. to provide strain at maximum strength and a gradual descending branch (softening) in the normal stress/ normal strain curve similar to that obtained from test results.

All nodes at the bottom of the lower masonry unit were restrained in every direction and a uniform vertical displacement was applied at upper nodes in the top masonry unit. The loaded nodes were restrained from horizontal movement, assuming a perfect bond between loading cap and masonry units in the prism test. A sample finite element mesh and stress distribution is shown in Figure 22. The stress distribution reflects the formation of shear cones in the prisms. Stress rise at the upper bed joint shows initiation of the failure at that joint. 


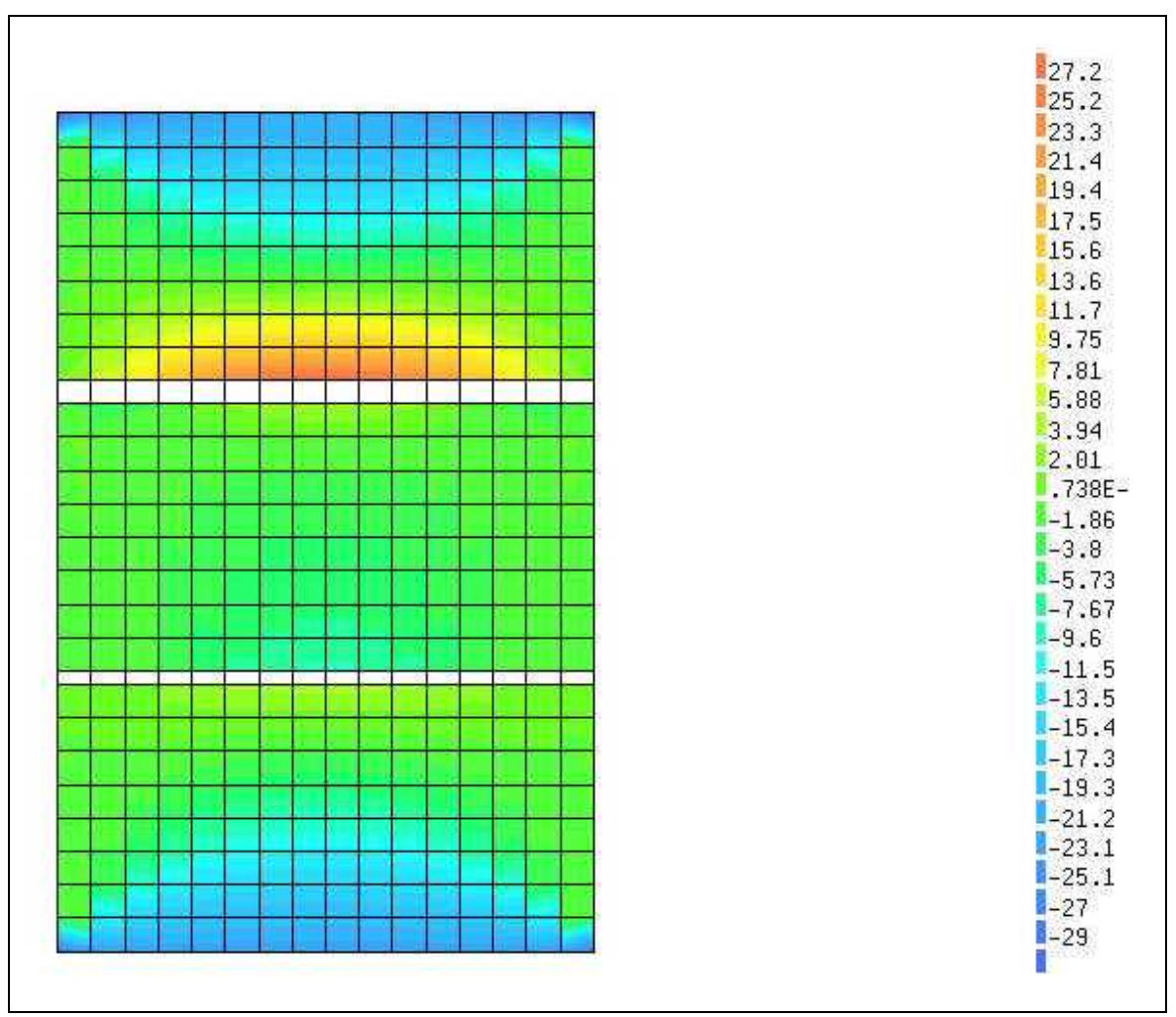

Figure 22. A sample finite element mesh and stress contour for masonry prism analyses.

Figure 23 shows normal stress/normal strain curves for hollow and solid block prisms. The maximum strength, strain at maximum strength, and softening curves agree well with the test results. The normal stress is calculated based on an equivalent thickness of $1.8 \mathrm{in}$. and $3.625 \mathrm{in}$. for hollow and solid block prisms, respectively. It should be noted that the failure of the prisms in the analysis was initiated and dominated by the failure of mortar joints. This type of failure is not precisely consistent with the laboratory tests in which failure is dominated by conic shear failure of the masonry units. The two-dimensional model used for the analysis is not capable of generating the confinement in the mortar required for transferring the failure to the masonry blocks. This inability to confine the mortar is a limitation of the two-dimensional model used in this study. 


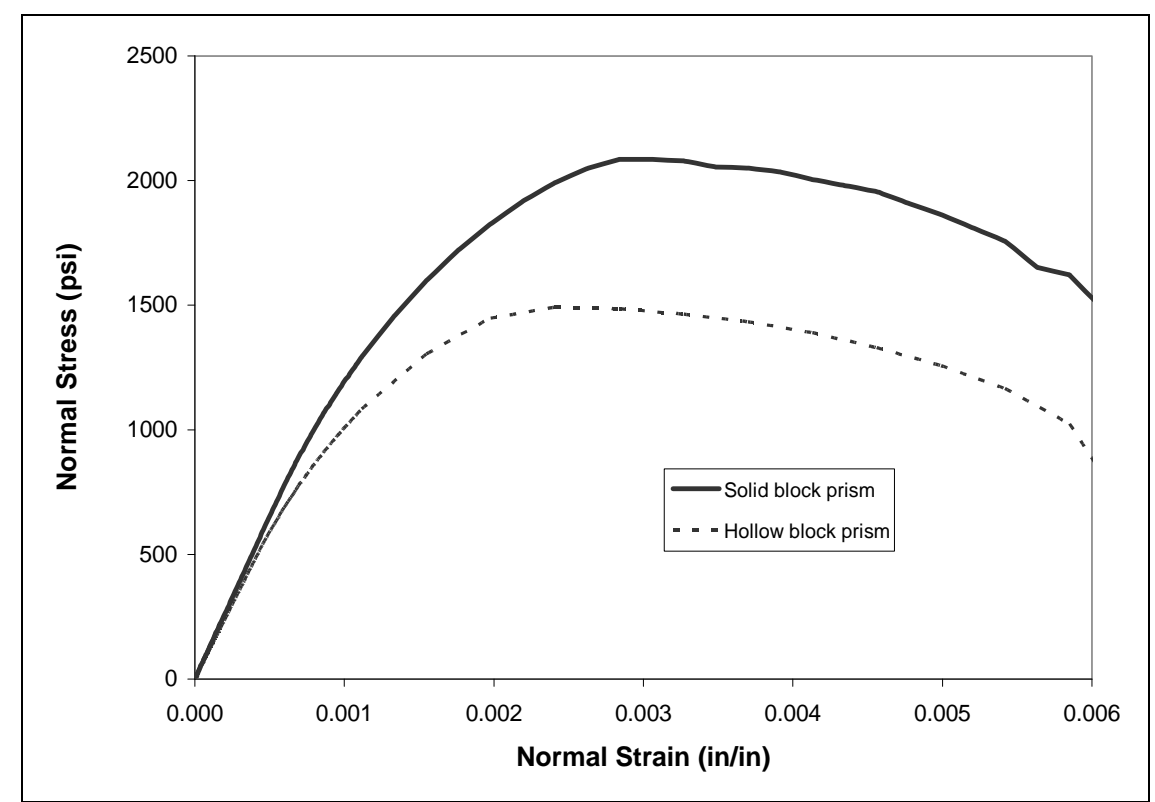

Figure 23. Normal stress/normal strain curves for hollow and solid block masonry prisms.

\section{Comparison of experimental and analytical results}

A prism built of three blocks and two bed joints was tested in compression. The blocks were modeled with the same material parameters as above. The joints were modeled using the aforementioned interface model. Loading was applied monotonically. The small relative stiffness of the joint with respect to the block, which could have potentially caused numerical problems, was increased by a factor of 10 . The material parameters for the prism masonry assembly, including CMU and interface elements (mortar), are given in Table 9. Stress contours are shown in Figure 24 and Figure 25.

Table 9. Material parameters for the prism masonry assembly.

\begin{tabular}{|c|c|c|c|c|c|c|c|c|c|c|c|c|c|c|}
\hline \multicolumn{15}{|c|}{ CMU Element Material Parameters } \\
\hline$E$ & $v$ & $\mathrm{f}_{\mathrm{t}}$ & $G_{f}^{\prime}$ & $\begin{array}{l}\text { Tensile } \\
\text { curve }\end{array}$ & $\begin{array}{l}\text { Shear* } \\
\text { curve }\end{array}$ & $\beta$ & $f_{c}^{\prime}$ & $\begin{array}{l}\text { Comp. } \\
\text { Curve }\end{array}$ & $\mathrm{G}_{\mathrm{c}}$ & Gf" & $f_{c}$ & $\mathrm{C}_{\mathrm{s}}$ & $\mathrm{G}_{\mathrm{fc}}$ & $\kappa_{p}$ \\
\hline $3.5 \mathrm{E}+6$ & 0.16 & 200 & 0.03 & Exponential & BEDIAG & 0.02 & 3,000 & Parabola & 22 & 16.1 & 1,500 & 1.0 & 2 & 0.006 \\
\hline \multicolumn{15}{|c|}{ Interface Element Material Parameters } \\
\hline $\mathrm{K}_{\mathrm{nn}}$ & $\mathrm{K}_{\mathrm{ss}}$ & $\mathrm{f}_{\mathrm{t}}$ & $\mathrm{G}_{\mathrm{f}}$ & c & $\phi_{\mathrm{i}}$ & $\Psi_{\mathrm{i}}$ & $\phi r$ & $\sigma_{u}$ & $\delta$ & $\mathrm{Gfl}^{\prime \prime}$ & $f_{c}$ & $\mathrm{C}_{\mathrm{s}}$ & $\mathrm{G}_{\mathrm{fc}}$ & $\kappa_{\mathrm{p}}$ \\
\hline $2.8 \mathrm{E}+4$ & $3.5 \mathrm{E}+4$ & 40 & 1.69 & 26 & 0.9 & 0.005 & 0.8 & 150 & 0.5 & 16.1 & 1,500 & 1.0 & 2 & 0.006 \\
\hline
\end{tabular}

* Shear is not defined for a rotating crack model. 


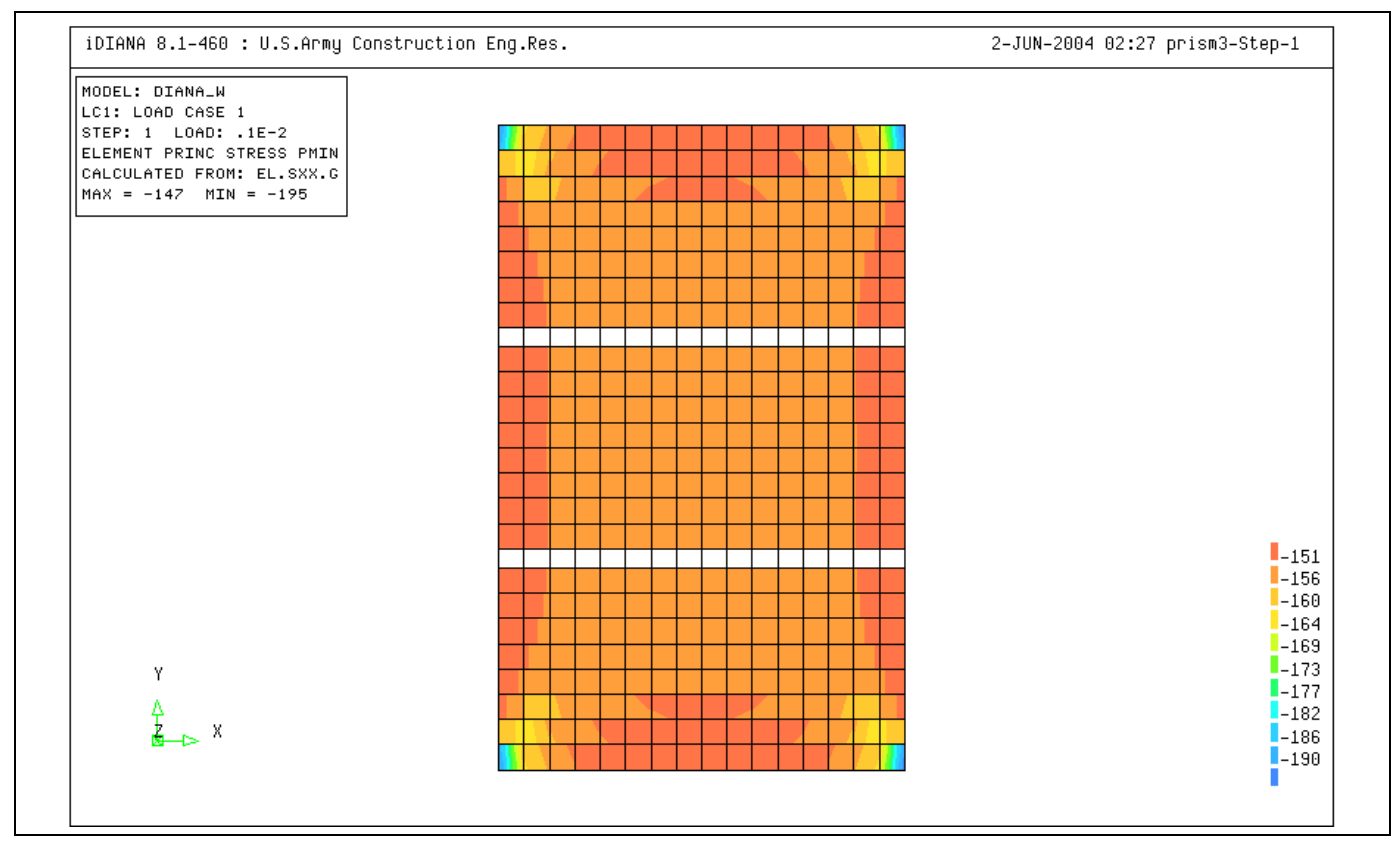

Figure 24. The prism at step 1.

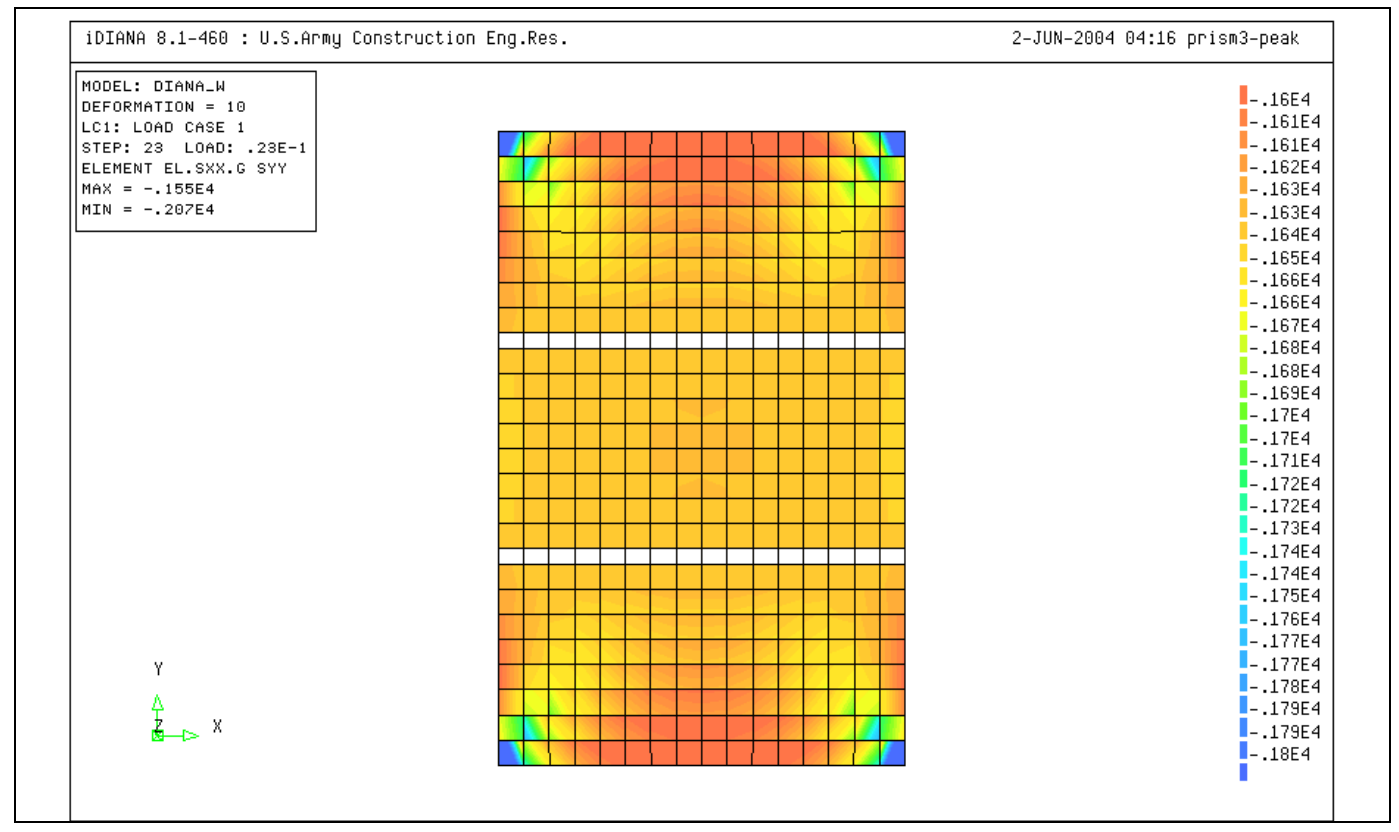

Figure 25. The prism at the peak load (step 23).

The diagonal localization of strains can be observed. These localization bands unload faster than adjacent material, causing overloading and a higher damage rate in the neighborhood. Figure 26 shows successful capture of peak and post peak regions. 


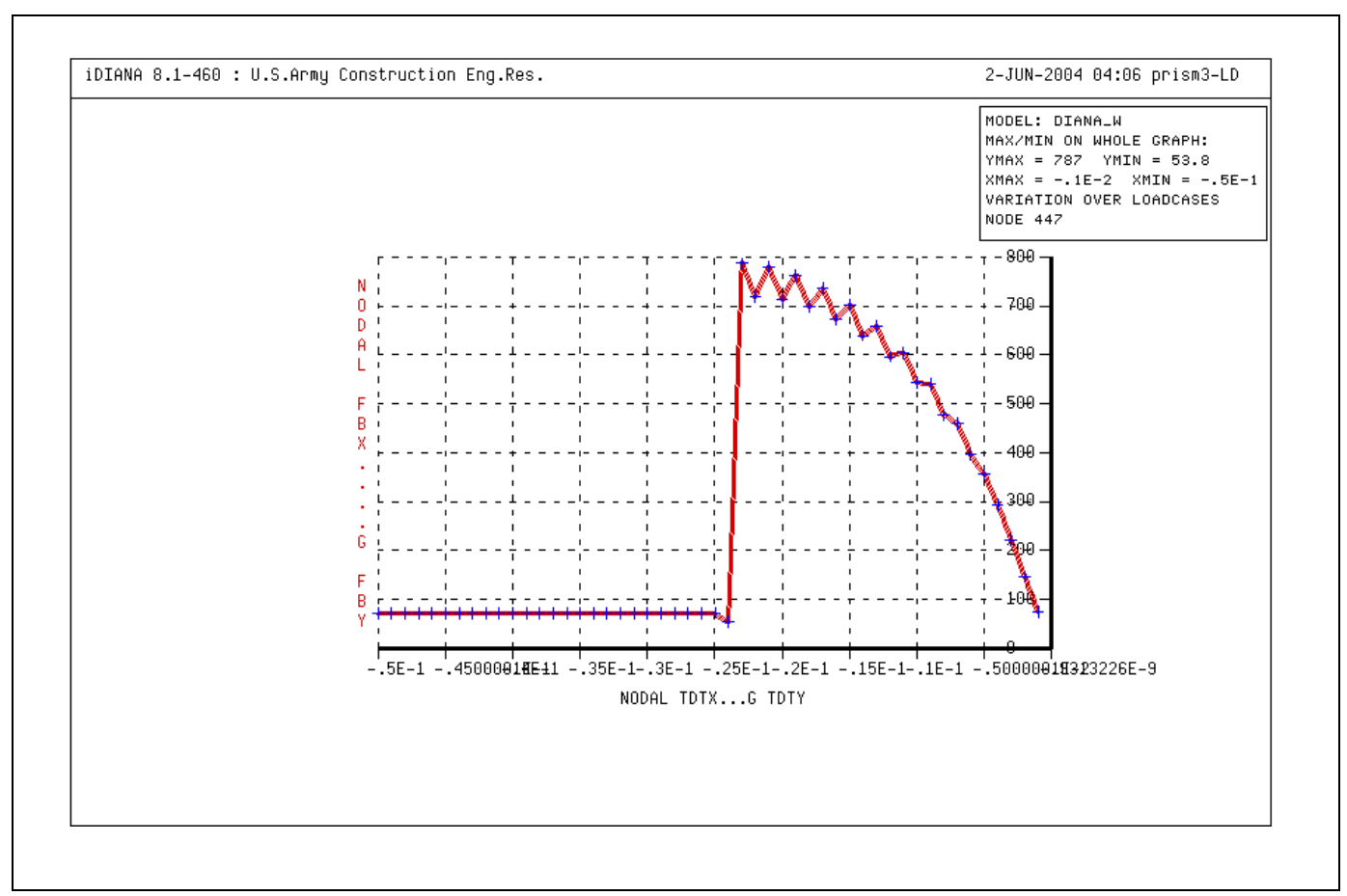

Figure 26. Load-displacement of node 447.

This behavior is equivalent to a peak of 1,600 psi at a strain of 0.002 . The strength appears to be acceptable, and it is an indication that the mortar joint has affected the prism's overall strength. In reality, a 3,000 psi block placed in a prism assembly will exhibit decreases in overall strength to $1,500 \mathrm{psi}$. The peak load strain of 0.002 , however, is rather small, indicating excessive damage propagation within the materials. Experimental data on different prisms indicate that this strain should range between 0.003 0.005. Element stress distribution is shown in Figure 27. 


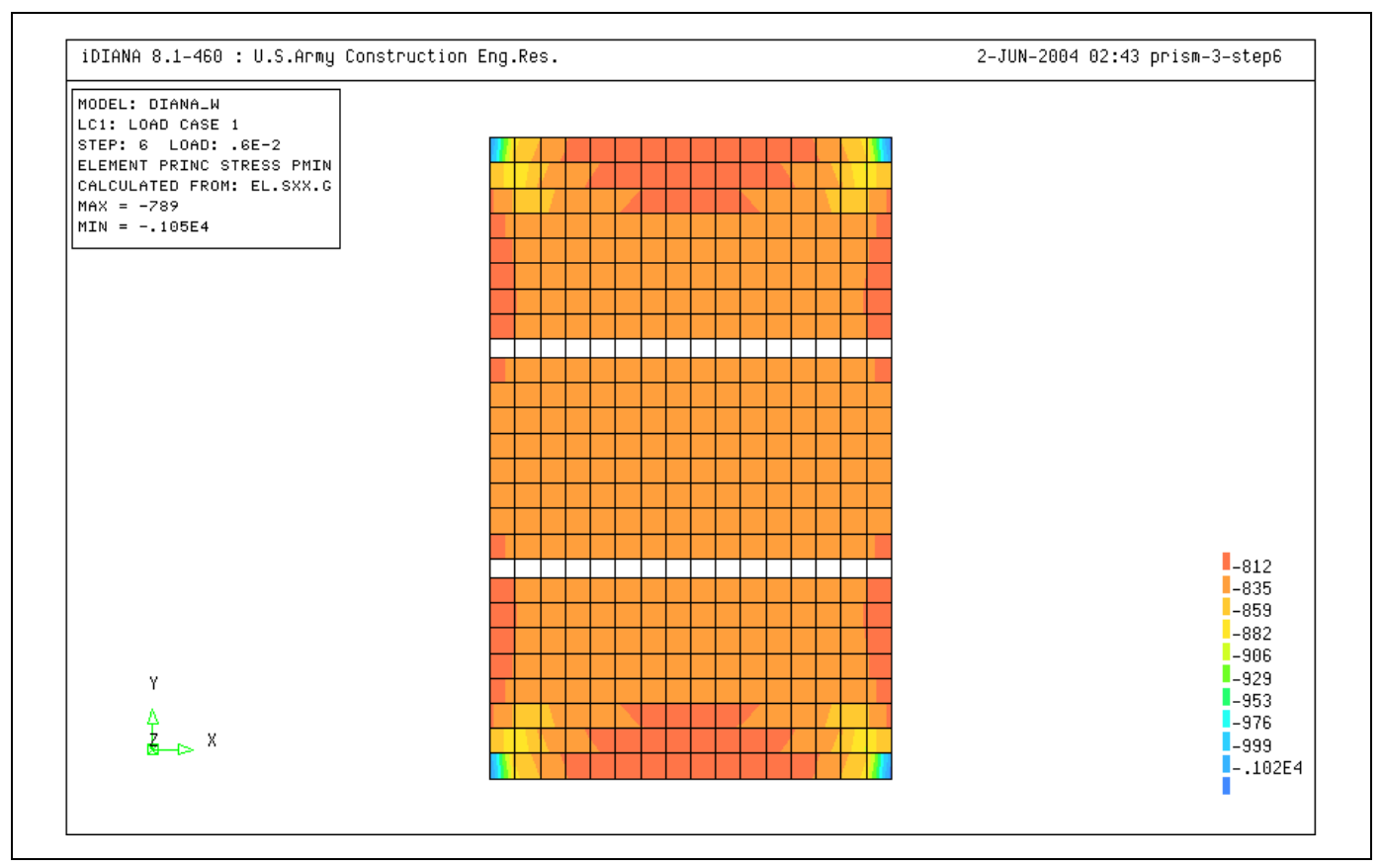

Figure 27. Element stress distribution step 6. 


\section{Modeling and Analysis of Masonry-Infilled R/C Frames}

This chapter examines the capabilities and identifies the limitations of the DIANA finite element program in simulating the behavior of masonryinfilled structures subjected to lateral loading. The purpose of the investigation is to establish a framework for future modeling and analytical studies of these highly nonlinear structures. Two specimens among those tested by Mehrabi et al. (1994) with distinctively different load-carrying and failure mechanisms are considered. Both specimens are based on frames that are not designed for high seismicity - so-called weak frames - which are susceptible to developing shear failure in the columns. This type of failure is of the greatest concern for R/C-infilled frame structures.

DIANA was first used to model and analyze one frame with a relatively weak infill in order to further calibrate the models for obtaining agreement between the analytical and experimental results. The failure of such a specimen is expected to be governed by shearing and slip along masonry bed joints (mechanism 5 in Figure 1). Then, the calibrated models were used in DIANA to analyze the performance of a second frame, this latter specimen having a relatively strong infill. The failure mechanism for this second frame would be expected to be governed by diagonal cracking of the infill and shear failure of columns (mechanism 2 in Figure 1). The goal of the investigation was to verify that the models calibrated with the results of one test could be applied to a different frame with repeatable validity.

\section{Modeling assumptions}

The specimens tested by Mehrabi et al. (1994) and used in this analytical study were half-scale frame models representing the interior bay at the bottom story of a prototype frame. The prototype frame was a six-story, three-bay, moment-resisting $\mathrm{R} / \mathrm{C}$ frame with a $45 \times 15 \mathrm{ft}$ tributary floor area at each story. Two types of frames were designed for the prototype structure with respect to the lateral loadings: one with a weak frame and weak infill, and one with a weak frame and strong infill. The weak infill design was based on the assumption of a strong wind load, and the strong infill design based on the assumption of equivalent static forces for strong 
seismic loading. The infill panels were constructed of $4 \times 4 \times 8$ in. (nominal) hollow-core and solid concrete masonry blocks to represent the weak and strong infill panels, respectively.

The accuracy and reliability of an analytical model for simulating the behavior of an infilled frame strongly depend on the capability of the model to predict the load-carrying and failure mechanisms as well as estimate the strength and deformations. The failure mechanisms of these specimens correspond with mechanisms 5 and 2 in Figure 1, respectively. Those mechanisms are common failures for frames with unreinforced masonry infill that are not designed for high seismicity, in accordance with recent design codes.

Geometry and details of the selected specimens are shown in Figure 28. Each test specimen was subjected to constant vertical loading and monotonically increasing lateral loading with the scheme shown in Figure 29. In this figure, P2 is 22 kips, P3 is 11 kips, and d is equal to $16.5 \mathrm{in}$. Figure 30 and Figure 31 show damage to the two specimens mapped after completion of the tests for weak and strong infill specimens, corresponding to mechanisms 5 and 2, respectively, in Figure 1.

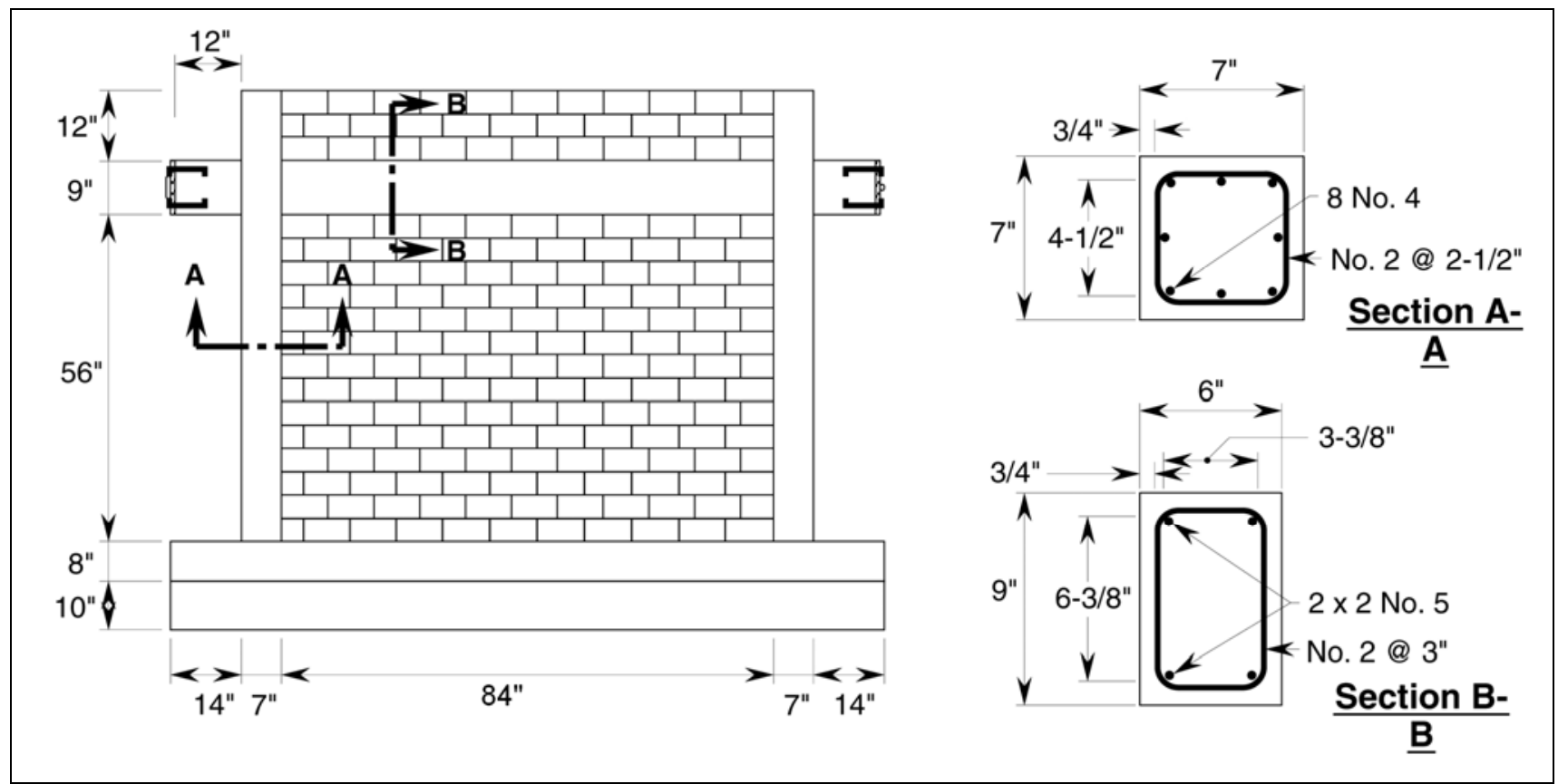

Figure 28. Geometry and details of test specimen (Mehrabi et al. 1994). 


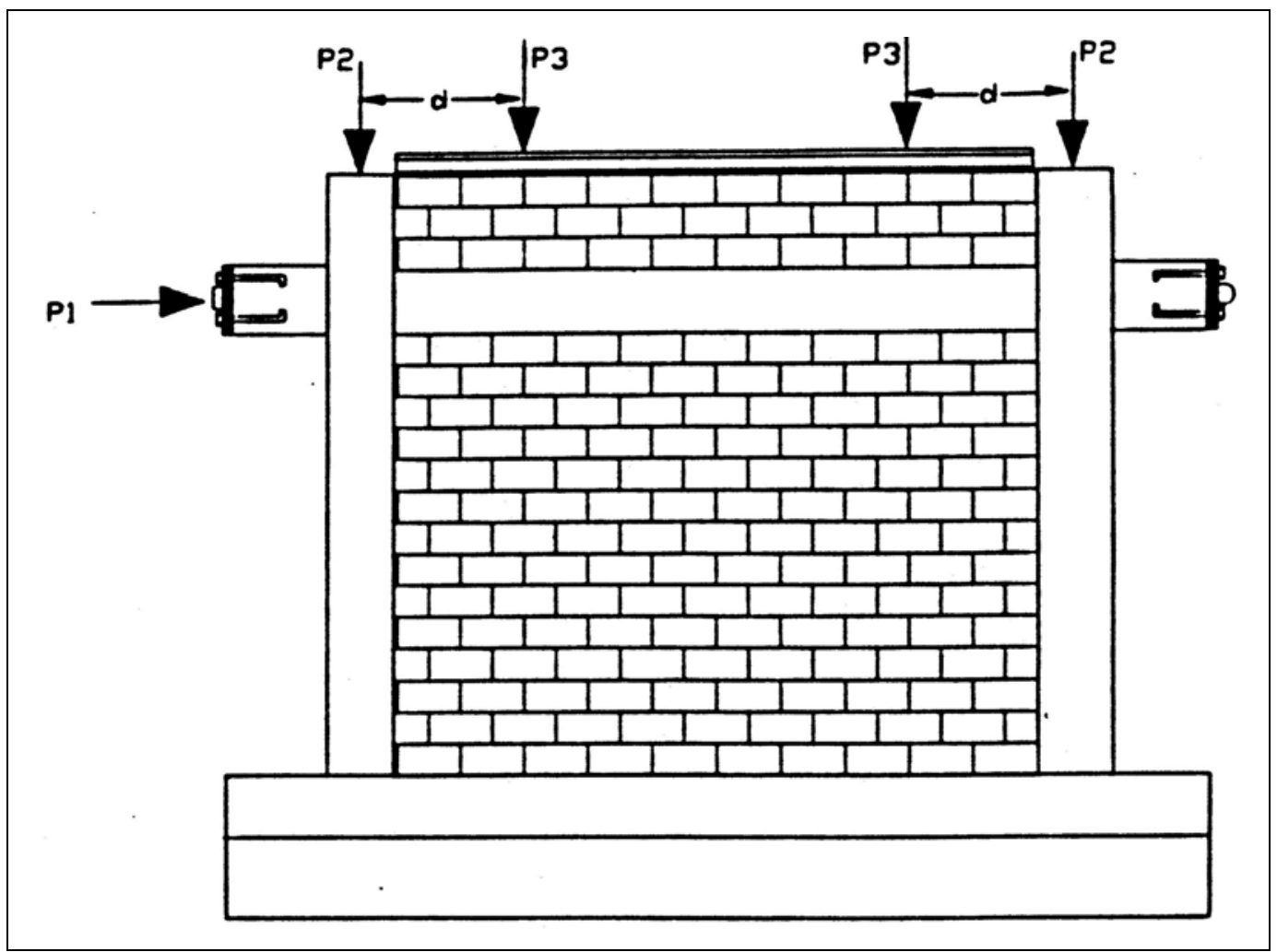

Figure 29. Loading scheme for test specimen (Mehrabi et al. 1994).

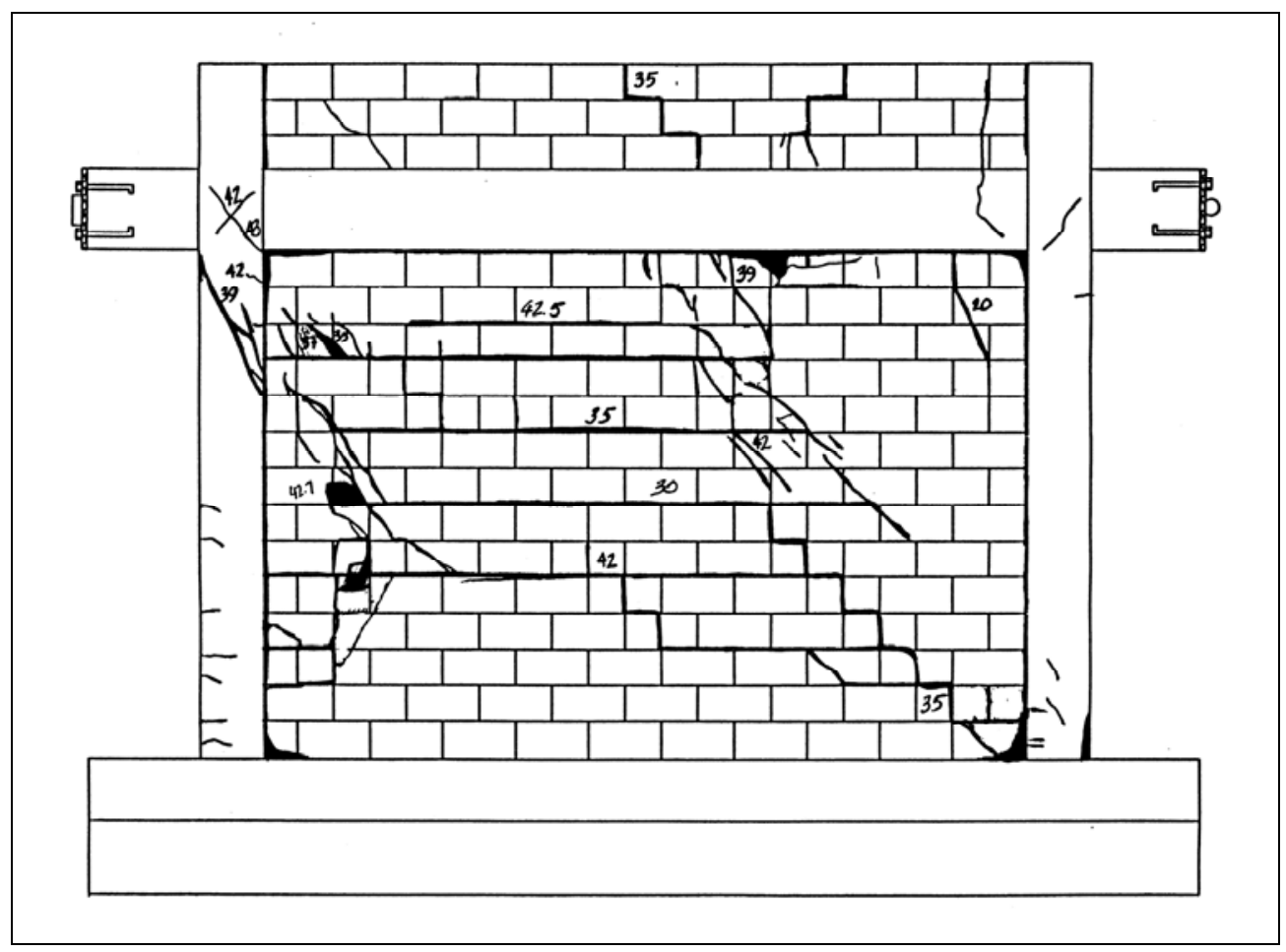

Figure 30. Failure pattern from laboratory test of frame with weak infill (Mehrabi et al. 1994). 


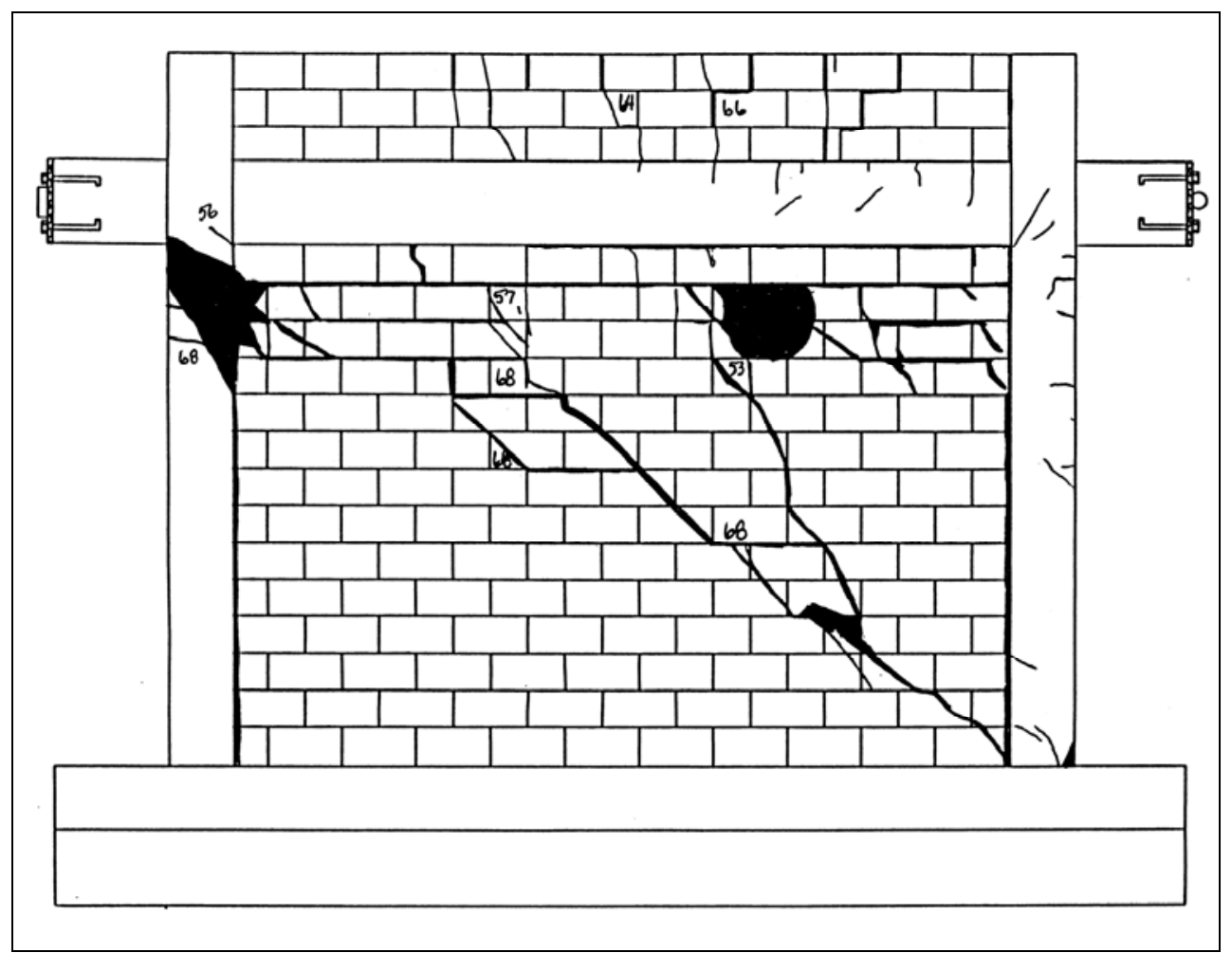

Figure 31. Failure pattern from laboratory test of frame with strong infill (Mehrabi et al. 1994).

Figure 32 and Figure 33 show deformed shapes of the finite element models for the weak infill specimen and strong infill specimen, respectively. These figures show opening and slip along the mortar joints for the weak infill specimen, and diagonal cracking and opening of mortar joints in infill and shear failure of the top end of the windward column for the specimen with strong infill. The numerical responses for the simulations were in good agreement with experimental test results. 


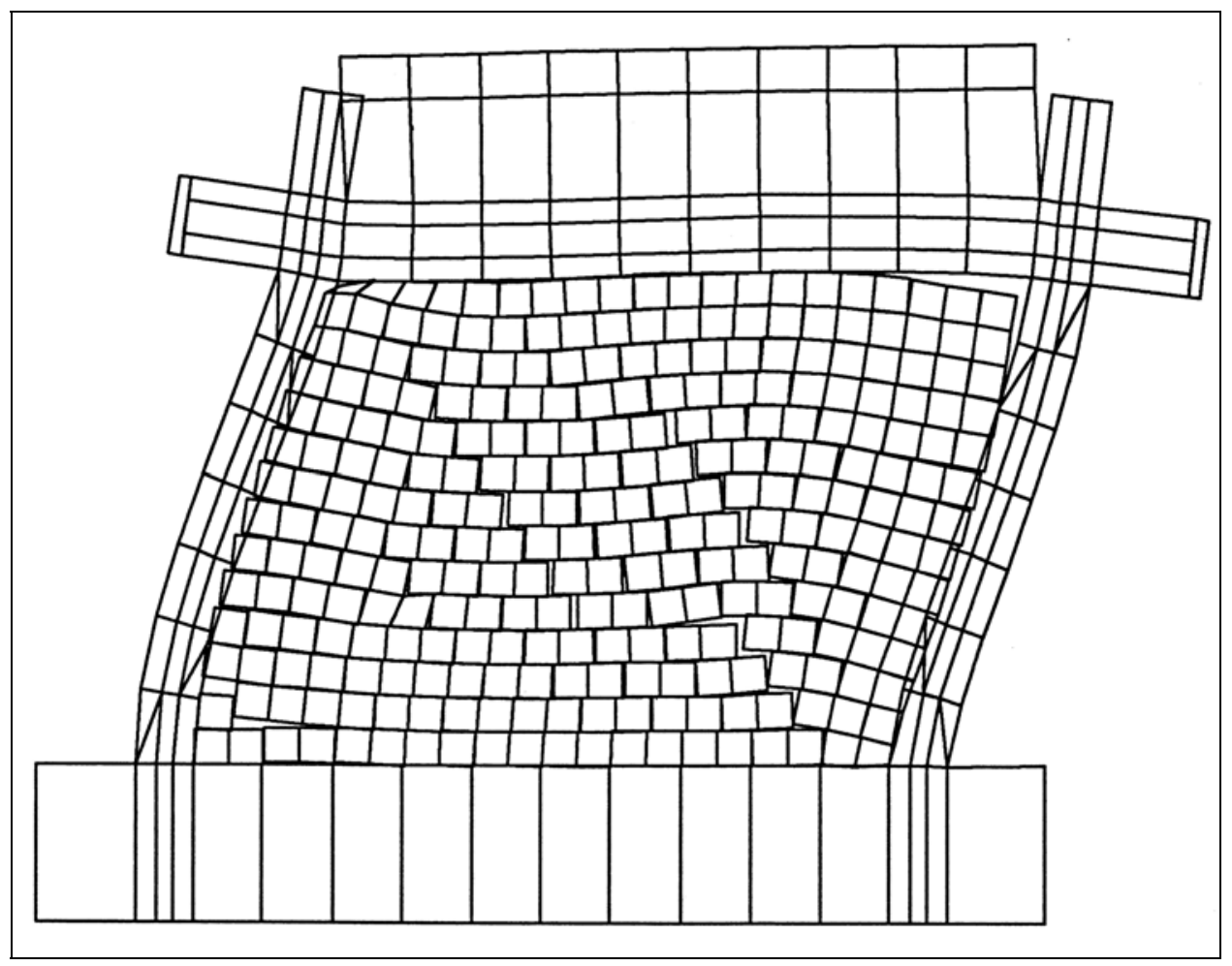

Figure 32. Deformed shape predicted by analysis of frame with weak infill (Mehrabi et al. 1994).

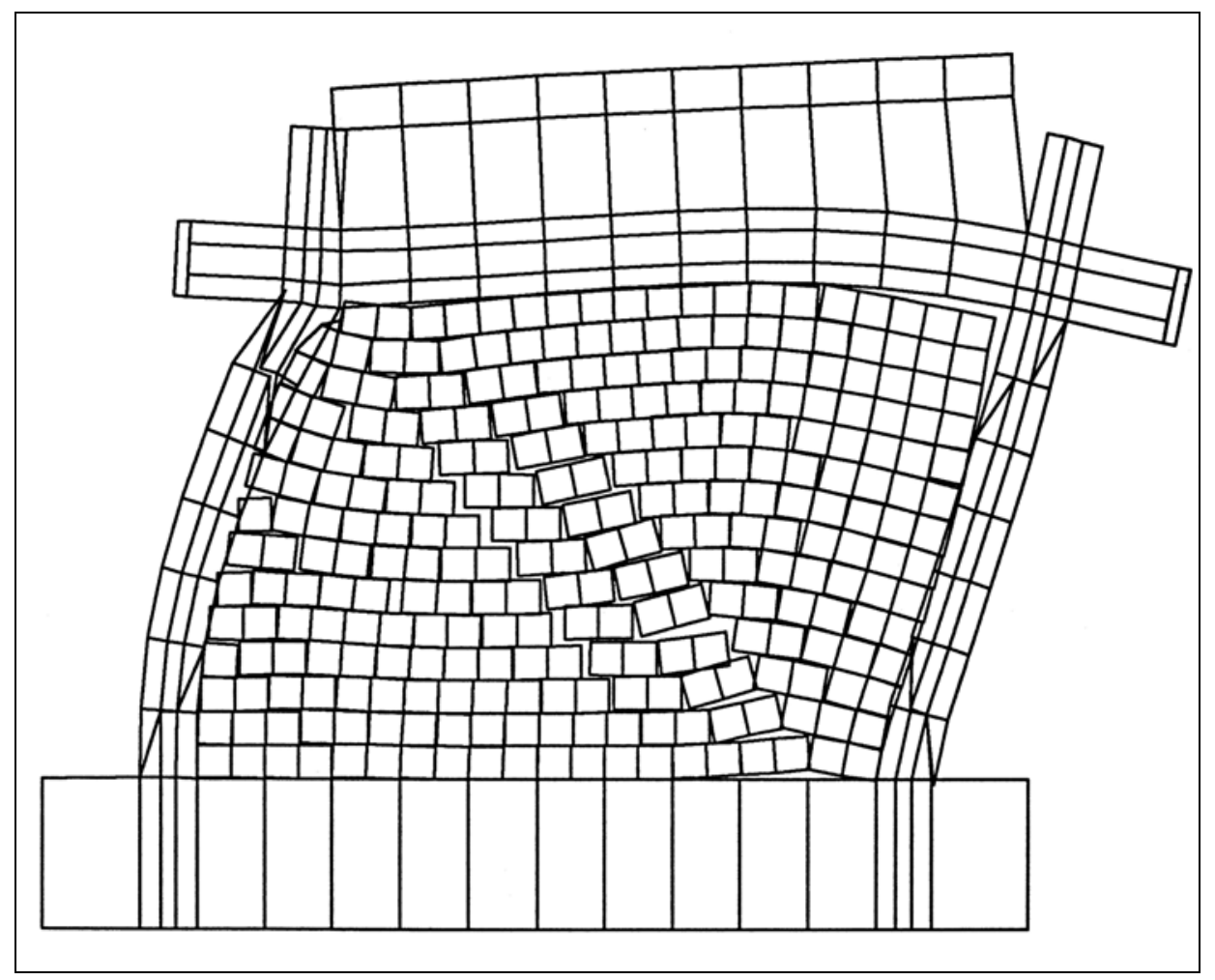

Figure 33. Deformed shape predicted by analysis of frame with strong infill (Mehrabi et al. 1994). 


\section{Development of infill panel model}

\section{Frame and infill elements}

The infilled frame with geometry and details shown in Figure 28 was modeled with the DIANA finite element program. Two-dimensional, plainstress, four-node elements with four integration points were used for modeling the concrete in $\mathrm{R} / \mathrm{C}$ frame and masonry units. Two-dimensional, four-node interface elements with two integration points were used for modeling mortar bed and head joints and joints between the infill and the frame. DIANA rotating-smeared-crack constitutive models for modeling the concrete and DIANA interface elements for modeling the mortar joints were utilized, as described previously. Reinforcement bars for the frame were modeled with DIANA elastic-hardening plastic, two-node discrete bar elements. The loading plates were modeled with linear elastic, fournode, plane-stress elements. The top loading beam was modeled with twonode beam elements using linear-elastic material with steel properties, while the frame footing was modeled with four-node plane stress elements with linear-elastic material with concrete properties. The finite element mesh is shown in Figure 34 at initial stages of lateral loading. Each masonry unit was discretized into two elements with an aspect ratio of 1 . The loading scheme followed that illustrated in Figure 29. Vertical load was first applied in increments to the maximum and then kept constant while lateral displacement loading was applied gradually.

\section{Parameter setting and analysis}

When analyzing infilled frames, Mehrabi et al. (1994) adjusted the normal and shear stiffnesses of mortar joints to about 30 times those calibrated by their laboratory direct shear test results. The need for adjustment was attributed to the inaccuracy of interface normal and shear displacements in the elastic region of laboratory test responses that occurred because of deflection of the test fixture. They differentiated among mortar bed joints, head joints, and joints between the wall and frame by introducing different interface material parameters and thicknesses. 


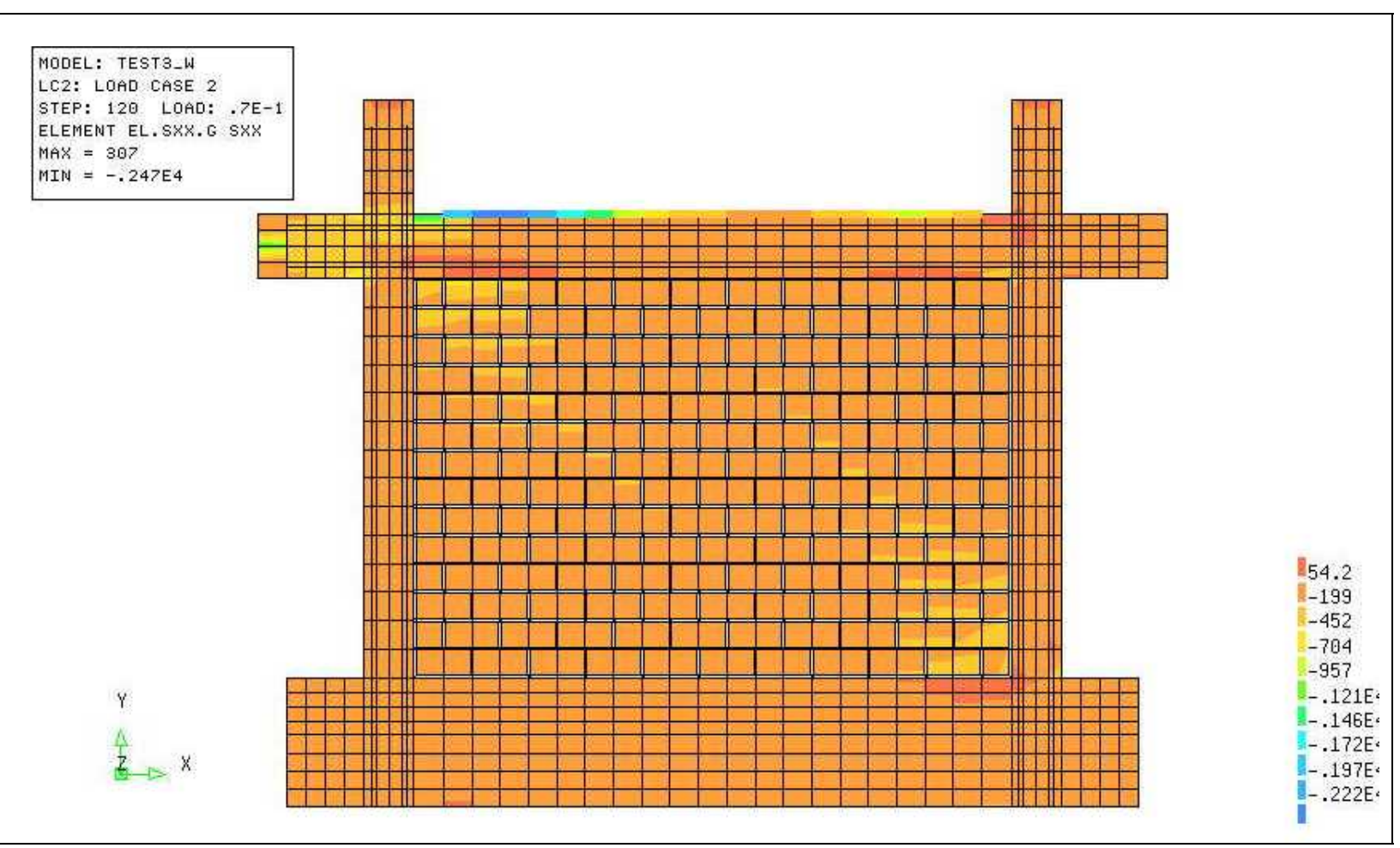

Figure 34. Finite element mesh for frame with weak infill analysis using DIANA.

Parameter setting for frame with weak infill

For the first trial using DIANA, material parameters were selected to agree with those used by Mehrabi et al. (1994). The parameters for the bed joints were those used for the prism analysis previously described, also reflected in Table 3. The use of the normal and shear stiffnesses from Table 10 resulted in divergence and a lack of solution at initial stages of the analysis. This divergence occurred with the initiation of shear cracking and slip at interfaces. The numerical process of determining the stress on the yield surface (return mapping) failed in tension-shear or compression-shear corner zones. Persistent efforts to prevent the divergence of the algorithm with reduction of step sizes and tolerances in the practical range, and application of various available solution methods did not resolve the convergence issue. It was concluded that sharp corners, especially at tension cutoff zones, need to be repaired in the yield surface of the interface model if this problem is to be avoided. Mehrabi et al. (1994) utilized a hyperbolic yield surface which avoided corners in the shear-tension zone, and their model did not include a compression cap. 
Table 10. Material parameters for concrete in frame and masonry units.

\begin{tabular}{|l|l|l|l|l|}
\hline Parameter & Description & $\begin{array}{l}\text { Concrete in } \\
\text { Frame }\end{array}$ & $\begin{array}{l}\text { Concrete in } \\
\text { masonry hollow } \\
\text { units }\end{array}$ & $\begin{array}{l}\text { Concrete in } \\
\text { masonry solid } \\
\text { units }\end{array}$ \\
\hline $\mathrm{E}$ & Modulus of elasticity & $3.55 \mathrm{E}+6(\mathrm{psi})$ & $2.0 \mathrm{E}+6(\mathrm{psi})$ & $2.0 \mathrm{E}+6(\mathrm{psi})$ \\
\hline$v$ & Poisson's ratio & 0.16 & 0.16 & 0.16 \\
\hline $\mathrm{ft}_{\mathrm{f}}$ & Tensile strength & $390(\mathrm{psi})$ & $240(\mathrm{psi})$ & $230(\mathrm{psi})$ \\
\hline $\mathrm{Gf}^{\prime}$ & First mode fracture energy & $0.09(\mathrm{psi}-\mathrm{in})$ & $0.09(\mathrm{psi}-\mathrm{in})$ & $0.09(\mathrm{psi}$-in) \\
\hline$\beta$ & Shear retention factor & $\mathrm{NA}$ & $\mathrm{NA}$ & $\mathrm{NA}$ \\
\hline $\mathrm{f}^{\prime} \mathrm{c}$ & Compressive strength & $3,900(\mathrm{psi})$ & $2,400(\mathrm{psi})$ & $2,300(\mathrm{psi})$ \\
\hline $\mathrm{G}_{\mathrm{fc}}$ & $\begin{array}{l}\text { Fracture energy in } \\
\text { compression }\end{array}$ & $22(\mathrm{psi}-\mathrm{in})$ & $22(\mathrm{psi}-\mathrm{in})$ & $22(\mathrm{psi}$-in) \\
\hline Tension Curve & $\begin{array}{l}\text { Shape of tensile } \\
\text { stress/strain curve }\end{array}$ & Exponential & Exponential & Exponential \\
\hline Compression Curve & $\begin{array}{l}\text { Shape of compressive } \\
\text { stress/strain curve }\end{array}$ & Parabolic & Parabolic & Parabolic \\
\hline
\end{tabular}

However, during verification of constitutive models in the first phase of this study, with the set of parameters calibrated on the basis of the laboratory material test results, the analysis did not encounter a convergence problem. That result was due to much lower normal and shear stiffness values than those utilized by Mehrabi et al. (1994) for their infilled frame analyses. Therefore, it was decided to carry out the analysis with lower stiffness values according to those used in the material-level investigation. Another trial analysis using DIANA confirmed conclusions by Mehrabi et al. (1994) that the use of these low stiffness values does not yield an agreement between experimental and analytical responses. This trial analysis clearly shows that low normal stiffness for interfaces resulted in transferring much of the vertical load to the frame columns and less of it to the infill wall. Since the shear resistance of the infill wall strongly depends on normal stresses, low normal stresses on infill resulted in significantly lower lateral resistance for the infilled frame. Also, lower shear stiffness for infill mortar joints resulted in a significantly lower initial stiffness for the analytical response curve than seen in the experimental results. To find an agreement between analytical and experimental results, higher stiffnesses need to be used.

To use a higher stiffness for interfaces and to avoid the numerical convergence problem, researchers decided to keep the stiffnesses at the lower values for all interfaces as the base stiffness parameters (for which a good 
numerical convergence is guaranteed at material level) and to increase the theoretical width of joints to provide the higher overall stiffness required for obtaining agreement with the experimental results. However, to avoid an unwanted and unrealistic increase in the overall interface strength values due to increase in width, the parameters affecting the strength (i.e., compressive strength, tensile strength, and cohesion) have to be reduced by the same proportion the thicknesses are increased. The confining stress, $\sigma_{u}$, is related only to evolution of dilatancy, so it is not reduced.

After a series of trial runs with various multiples of width increase, a tenfold increase in the stiffness of bed joints over the base values (estimated originally by calibration using material test results) was found to provide a good agreement between the analytical and experimental responses for the frame with weak infill. The stiffness of the head joints and the joints between the frame and the infill were adjusted accordingly, keeping the same proportion considered by Mehrabi et al. (1994) in their modeling effort with respect to the bed joints. Material parameters for the concrete material in the frame and masonry units were calculated according to the test results provided by Mehrabi et al. (1994) and the verification process in this study. Table 10 shows material parameters and their definition for the concrete used in the frame and the masonry units. Table 11 shows the target material parameters and the parameters actually used for bed joints, head joints, and joints between frame and wall, respectively.

Table 11. Material parameters for hollow block infill, DIANA interface model.

\begin{tabular}{|c|c|c|c|c|c|c|c|c|}
\hline Parameter Set & $\begin{array}{l}\text { Width } \\
\text { (in.) }\end{array}$ & $\begin{array}{l}\mathrm{K}_{\mathrm{nn}} \\
\text { (psi) }\end{array}$ & $\begin{array}{l}\mathrm{K}_{\mathrm{ss}} \\
\text { (psi) }\end{array}$ & $\begin{array}{l}\mathrm{ft}_{\mathrm{t}} \\
\text { (psi) }\end{array}$ & $\begin{array}{l}c_{o} \\
\text { (psi) }\end{array}$ & $\operatorname{tg} \phi_{i}$ & $\operatorname{tg} \phi_{r}$ & $\begin{array}{l}f_{c}^{\prime} \\
\text { (psi) }\end{array}$ \\
\hline $\begin{array}{l}\text { Target values for bed } \\
\text { joints }\end{array}$ & 1.25 & 280,000 & 350,000 & 40 & 40 & 0.9 & 0.75 & 1,500 \\
\hline $\begin{array}{l}\text { Actual values used } \\
\text { for bed joints }\end{array}$ & 12.5 & 28,000 & 35,000 & 4 & 4 & 0.9 & 0.75 & 150 \\
\hline $\begin{array}{l}\text { Target values for } \\
\text { head joint }\end{array}$ & 1.25 & 215,300 & 269,200 & 10 & 10 & 0.8 & 0.7 & 1,500 \\
\hline $\begin{array}{l}\text { Actual values used } \\
\text { for head joint }\end{array}$ & 12.5 & 21,530 & 26,920 & 1 & 1 & 0.8 & 0.7 & 150 \\
\hline $\begin{array}{l}\text { Target values } \\
\text { For frame/ } \\
\text { wall joints }\end{array}$ & 1.4 & 215,300 & 269,200 & 20 & 20 & 0.8 & 0.7 & 1,500 \\
\hline $\begin{array}{l}\text { Actual values used } \\
\text { for frame/wall joints }\end{array}$ & 14 & 21,530 & 26,920 & 2 & 2 & 0.8 & 0.7 & 150 \\
\hline
\end{tabular}


Analysis results for frame with weak infill

Within the geometry and material properties described above, the analysis of the selected masonry-infilled R/ C frame with weak infill was carried out for a maximum lateral displacement of 0.8 in. Figure 34 shows the principal stress contour at $0.07 \mathrm{in}$. lateral displacement, indicating signs of forming the diagonal struts that are the load carrying mechanism of infilled frames at initial loading stages.

Figure 35 shows the deformed shape and principal stress contour at 0.31 in. lateral deflection before maximum strength is reached. This figure shows separation and slip at bed and head joints, which is the governing failure mechanism for this infilled frame. It also shows that stress at loaded corners of the infill has reached nearly the compressive strength of the masonry, signaling crushing at loaded corners under higher lateral displacements. These results agree well with the experimental and analytical results by Mehrabi et al. (1994) and show the capability of the models in predicting the load carrying and failure mechanisms of the $\mathrm{R} / \mathrm{C}$ frame with weak masonry infill.

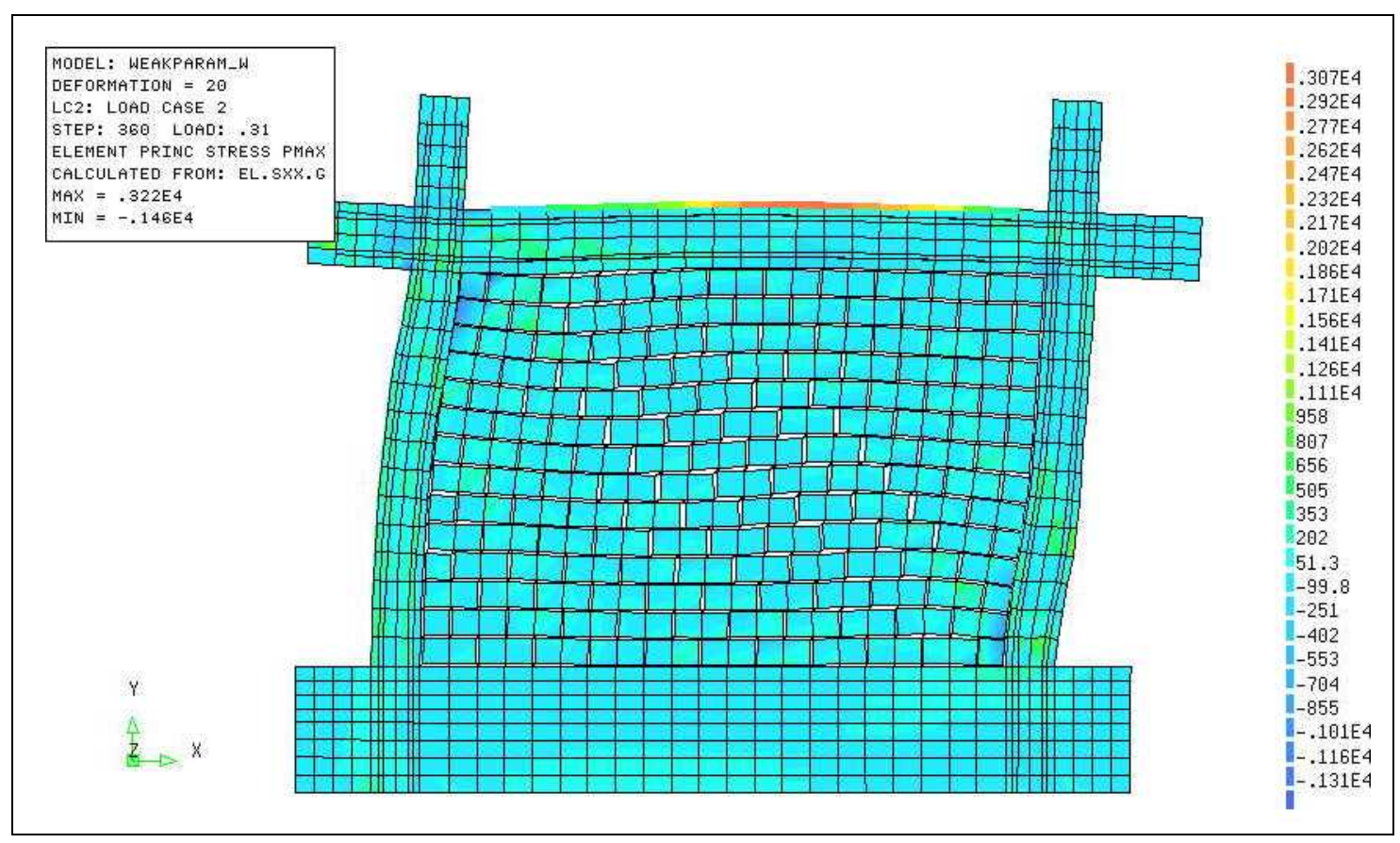

Figure 35. Deformed shape and stress contour for frame with weak infill, analysis using DIANA.

Figure 36 shows response curves obtained from this analysis compared with those from the laboratory test. Stiffness, response trend (including 
initiation of nonlinear behavior due to mortar joint shear cracking and separation), and lateral resistance obtained numerically agree well with the experimental results.

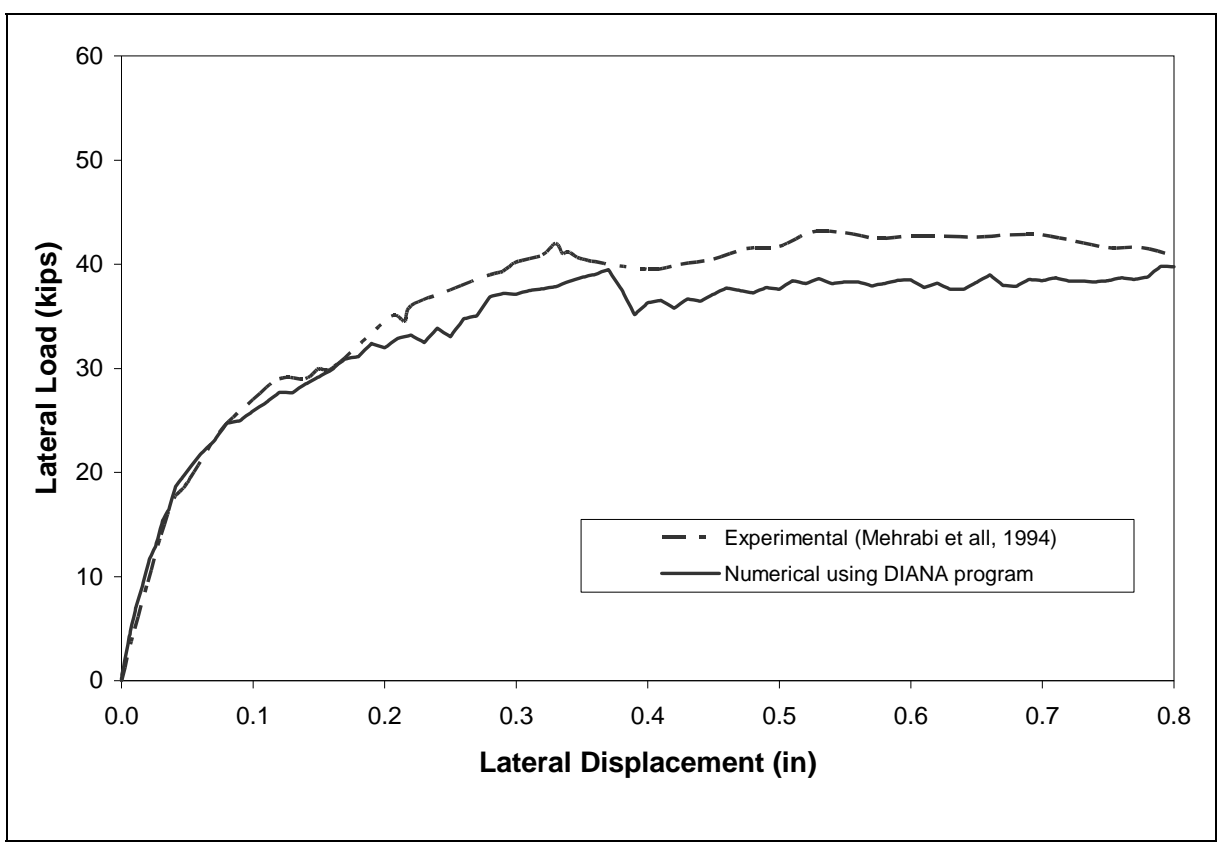

Figure 36. Experimental and numerical (DIANA) lateral load/lateral displacement curves for frame with weak infill.

Parameter setting for frame with strong infill

To examine the capability of the calibrated models to predict the behavior of an infilled frame with different characteristics, the FE model created and calibrated for analysis of the frame with weak infill was used for analysis of the frame with strong infill. The only parameter in the interface model needing adjustment was the compressive strength (or the compression cap), $\mathrm{f}_{\mathrm{c}}$, to reflect the higher strength of a masonry assembly made of solid blocks. The width of mortar joints also had to be adjusted to higher values. These changes are shown in Table 12. A thickness of $3.625 \mathrm{in}$. was used for masonry units in the infill. The model was then analyzed using the same loading scheme that was applied to the frame with weak infill.

Table 12. Material parameters for mortar joints in solid block infill that are different from hollow block infill, DIANA interface.

\begin{tabular}{|l|l|l|l|l|}
\hline $\begin{array}{l}\text { Parameter } \\
\text { Set }\end{array}$ & $\begin{array}{l}\text { Width of Bed } \\
\text { Joints (in.) }\end{array}$ & $\begin{array}{l}\text { Width of Head } \\
\text { Joints (in.) }\end{array}$ & $\begin{array}{l}\text { Width of Frame to } \\
\text { Wall Joints (in.) }\end{array}$ & f'c $_{c}$ (psi) \\
\hline Target values & 3.5 & 3 & 3.5 & 2,000 \\
\hline Actual values used & 35 & 30 & 35 & 200 \\
\hline
\end{tabular}


Analysis results for frame with strong infill

The analysis results indicated that the predicted behavior of the frame with strong infill using the models described above agreed well with the experimental behavior for the initial portion of the response curve, i.e., for lateral displacement smaller than 0.2 in. The analytical response did not flatten, however, and the lateral resistance continued to increase with increasing displacement far beyond the strength obtained in the experimental test (Figure 37). Review of the numerical results indicated that the shear failure at the top end of the windward column, expected to govern the failure of the infilled frame based on the experimental results, never occurred. Furthermore, with stronger mortar joints in strong infill, sliding of bed joints did not occur. Only some diagonal cracking and mortar joint separation were observed. This behavior resulted in development of a confined diagonal compression strut in the infill, which provided much higher lateral strength than expected. This problem was attributed to the inefficiency of the smeared crack model for concrete in the R/C frame for modeling the shear failure.

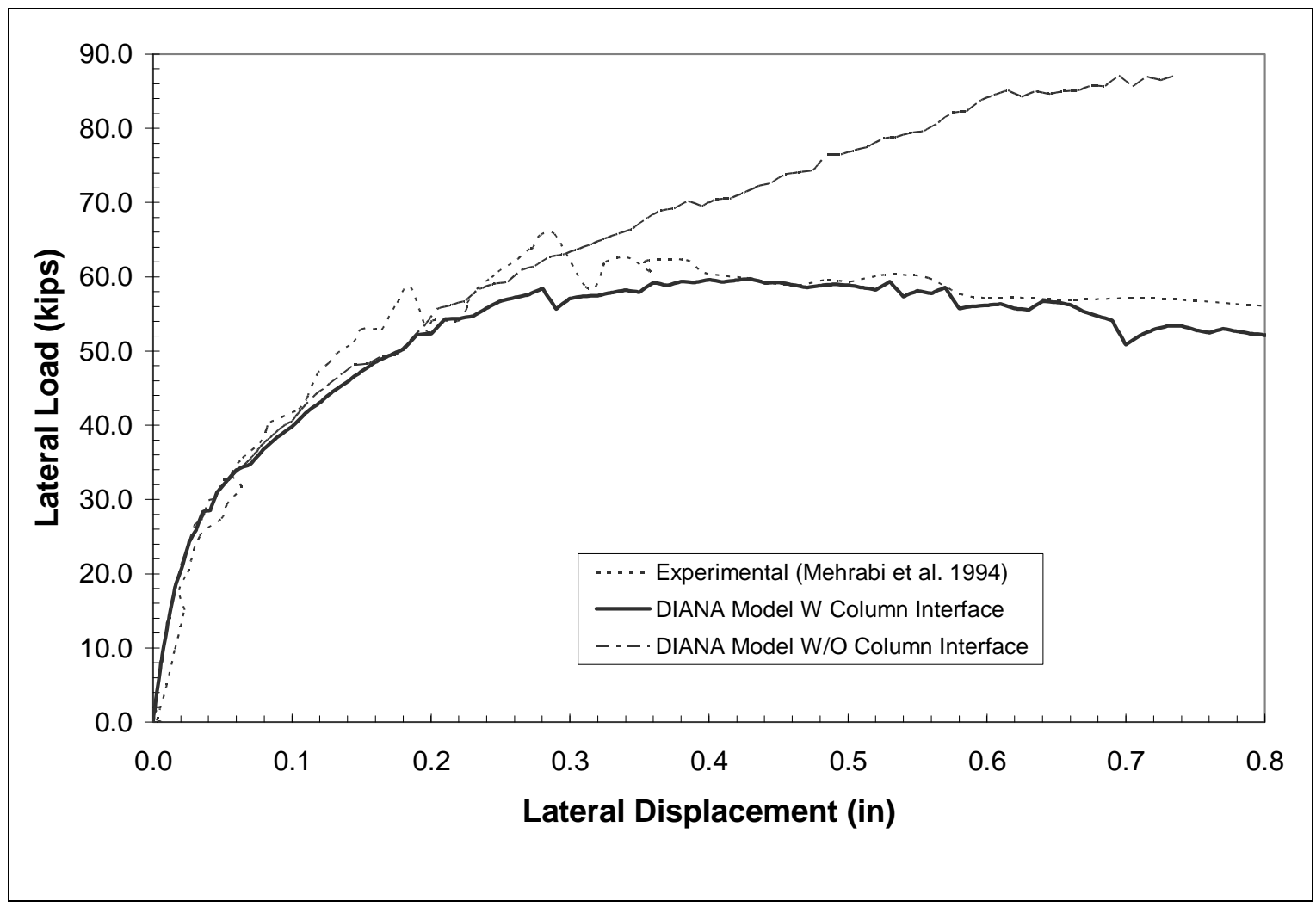

Figure 37. Experimental and numerical (DIANA) lateral load/lateral displacement curves for frame with strong infill. 
To overcome this modeling problem, a discontinuity in the form of an interface model was introduced at the column ends. This allowed the shear failure of the columns along these interfaces, as it was anticipated for this infilled frame. The material properties of the interface element at the column ends were similar to those of the interfaces in the masonry. However, some parameters, e.g., tensile strength, cohesion, and compressive strength, were adjusted to reflect properties of concrete in the frame. To avoid convergence problems, the method of increasing interface thicknesses adopted for the case of interfaces in infill was used here as well.

With the above modification, the model was analyzed again. As it can be seen in Figure 37, this time the response agreed well with the experimental results. Figure 38 shows the deformed shape and principal stress contour at $0.215 \mathrm{in}$. lateral displacement before shear failure of the column occurs.

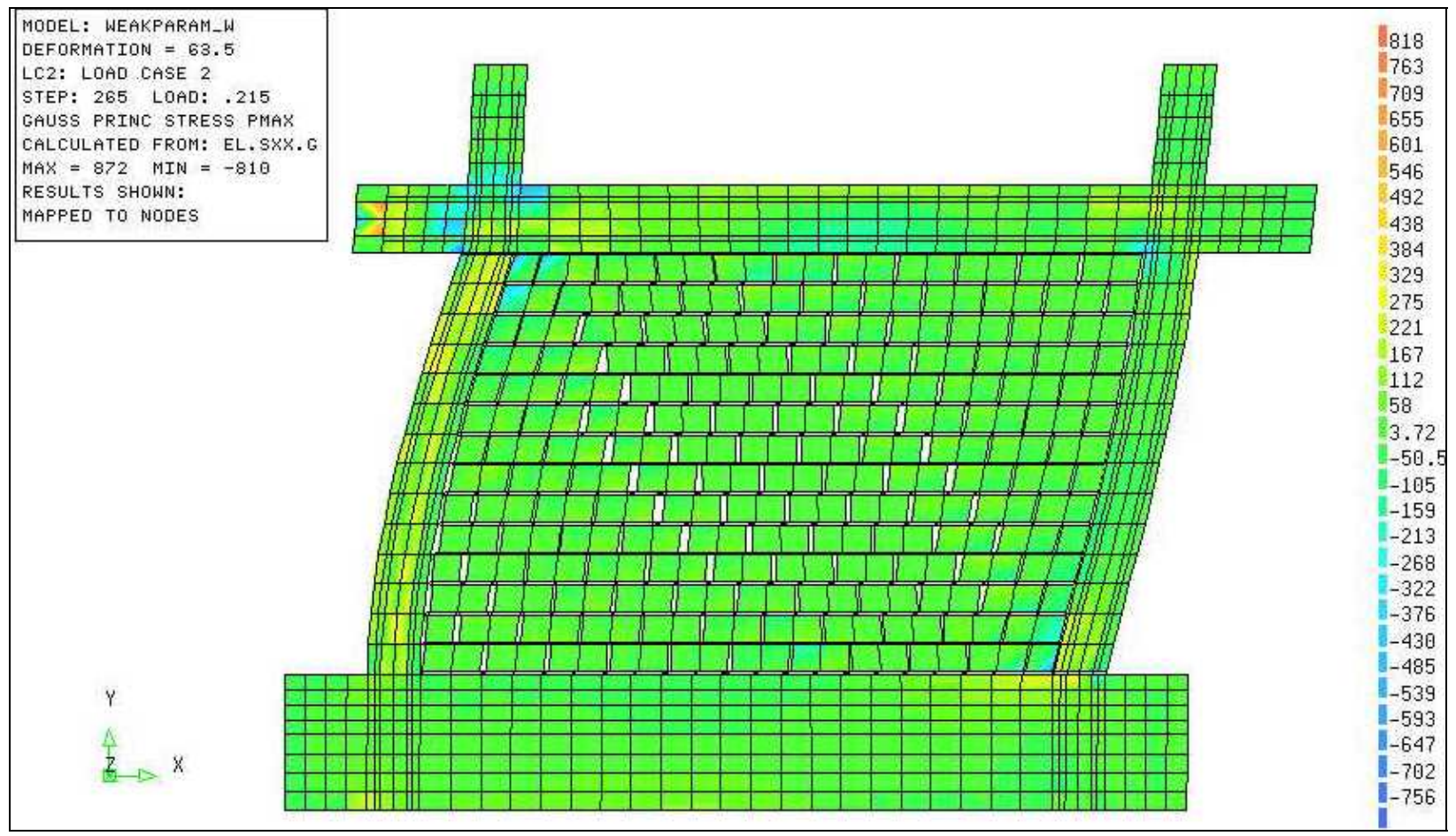

Figure 38. Deformed shape and stress contour for frame with strong infill at $0.215 \mathrm{in}$. lateral displacement, analysis using DIANA.

Separation of head and bed joints in a diagonal pattern and development of compression zones at loaded corners can be seen in Figure 38. Figure 39 shows the deformed shape and displacement field contour at $0.795 \mathrm{in}$. lateral displacement. This figure shows the shear failure of the top end of the windward column, as illustrated also by the experimental results in Figure 31. A large part of the lateral displacement has been absorbed by the shear 
failure of the column and displacement of the upper right portion of the frame and the infill. Load carrying and failure mechanisms of the modified model agree well with the experimental results.

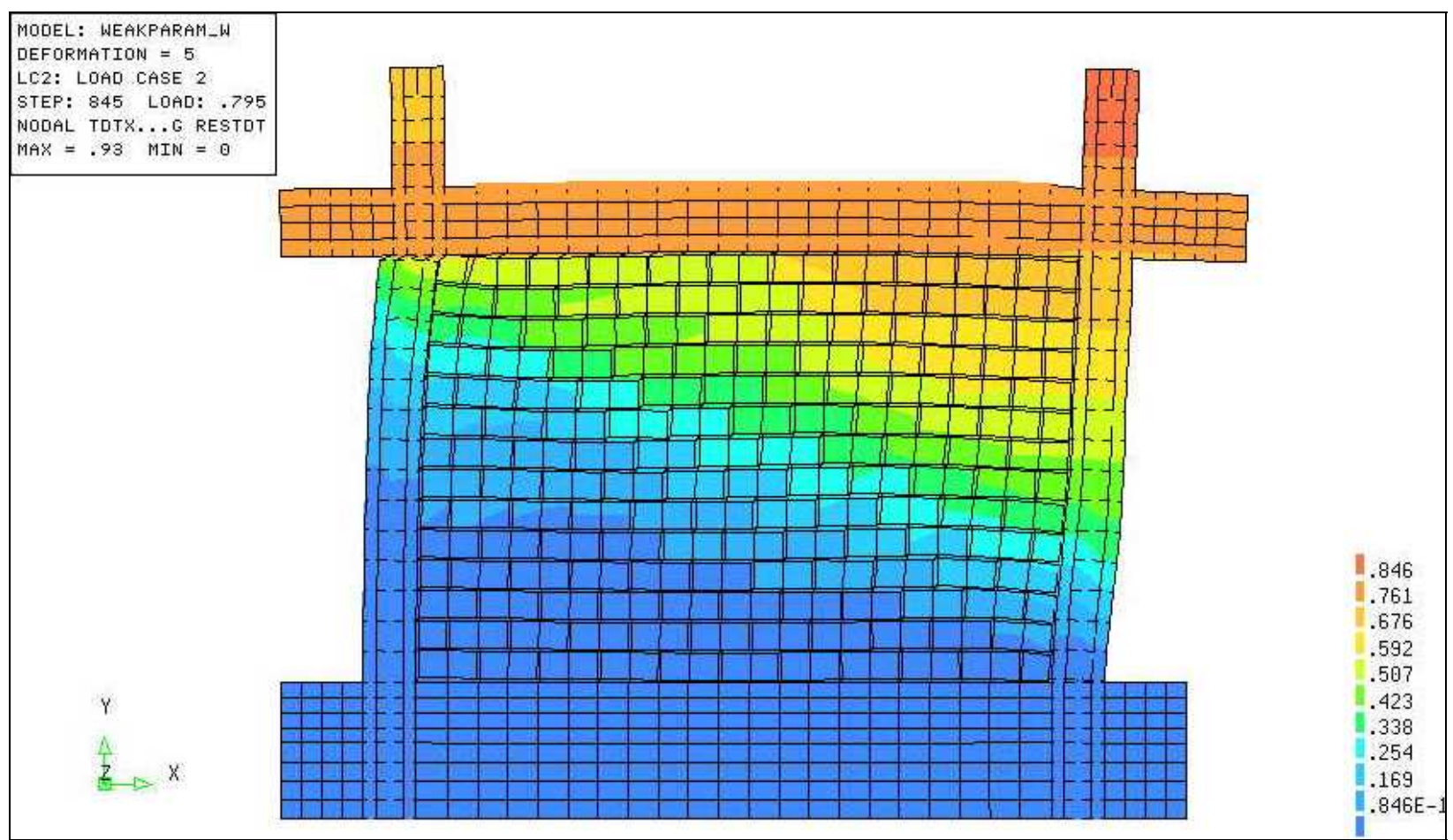

Figure 39. Deformed shape and displacement field contour for frame with strong infill at 0.795 in. lateral displacement, analysis using DIANA. 


\section{Conclusions}

The objective of this work was to investigate the utility and effectiveness of numerical finite element modeling, simulation, and analysis to predict the performance characteristics of masonry-infilled wall panels and constituent materials subjected to lateral loading. One purpose of the work was to determine whether numerical analysis, based on well calibrated finite element models and parametric studies, can serve as a valid substitute for expensive physical modeling and testing of concrete and masonry structures.

This investigation identified a modeling approach that addresses the discontinuities in masonry by introducing interface elements that help to represent the masonry joints more accurately than in the past. Through an extensive literature review, the authors identified constitutive material models for numerical analysis of $\mathrm{R} / \mathrm{C}$ frames infilled with unreinforced concrete masonry blocks, and demonstrated their capabilities through verification studies. A combination of continuum and interface constitutive models was selected as the most appropriate approach.

In order to facilitate the use of these models by researchers and designers, a commercial finite element program with compatible capabilities was identified. That program, DIANA, was employed to test the constitutive models using data from previous experimental tests, and to assess the strengths, weaknesses, capabilities, and limitations of those models.

First DIANA was used to analyze masonry prisms constructed of hollow and solid blocks. Next, a frame with weak infill (hollow blocks) was modeled and analyzed, and the results were used to perform further calibration of the models to obtain agreement between analytical and experimental results. The failure of this modeled frame was governed by shear cracking and slip along masonry bed joints. Then a second frame, one with a strong infill (solid blocks), was developed using the calibrated models, and analyzed using DIANA. The goal was to verify that the constitutive models calibrated with the results of one test would be valid when used in a different structural model. The failure mechanism for this second frame was expected to be governed by diagonal cracking in the infill and shear failure at the top end of the windward column. However, modeling of the second frame required the introduction of interface elements in the columns to 
allow shear failure of the columns, which did not occur as expected using only the smeared crack model for the concrete material in the frame.

The models used in DIANA showed good capabilities for modeling and predicting load-carrying and failure mechanisms for such complex structures as infilled frames. Such capabilities are recognized to be critical for reliably predicting the strength and ductility of $\mathrm{R} / \mathrm{C}$ infilled frame designs. A significant limitation of the models in DIANA is a convergence problem with the numerical scheme in return mapping on the yield surface for higher stiffnesses for interface elements, which is a significant impediment for a robust and reliable solution. A short-term solution was implemented to overcome this problem. It is believed that the numerical inefficiency of the models can be overcome by improvements to the failure surface and return mapping schemes of the constitutive model for interface elements. For the case of potential shear failure in columns, it was shown that the use of interface elements in the column ends can compensate for inability of the smeared crack formulation to model shear failure. In any case, it is realized that for successful use of any FE program, the model parameters need to be calibrated using appropriate material- and structural-level experimental results. Once calibrated, the models can be used reliably for parametric studies of the behavior of infilled frames subjected to lateral loading. 


\section{References}

Al-Chaar, G. K. 2002. Evaluating strength and stiffness of unreinforced masonry infill structures. ERDC/ CERL TR-02-1. Champaign, IL: Engineer Research and Development Center - Construction Engineering Research Laboratory

Al-Chaar, G. K. 1998. Non-ductile behavior of reinforced concrete frame with masonry infill panels subjected to in-plane loading. USACERL Technical Manuscript TM98/18.

Bertero, V.V., and S. Brokken. 1983. Infills in seismic resistant building. J ournal of Structural Engineering 109(6): 1337- 1361. Reston, VA: American Society of Civil Engineers.

Buonopane, S.G., and R.N. White. 1999. Pseudodynamic testing of masonry infilled reinforced concrete frame. J ournal of Structural Engineering 125(6): 578-589. Reston, VA: American Society of Civil Engineers.

Dhanasekar, M., and A.W. Page. 1986. The influence of brick masonry infill properties on the behavior of infilled frames. Proceedings of the Institute of Civil Engineers 81(2): 593- 606.

DIANA 8.1 Finite Element Program. 2002. Users' Manual, FEMSYS, TNO Building and Construction Research, Department of Computational Mechanics, Delft, The Netherlands.

Fiorato, A.E., M.A. Sozen, and W.L. Gamble. 1970. "An investigation of the interaction of reinforced concrete frames with masonry filler walls," Report No. UILU-ENG-70100, Dept. of Civil Engineering. Urbana, IL: University of Illinois at UrbanaChampaign.

Hordijk, D.A. 1991. Local approach to fatigue of concrete. PhD thesis. Delft, The Netherlands: Delft University of Technology.

Hsieh, S.S., E.C. Ting, and W.F. Chen. 1988. Application of a plastic-fracture model to concrete structures. Computers and Structures 23(3): 373- 393. Pergamon Press.

Klingner, R.E., and V.V. Bertero. 1976. Infilled frames in earthquake-resistant construction, Report No. EERC/ 76-32. Berkeley, CA: University of California Earthquake Engineering Research Center.

Liauw, T.C., and Lo, C.Q. 1988. "Multibay infilled frames without shear connectors," ACI Structural J ournal, ACI, U.S.A. J uly-Aug 1988, 423-428.

Lotfi, H.R., and P.B. Shing. 1991. "An Appraisal of Smeared Crack Models for Masonry Shear Wall Analysis," Computers and Structures, 41(3), 413-425.

Lotfi, H.R., and P.B. Shing. 1994. An interface model applied to fracture of masonry structures. J ournal of Structural Engineering 120(1), 63-80.Reston, VA: ASCE. 
Lourenco, P.B. 1996. “Computational strategies for masonry structures,” Doctoral Thesis, Civil Engineering Department, Delft University, The Netherlands.

Mehrabi, A.B., and P.B. Shing. 1997. "Finite element modeling of masonry-infilled rc frames," J ournal of Structural Engineering, ASCE, U.S.A., 123( 5), 604-613.

Mehrabi, A.B., P.B. Shing, M.P. Schuller, and J .L. Noland. 1994. "Performance of masonry-infilled R/C frames under in-plane lateral loads," Report No. CU/SR94-6, Dept. of Civil, Environmental, and Architectural Engineering. Boulder, CO: University of Colorado.

Mosalam, K.M., and G.H. Paulino. 1997. Evolutionary characteristic length method for smeared cracking finite element methods. Finite Elements in Analysis and Design 27(1): 99- 108.

Rots, J .G. 1991. Numerical simulation of cracking in structural masonry. HERON 36(2), 49- 63. The Netherlands: Netherlands School for Advanced Studies in Construction.

Rots, J .G., and R. Borst. 1987. “Analysis of mixed-mode fracture in concrete," J ournal of Engineering Mechanics, ASCE, 113(11), 1739- 1758.

Schmidt, T. 1989. An approach of modeling masonry infilled frames by the f.e. method and a modified equivalent strut method. "Annual J ournal on Concrete and Concrete Structures.” Darmstadt, Germany: Darmstadt University.

Stafford Smith, B. 1962. "Lateral stiffness of infilled frames. J ournal of the Structural Division, ASCE, U.S.A., 88(6), 183-199.

Willam, K., E. Pramono, and S. Sture. J une 1987. Fundamental issues of smeared crack models. "SEM/ RILEM International Conference on Fracture of Concrete and Rock." J une, Shah, and Swartz, eds. Houston, TX.

Willamk K.J ., and E.P. Warnke. 1974. Constitutive model for the triaxial behavior of concrete. "Seminar on Concrete Structures Subjected to Triaxial Stresses," May 17 - 19, 1974, Bergamo, Italy. Istituto Sperimentale Modelli e Strutture.

Zarnic, R., and M. Tomazevic. February 1985. Study of the behavior of masonry infilled reinforced concrete frames subjected to seismic loading. "Proceedings of the 7th International Conference on Brick Masonry," 1315- 1325. Melbourne, Australia. 


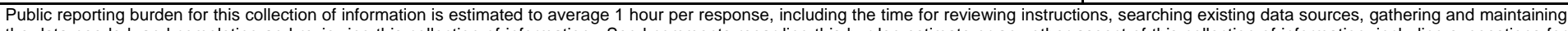

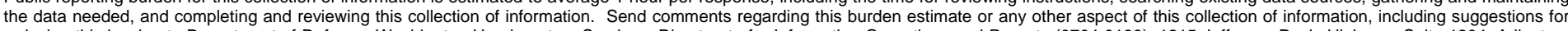

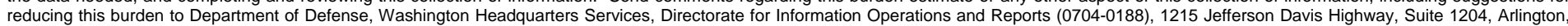

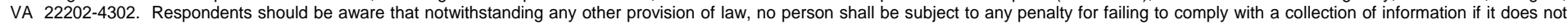
display a currently valid OMB control number. PLEASE DO NOT RETURN YOUR FORM TO THE ABOVE ADDRESS.
1. REPORT DATE (DD-MM-YYYY)
2. REPORT TYPE
3. DATES COVERED (From - To)

March 2008 Final

\section{TITLE AND SUBTITLE}

Constitutive Models for Nonlinear Finite Element Analysis of Masonry Prisms and Infill Walls

5a. CONTRACT NUMBER

5b. GRANT NUMBER

5c. PROGRAM ELEMENT NUMBER

AT23

6. AUTHOR(S)

Ghassan K. Al-Chaar and Armin B. Mehrabi

5d. PROJECT NUMBER

8740

5e. TASK NUMBER

5f. WORK UNIT NUMBER

7. PERFORMING ORGANIZATION NAME(S) AND ADDRESS(ES)

U.S. Army Engineer Research and Development Center

Construction Engineering Research Laboratory

NUMBER

ERDC/CERL TR-08-19

P.O. Box 9005

Champaign, IL 61826-9005

9. SPONSORING I MONITORING AGENCY NAME(S) AND ADDRESS(ES)

10. SPONSOR/MONITOR'S ACRONYM(S)

Headquarters, U.S. Army Corps of Engineers

441 G Street NW

Washington, DC 20314-1000

11. SPONSOR/MONITOR'S REPORT NUMBER(S)

\section{DISTRIBUTION / AVAILABILITY STATEMENT}

Approved for public release; distribution is unlimited.

\section{SUPPLEMENTARY NOTES}

\section{ABSTRACT}

After much previous research, many controversial issues related to well developed design recommendations and well accepted analytical procedures for infilled frames are still unresolved. The main difficulty in evaluating the performance of bearing and shear wall structures is determining the type of interaction between the infill and the frame, which has a major impact on the structural behavior and load-resisting mechanism. A simplified model that captures the characteristics of infill masonry would be valuable, but developing one requires understanding of masonry-infilled frame behavior in much more detail than strut or beam behavior. Numerical simulations using well calibrated constitutive models are needed for parametric studies to facilitate the development and calibration of a simple, accurate infill masonry model. The objective of this study was to identify suitable numerical constitutive models and demonstrate their capabilities. Two were studied here: a cohesive interface model to simulate the behavior of mortar joints between masonry units as well as the behavior of the frame-to-panel interface; and a smeared crack finite element formulation. The interface model was able to account for the shearing, residual shear strength, and opening and closing of joints under cyclic shear loads in simple combinations of concrete blocks and mortar joints.

\section{SUBJECT TERMS}

reinforced concrete construction, masonry infilled frames, finite element models, DIANA, structural engineering

\section{SECURITY CLASSIFICATION OF:}

\section{a. REPORT}

Unclassified

\section{b. ABSTRACT}

Unclassified

\section{c. THIS PAGE}

Unclassified
17. LIMITATION OF ABSTRACT

\section{NUMBER OF PAGES}

69 19a. NAME OF RESPONSIBLE PERSON

19b. TELEPHONE NUMBER (include
area code) 